Bram

abs Unogenctatidejotem devein

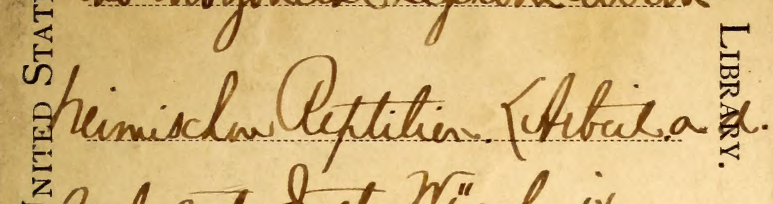

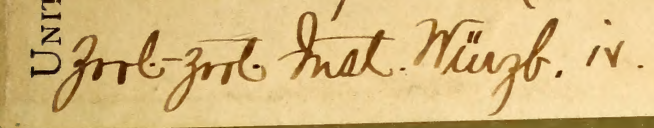

$$
\begin{aligned}
& \text { QL } \\
& 669.2 \\
& \text { B82 } \\
& \text { REPT. }
\end{aligned}
$$



DER

\section{EINHEIVISCHEN REPTILIEN.}

\section{ALS HABILITATIONS -SCHRIFT}

DER

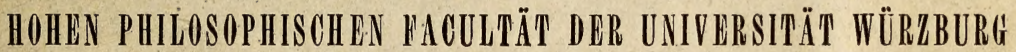

$$
\begin{aligned}
& \text { VORGELEGT VON } \\
& \text { D. M. BR A UN. }
\end{aligned}
$$

(SEPARAT-ABDRUCK AUS ARBEIT. A. D. ZOOL-ZOOT. INST. WÜRZB., BAND IV.)

\section{WÜRZBURG.}

J. STA UDINGER'SCHE BUCHHANDLUNG. 1878. 



\section{DAS UROGENITAL-SYSTEM}

DER

\section{EINHEIMISCHEN REPTILIEN.}

\section{ALS HABILITATIONS -SCHRIFT}

DER

HOHEN PHILOSOPHISCHEN PACULTÄT DER UNIVERSITÄT WÜRZBURG
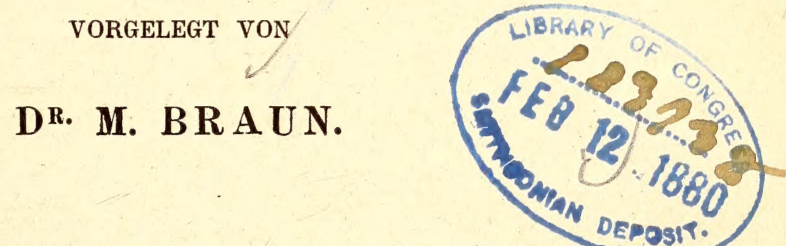

(SEPARAT-ABDRUCK AUS ARBETT. A. D. ZOOL.-ZOOT. INST. WÜRZB., BAND IW.)

\section{WÜRZBURG.}

J. STAUDINGER'SCHE BUCHHANDLUNG. 1878. 
(1) 


\section{Das Urogenitalsystem der einheimischen Reptilien}

entwicklungsgeschichtlich und anatomisch bearbeitet

von

DR. MED. \& PHIL. MAX BRAUN.

(Mit Taf. V-X.)

Im Sommer 1875 begann ich im Anschluss an die Entdeckungen Sempers und Spengels bei Plagiostomen und Amphibien eine Untersuchung über die Entwicklung des Urogenitalsystems der Reptilien, um zu erfahren, in wie weit sich die durch die genannten Autoren bei niederen Wirbelthieren, Anamnia, gefundenen Verhältnisse bei den Amnioten, und zwar bei der niedersten Klasse derselben, erhalten haben. Die literarischen Angaben über dieses Kapitel sind sehr spärlich; sie stammen entweder aus einer Zeit, in der von histologisch-embryologischer Forschung noch keine Rede war, oder sind ganz sporadisch bei Gelegenheit der Untersuchung der Entwicklung: des Hühnchens oder andrer, medicinischer Hausthiere gemacht, indem man von dem guten Glauben ausging, dass, da Reptilien und Vögel so sehr verwandt seien, sich auf erstere das bei den Vögeln Gefundene ohne Zwang übertragen lasse; naturgemässer wäre es freilich ggewesen, man hätte mit der niedersten Klasse der Amnioten begonnen und dann erst zu erforschen gesucht, wie weit sich der da gefundene Typus auch höher hinauf verfolgen lasse; doch theils Bequemlichkeit des zu untersuchenden Materiales, theils alt hergebrachte Sitte liessen die Forscher immer beim Hühnchen verweilen.

In Folgendem gebe ich zuerst eine kurze historische Uebersicht über unsere Kenntnisse des Urogenitalsystems der Reptilien in entwicklungsgeschichtlicher Beziehung, die jedoch auf absolute Vollständigkeit keinen Anspruch macht, wenn ich auch hoffe, etwas Wesentliches nicht übersehen zu haben; hierauf werde ich zur Beschreibung meiner Befunde übergehen und endlich diese mit den Angaben über höher und niedriger stehende Wirbelthiere, wobei ich naturgemäss von der Semperschen Arbeit über das Urogenitalsystem der Plagiostomen ausgehe, vergleichen. 


\section{Historische Uebersicht.}

Die ersten, welche bereits 1811 die Urnieren bei Reptilien gesehen haben, sind Emmert und Hochstetter $;^{1}$ ) sie sagen (pag. 94) von einem Eidechsenembryo aus ziemlich frühem Stadium, dass ,zu beiden Seiten der Bauchhöhle röthliche, schwammige Organe, wahrscheinlich die Nieren" liegen; die letztere Deutung ist unrichtig, sicherlich waren es die Urnieren, welche beide vor sich hatten, da die Nieren viel später entstehen, und da ferner in ihrer Abbildung (tab. I. fig. 3) der Buchstabe d dicht unterhalb des Herzens neben dem Darm steht, wo in diesem Stadium die Urnieren liegen. Ueber die weiteren Schicksale dieses Körpers fehlen jegliche Angaben bei den genannten Autoren, die hauptsächlich über das Amnion, den Kreislauf und die gröberen Formen des Embryo berichten.

Richtigere und bei weitem ausführlichere Mittheilungen verdanken wir H. Rathke, ${ }^{2}$ ) dem fruchtbarsten Autor auf dem Gebiete der Entwicklungsgeschichte der Reptilien; er berichtet uns (l. c. p. 44-48) hauptsächlich über die männlichen Geschlechtsorgane von Embryonen und jungen Thieren der Lacerta agilis, fand den Nebenhoden vor jeder Niere liegend, an dessen innern Seite den kleinen, weissen Hoden und an der obern Seite des Nebenhodens anliegend den röhrenförmigen

1) Untersuchung über die Entwicklung der Eidechsen in ihren Eiern. Reils und Autenrieths Arch. f. Physiologie. Bd. X. p. 84-122. 1811.

2) Beobachtungen und Betrachtungen über die Entwicklung der Geschlechtswerkzeuge bei den Wirbelthieren in "Neuste Schriften der naturf. Gesellschaft in Danzig. I. Bd. 4. Heft. Halle 1825, « Auch unter dem Titel: Beiträge zur Geschichte der Thierwelt. Heft III. 
Samenleiter, der sich zur untern Fläche der Niere hinbegab und dem der andern Seite aufs innigste sich annäherte; bei einer noch nicht halb ausgewachsenen Lacerta agilis war der Nebenhoden länglich, platt gedrückt, gelblich gefärbt und bestand deutlich aus einer Verknäulung von Gefässen, der Hode hing mit einem Samengefäss mit dem Nebenhoden zusammen; den Samenleiter beschreibt R. als wurmförmig gewunden. Mit zunehmendem Alter. nimmt die vordere Hälfte des Samenleiters sehr an Dicke zu und wird keulenförmig, der Nebenhoden dagegen nimmt $a b$ und stellt ein auf der innern Seite des Samenleiters liegendes kleines, gelblich gefärbtes Stück dar, das er bei einigen recht grossen Exemplaren nicht fand. Der Hode besteht zuletzt aus mehreren, knäuelförmig zusammengewickelten Gefässen, die mit einem oder wenigen Ausführungsgängen durch den Nebenhoden oder bei dessen Mangel direkt zum Samenleiter gehen. Vom Eierstock bemerkt R. nur, dass er sich zu einem einkammrigen Sack, ähnlich wie bei den geschwänzten Batrachiern, ausbildet, dass die Eier sich auf der Binnenfläche desselben entwickeln und wahrscheinlich durch eine am vordern Ende desselben gelegene Mündung entleert werden.

Ich will gleich hier bemerken, dass das, was Rathke Nebenhoden nennt, ein solcher nicht ist, sondern der bekannte, goldgelbe Körper, der später als Nebenniere, jüngstens als Paradidymis resp. Paroophoron, Giralde'sches Organ gedeutet ist.

J. Müller bestreitet die Angaben Rathke's, dass ,jene räthselhaften Organe" (Urnieren) bei den Weibchen ganz verschwinden, bei den Männchen dagegen zum Nebenhoden werden, weil der knäuelförmige Anfang des vas deferens keine Aehnlichkeit mit dem Bau des Wolff'schen Körpers hat; es sei allerdings bei jungen Schlangen und Eidechsen noch ein Rest des Wolff'schen Körpers vorhanden, doch verschwinde derselbe völlig. Wichtig ist eine Bemerkung Müllers über den 'Wolff'schen Körper von einem Embryo der Lacerta viridis aus frühester Zeit: die Blinddärmchen (Urnierenkanälchen) entstehen parallel, entlang der ganzen Wirbelsäule auf beiden Seiten, vom Herzen an bis zum Schwanz; sie erscheinen zuerst als Cylinderchen, die am Ende dicker sind oder als gestielte Bläschen, und scheinen an der hintern Fläche verbunden; seine Abbildung (1. c. tab. I. fig. 10) bestätigt dies, es ist nur zu bedauern, dass Müller nicht auch die Körpersegmente mitzeich-

^) Bildungsgeschichte der Genitalien etc. Düsseldorf. 1830. p. 17-20. 
net; wie ich weiter unten zeigen werde, ist die Zahl „der gestielten Bläschen " in diesem Stadium noch vollkommen übereinstimmend mit der Zahl der Körpersegmente, eine nur etwas genauere Ausführung der Zeichnung hätte wahrscheinlich auf dieses Verhältniss aufmerksam gemacht Dass Müller mit dem Stiel der Blase nicht die von mir gefundene Einstülpung vom Peritoneum her, sondern die Verbindung der Blase mit dem Ausführungsgang bezeichnet, scheint mir sicher aus seinen Worten und seiner Abbildung hervorzugehen. - Bei fast ausgebildeten EidechsenEmbryonen entdeckte Nüller die bleibenden Nieren im hintersten Theil der Bauchhöhle; die Geschlechtsorgane lagen an der innern Seite des obern breiteren Theiles des Wolff'schen Körpers; die Eileiter - nach Müller nur beim Weibchen vorhanden, nach Aussen von den Urnieren: den ductus deferens lässt Müller direct aus dem Ausführungsgang des Wolff'schen Körpers hervorgehen. Bei ausgewachsenen Schlangen hat Müller keine Spur der eigenthümlichen Blinddärmchen des Wolff'schen Körpers gefunden, dagegen bestand der Nebenhoden nur aus deutlichen Windungen des Samenganges.

Ziemlich spärlich sind im Verhältniss zu der umfangreichen Untersuchung über andre Systeme Rathke's ${ }^{1}$ ) Angaben über die Entwicklung des Urogenitalsystems der Natter; die Urnieren bilden sich aus einer von vorn nach hinten liegenden Reihe von Bläschen, die alle mit ihrem einen Ende an einen gemeinschaftlichen Kanal angeheftet sind; sie reichen vorn bis beinahe dicht an den Schlundkopf. Später wandeln sich die kugelförmigen Beutelchen in Kanäle um, indem sie zuerst retortenförmig, dann keulenförmig und zuletzt cylindrisch werden. Ausdrücklich bemerkt Rathke (1. c. p. 47), dass sich die Bläschen in etwas geringerer Zahl als die Wirbelbeinkörper bilden, so dass nicht immer unter der Anlage eines von diesen Körpern ein solches Beutelchen gefunden werden kann. Was die Herkunft der Urnieren anlangt, so hält R. es für höchst wahrscheinlich, dass ihnen entweder das Gekröse selbst oder neben diesem das Gefässblatt der Keimhaut den Ursprung giebt. Wie die Entstehung der Beutelchen von vorn nach hinten fortschreitet, so geht es auch mit der Bildung der Kanälchen und der Malpighischen Körperchen; letztere liegen sehr oberflächlich an der innern Seite der Urniere in einer einfachen Reihe, die jedoch später im mittleren Theil doppelt wird; ihr Blut erhalten die Körperchen direct aus der Aorta. Die Urnieren

1) Entwicklungsgeschichte der Natter. Königsberg 1839. p. 18, 19, 47, 78; $95-97 ; 154-162 ; 207-209$. 
nehmen an Länge bis zum Ausschlüpfen der Natter aus dem Ei zu. Die Nieren entstehen im hintersten Theil der Leibeshöhle und lassen später eine Reihe kolbenförmige Körperchen erkennen, die an einem zarten Kanal hängen, welcher neben dem Urnierenkanal an den Darm geheftet ist; hieran schliessen sich an der vordern und hintern Seite, also in zwei Reihen kleine, ovale Bläschen an, die später sich in Kanäle umwandeln; auch die Malpighischen Körperchen der Niere bilden zuerst eine einfache Reihe, welche Regelmässigkeit jedoch noch vor dem Auskriechen verloren geht, indem an der medialen Seite der Nierenfläche immer neue entstehen und die älteren lateralwärts drängen.

Die Geschlechtswerkzeuge - immer von der Natter - entstehen als zwei weissliche, sehr dünne Streifen an der innern Seite der Urnieren, über die Hälfte der Länge der Urnieren einnehmend; später runden sie sich allmählig ab, bleiben aber immer noch fadenförmig. In den Ovarien, die sich vom Wolff'schen Körper abschnüren und nur durch eine Bauchfellfalte mit demselben zusammenhängen, entsteht eine kleine, von zwei Schichten begrenzte Höhlung, im Hoden dagegen eigenthümliche Kanäle, die Samengefässe, welche $R$. als Windungen eines einzigen Kanales auffasst, den er in Parallele zu der Höhlung im Ovarium bringt. Bei neugeborenen Nattern ist von Dottern noch keine Spur zu merken. In den Hoden nehmen die Samengefässe an Weite und Länge zu, scheinen jedoch noch immer starke Windungen eines einzigen Kanals zu sein, der aus dem vordern Ende des Hodens in der Substanz der Urniere eintritt.

Von den ausführenden Gängen entstehen Ei- und Samenleiter, welch letzteren R. mit dem ersteren homologisirt, an der äussern, konvexen Seite der Urnieren, heben sich später von dieser ab, sind vorn noch blind und münden in das Ende des Darmkanals neben Urnierengang und Harnleiter. In der Mitte der dritten Periode bricht der Eileiter nach vorn durch und vergrössert sich allmählig. Auch der Samenleiter erhält eine solche spaltförmige Oeffnung, bildet sich jedoch nicht weiter aus, sondern wird ganz resorbirt, von hinten angefangen. Aus diesem Verhalten bringt $\mathbf{R}$. diese Kanäle beim Männchen in Parallele mit den männlichen Brüsten, den weiblichen Ruthen, welche ohne zu funktioniren auf einem mehr atrophischen Zustande verharren. Zum persistirenden Samenleiter werden nun die Wolff'schen Gänge.

Die äusseren Geschlechtstheile habe ich ausserhalb des Bereiches meiner Untersuchung gelassen, darum verzichte ich auch hier auf eine Angabe unsrer Kenntnisse über deren Bau und Entwicklung. 
Nun folgen der Jahreszahl nach kleinere Mittheilungen; so entdeckte Remak ${ }^{1}$ ) eine starke Flimmerung in den Urnierenkanälchen bei Eidechsen, die am lebhaftesten in der Nähe des Malpighischen Körperchens stattfindet. Wohl gleichzeitig berichtet Kölliker ${ }^{2}$ ) über denselben Punkt und schreibt den Kanälchen ein geschichtetes Epithel zu, dessen oberste Lage flimmert. Bidder ${ }^{3}$ ) bestreitet diese leicht zu sehende Flimmerung bei Reptilienembryonen und wendet sich daun zu dem Streit zwischen J. Müller und Rathke bezüglich der Betheiligung des Wolff'schen Körpers an der Bildung des Nebenhodens, von denen der erstere nur den Ausführungsgang persistiren, während letzterer auch die Kanälchen der Urniere daran Theil nehmen lässt. Bidder schliesst sich den Rathke'schen Angaben an und kommt nach eignen Untersuchungé an Lacerta agilis zu dem Schluss (p. 70), dass bei beiden Geschlechtern die Wolff"schen Körper der Eidechsen in die keimleitenden Organe ungewandelt werden: bei den Männchen in Nebenhoden und vas deferens, bei den Weibchen in die Ovidukte, mit dem Unterschiede jedoch, dass zu ersterer Umbildung der Wolff'sche Körper selbst, zu letzterer dagegen nur sein Ausführungsgang verwendet wird und dass im ersteren Fall von dem Ausführungsgang doch einíge Spuren zurückbleiben, während im zweiten die drüsige Substanz selbst durchaus und spurlos verschwindet." Beides ist nicht richtig.

Auch in Rathke's ${ }^{4}$ ) Untersuchungen „über die Entwicklung der Schildkröten" sind es noch immer äussere Formverhältnisse der Organe, welche diesen unermüdlichen Embryologen fast ganz fesseln. Der Wolff'sche Körper bestand bei einem Embryo von Emys europaea aus der ersten Hälfte des Fruchtlebens jederseits aus einer einfachen Reihe kleiner dickwandiger Bläschen, die vorn und hinten fast kuglig waren, im mittleren Theil jedoch Kolbenform besassen und quer lagen; am äussern Rande verlief der Wolff'sche Gang. Selbst bei schon ausgeschlüpften jungen Schildkröten sind noch bedeutende Reste der Urniere vorhanden, die nach hinten über die Niere hinwegragen, jedoch später

$\left.{ }^{1}\right)$ Ueber Wimperbewegung in den Kanälchen des Wolff'schen Körpers bei Eidechsenembryonen. Frorieps neue Notizen XXXV. Bd. 1845. p. 308, 309.

$\left.{ }^{2}\right)$ Ueber Flimmerbewegung in den Primordialnieren. Müll. Arch. für Anatomie und Physiologie. Jahrg. 1845. p. 518-523.

๑) Männl. Geschlechts - und Harnwerkzeuge der nackten Amphibien. Dorpat. 1846. p. 62. Anmerk. 2 u. p. 66.

$\left.{ }^{4}\right)$ Ueber die Entwicklung der Schildkröten. Braunschweig 1848, p. 21, 43, $198-204,245-248$. 
schwinden. Einen dem weiblichen Eileiter analogen Gang beim Männchen konnte Rathke nicht auffinden, doch glaubt er, dass derselbe vorhanden, nur frühzeitig resorbirt werde.

Die grosse Arbeit von Lereboullet ${ }^{1}$ ) verbreitet sich ebenfalls nur über die gröbere Anatomie des Urogenitalsystems von Lacerta stirpium, wegen deren ich auf das Original verweisen muss.

Gelegentlich seiner Untersuchungen über Fische und Reptilien macht Leydig ${ }^{2}$ ) auch einige hierher gehörige Bemerkungen; zuerst constatirt er mit Remak und Kölliker, welche Flimmerbewegung in den Urnieren der Eidechsenembryonen gesehen hatten, auch dieselbe bei Anguis fragilis. Bei Vergleichung der gewonnenen Resultate über die Harn- und Geschlechtsverhältnisse der Batrachier mit den Kenntnissen darüber bei höheren Wirbelthieren, namentlich Eidechsen, schliesst er sich den Aussprüchen Rathke's und Bidder's über die Umwandlung des Wolffschen Körpers in den Nebenhoden beim Männchen an; beim Weibchen findet sich ein Rest desselben, seitlich von der ockergelben Nebenniere gelegen, ein $\mathrm{Nebeneierstock;} \mathrm{übrigens} \mathrm{geht} \mathrm{nach} \mathrm{Leydig}$ nicht die ganze Urniere in den Nebenhoden über, ein Theil schwindet und ein kleiner Rest hleibt als Knäuel eines noch von Epithel ausgekleideten Kanals nach vorn vom Nebenhoden liegen; der Wolffsche Gang wird beim Männchen Samenleiter, beim Weibchen Eileiter.

Sehr zu bedauern ist es, dass Clark $^{3}$ ) bei der Menge des ihm zu Gebote stehenden Materiales nicht eingehendere Studien über die Entwicklung des Urogenitalsystems bei Schildkröten veröffentlicht hat; was ich darüber gefunden habe, ist Folgendes: die Wolffschen Körper nehmen die Hälfte der Körperlänge ein, sind am breitesten in der Mitte und bestehen der ganzen Länge nach aus schräg liegenden Querstreifen; auf ihnen erscheinen die Gefässe als rothe Zickzacklinien, welche in die Bauchvenen einmünden; dorsal auf ihnen liegen die breiten Ausführungsgänge derselben. Später entwickelt sich auf der dorsalen Fläche jeder Urniere näher der Mittellinie gelegen die Niere, anscheinend durch eine Metamorphose des Wolffschen Körpers; die Kanälchen der Niere sind

1) Recherches sur l'anatomie des organes genitaux des animaux vertébrés in Nov. act. Acad. caes. Leop.-Gar. nat. cur. tom. XV. 1851. p. 1-228.

$\left.{ }^{2}\right)$ Anatomisch-histologische Untersuchungen über Fische und Reptilien. Berlin 1853. p. $87 \cdot 91$.

$\left.{ }^{3}\right)$ Clark: Embryology "of the Turtle in Natural history of the unitad states. Vol. II. part. III. 1857. 
mehr gewunden, nehmen in ihrem Verlauf einen glomerulus auf und münden mit kurzen, dicken tubuli uriniferi wahrscheinlich in den Ausführungsgang, als welchen er den Wolff'schen Gang aufzufassen scheint. Auf der Unterseite der Urniere erscheint als weisses, spindelförmiges Band die Genitaldrüse.

Auch Lereboullet ${ }^{1}$ ) schenkte in seinen Untersuchungen über die Entwicklung der Eidechse dem Urogenitalsystem sehr wenig Aufmerksamkeit; nach ihm erscheinen die Primordialnieren in der Gestalt zweier Bänder, die aus durchscheinenden, in Reihen angeordneten Bläschen zusammengesetzt sind; jedes Band ist nach aussen durch einen Exkretionskanal begrenzt, der zur seitlichen Begrenzung der Allantois herabsteigt Später zeigen die Wolff'schen Körper, namentlich vorn, gewundene Blindsäckchen, welche aus den Blasen hervorgegangen sind. Am 8. Tage nach der Eiablage - es handelt sich um Lacerta agilis bieten die Wolff'schen Körper eine sehr bemerkenswerthe Struktur: sie bilden cylindrische, ein wenig abgeplattete Massen, die in der Höhe des Herzens beginnen und sich allmählig nach hinten verschmälern. An den schon vorhandenen Kanälchen, die sich mannigfach unter einander verschlingen, unterscheidet Lereboullet (cf. l. c. Pl. 5, fig. 50) zwei Abschnitte; der secernirende Theil, tube ondulé, ist gewunden, viel dicker und von granulirten Zellen ausgekleidet, die Ausführungsgänge und unmittelbare Fortsetzung der vorigen, tube droit, verlaufen grade, enthalten Cylinderepithel und sind mit grosser Regelmässigkeit der eine hinter den andern an den Wolff'schen Gang angeheftet. Ueber die Geschlechtsorgane und bleibenden Nieren finde ich Nichts.

Eine Zusammenfassung des Wissens über die Entwicklung der Wirbelthiere findet sich in Rathke's Entwicklungsgeschichte der Wirbelthiere. Leipzig 1861. Cap. XII n. XIII. p. 163-184, worauf ich verweise.

Auch in Rathke's letzter Arbeit über die Krokodile ${ }^{2}$ ) sind es fast nur äussere Formverhältnisse, welche sein Interesse fesseln; über die Entwicklung der Nieren giebt er Folgendes an: die Ni e r e n bestehen aus kleinen Beutelchen, die sich allmählich in ebenso viele Röhrchen, diese aber in ebenso viele Zweige des Harnleiters umwandeln, von denen jeder eine bedeutende Menge Harnkanälchen aussendet. Später gruppiren

1) Recherches sur le développement du lézard; ann. d. scienc. nat. Zoologie. Tom. XVII. 1862. Paris. p. 89-157.

2) Rathke: Untersuchungen über die Entwickelung und den Körperbau der Krokodile. Braunschweig 1866. Cap. X. XI. p. 171-199. 
sich die Zweige um ihre Harnkanälchen, die anfangs dicht neben einander liegen, der Art, dass die Harnkanälchen je eines Zweiges in zwei Schichten auseinander gehen, von denen die einander zugekehrten Schichten zweier benachbarter Zweige beisammen bleiben und ein Nierenblatt oder doch einen Theil desselben bilden.

So umfassend Waldeyers ${ }^{1}$ ) Untersuchungen über das Ovarium der höheren Wirbelthiere sind, so wenig bringen sie über die Reptilien, weil "bei der grossen, man darf wohl sagen, fast vollständigen Uebereinstimmung ..... zwischen der Eibildung der Vögel und Reptilien .... es nicht erforderlich erschien, eine grössere Zahl von Species zu untersuchen." Von Lacerta agilis konstatirt W. ein den ganzen Eierstock überziehendes Epithel von ganz derselben Beschaffenheit wie bei den Vögeln; es setzt sich mit scharfer Grenze gegen das Peritonealepithel ab, muss daher auch als echtes Epithelium angesehen werden. Die Follikelbildung wurde nicht untersucht, da bei erwachsenen Eidechsen keine Spur einer solchen vom Epithel aus gefunden werden konnte, doch liessen sich einzelne, kleine Zellenhaufen in dem spärlichen Ovarialstrome nachweisen. Hierauf folgt eine Beschreibung von Eifollikeln, namentlich von jüngeren, aus der hervorzuheben ist, dass das Epithel immer mehrschichtig erscheint und aus grossen, blassen und kleinen getrübten Zellen besteht; letztere, im Leben zwischen den grossen zerstreut, liegen nach dem Erhärten an der Peripherie. Die grösseren Zellen reichen mit ihren Fortsätzen bis durch die Zona radiata an den Dotter hinan, es scheinen sich ihre Enden direkt in Dotterbestandtheile umzuwandeln.

Der letztere Punkt ist später von Eimer ${ }^{2}$ ) genauer bearbeitet und wohl erschöpfend dargestellt worden; ein Theil der Follikelepithelien funktionirt als einzellige Drüsen, die ihr Sekret dem Dotter beimengen und zwar - fast möchte man sagen durch Ausführungsgänge, welche die Dottermembran durchbohren; übrigens neigt Eimer mehr der Ansicht zu, dass die Follikelzellen nur mehr die Wege sind, durch welche aus dem Blut Nährmaterial zum Dotter gelangen kann, während Saftröhrchen und Poren vielleicht auch der Ausscheidung von Stoffen aus dem Ei dienen. Ihm wächst das Ei wie jede Zelle oder Organismus - durch

1) W. Waldeyer: Eierstock und Ei. Ein Beitrag zur Anatomie und Entwicklungsgeschichte der Sexualorgane. Leipzig 1870. p. 69-72.

2) Th. Eimer: Untersuchungen über die Eier der Reptilien. I. II. M. Schultze's Arch. f. mikr. Anat. Bd. VIII. 1872. p. 216-243. p. 397-434. 
Assimilirung von aussen aufgenommenen Ernährungsmateriales, als Zelle muss es auch ausscheiden; erst mit dem Auftreten des Binnenepithels im Ei hört das Ei auf, eine einfache Zelle zu sein, es muss "als Zelle mit endogener Brut betrachtet werden". Dieses Binnenepithel, dessen Existenz schon Clark bei Schildkröteneiern behauptet hat, soll als einschichtige Lage platter Zellen aussen auf dem Dotter, also nach innen von der Dotterhaut bei Eiern von bestimmter Grösse auftreten und selbst noch im Eileiterei zu erkennen sein.

Diese Angaben haben den stärksten Widerspruch von Seiten Ludwig's ${ }^{1}$ ) erfahren, der weder bei Schildkröteneiern noch bei Eiern der von Eimer untersuchten Reptilien irgend eine Spur von dem Binnenepithel entdecken konnte; für Clark gelingt es Ludwig nachzuweisen, dass dieser selbst über das Vorhandensein des Binnenepithels nicht klar war, während der Mangel an hierauf bezüglichen Abbildungen bei Eimer eine Entscheidung darüber, was E. gesehen hat, unmöglich macht. Bei Eileitereiern glaubt Ludwig annehmen zu müssen, dass Eimer Theile des Embryos für das Binnenepittel ansah. Eine weitere Mittheilung über diesen strittigen Punkt ist bisher nicht erfolgt.

Endlich habe ich noch die Untersuchungen Leydig's ${ }^{2}$ ) zu erwähnen, der bei Gelegenheit seiner faunistischen Studien die Anatomie nicht vernachlässigt und eine Reihe von Punkten zum Theil neu aufstellt, zum Theil berichtigt. Seine anatomischen Angaben hier kurz wiederzugeben, ist nicht gut möglich; uns interessirt hier mehr die Entwicklungsgeschichte, worüber Leydig auch Einiges publicirt: Die bleibende Niere (bei Lacerta agilis) geht aus Kanälchen hervor, welche hinter dem Wolffschen Körper aus dem Wolffschen Gang hervorsprossen und durch ihre Wucherung einen Drüsenkörper bilden, der beim neugeborenen Thier schon ganz die Form der ausgewachsenen Thiere angenommen hat. Beim Eierstock hat Leydig die Ursprungsstelle der Follikel in der "Keimstätte" entdeckt, welche auf dem Ovarium die Form eines spindelförmigen Doppelwulstes besitzt, dessen Elemente Leydig als nicht vom Peritoneum stammend ansieht, während die Hauptmasse des Ovariums, das Stroma, eine lokale spindelförmige Verdickung des bindegewebigen Stratums des Bauchfelles ist; das bindegewebige Gerüst zerlegt nun durch Einwuchern in die Keimstätte die Zellen desselben in

1) H. Ludwig: Eibildung im Thierreich. Diese Arbeiten Bd. I. p. 443 etc.

2) F. Leydig: Die in Deutschland lebenden Arten der Saurier. Tübingen 1872 p. $127-154$. 
einzelne Follikel, ähnlich wie Leydig die Hoden $\mathrm{ka} n$ ä $1 \mathrm{ch}$ e $\mathrm{n}$ aus einem soliden Zellenkörper hervorgehen lässt, der durch Abscheidung von Bindesubstanz in Cylinder zerlegt wird.

Leydig hat auch Reste embryonaler Organe aufgefunden, so einen Rest der Tube in Form eines kleinen Blindsackes bei männlichen Eidechsen und Blindschleichen; ferner Theile des Wolffschen Körpers und seines Ausführungsganges bei weiblichen Eidechsen und Blindschleichen; den goldgelben Körper, der früher allgemein als Nebenniere galt, fasst er als einen besonderen Theil des Wolffschen Körpers auf, wegen seiner Zusammensetzung aus gewundenen Kanälchen; er nennt diesen Körper beim Männchen Paradidimys, beim Weibchen Paroophoron oder Parovarium.

Aus dieser kurzen literarischen Uebersicht ersehen wir, welche Lücken und Widersprüche noch in entwicklungsgeschichtlicher Beziehung über das Urogenitalsystem der Reptilien bestehen, dass eigentlich keine Arbeit existirt, welche auch nur ein Organ der Reptilien in der Weise behandelt, wie wir es von einigen höheren und niederen Wirbelthieren besitzen. Es ist dies um so mehr zu verwundern, als die Beschaffung des Materiales keine so grossen Schwierigkeiten bietet wie z. B. bei Sängethieren; so bequem wie beim Huhn ist es freilich nicht. Um Anderen den Glauben an die Schwierigkeiten zu benehmen, will ich meine Erfahrungen über Zucht der Reptilien hier mittheilen. 


\section{Untersuchungs-Methoden.}

In das Bereich meiner Untersuchung zog ich zuerst nur einheimische Reptilien, vor Allen Lacerta agilis, Anguis fragilis, Tropidonotus natrix und Coronella laevis; erst später konnte ich auch Embryonen von Platydactylus facetanus, dem gewöhnlichen Mittelmeergecko und in allerletzter Zeit auch von Phyllodactylus europaeus untersuchen; ferner jüngere und ausgewachsene Thiere von Lacerta muralis verschiedener Fundorte, von den Balearen, aus Italien und Dalmatien, von Lacerta Lilfordi, Lacerta faraglionensis und Vipera berus.

Anguis fragilis ist, wie bekannt, so gut wie lebendiggebärend, die Jungen verlassen das Ei sofort nach der Geburt; man ist deshalb, um die verschiedenen Entwicklungsstadien zu erhalten, genöthigt, trächtige Weibchen von Ende Mai bis Juli zu tödten, die Embryonen aus den Eileitern unter Salzwasser von 1\% herauszupräpariren und dann gestreckt in Chromsäure zu erhärten. Diese Methode, an die sich die bekannte Behandlung mit verdünntem Spiritus bis zum Einbetten in Paraffin anschliesst, lieferte mir die besten Resultate; schlechte Präparate bekam ich bei Behandlung mit Müllerscher Flüssigkeit, eine Erfahrung, die auch Kölliker ${ }^{1}$ ) bei Kaninchenembryonen gemacht hat. Auf die ebendaselbst gegebene Empfehlung der Ueberosmiumsäure versuchte ich auch diese und kann dieselbe für kleine Embryonen, die man ganz in Lack aufbewahren will, empfehlen; man lässt dieselben in der Conservirungsflüssigkeit, die man $\check{-}-10$ pro mille anwendet, bis eine schwache Bräunung eingetreten ist, spült mit destillirtem Wasser ab und behandelt

$\left.{ }^{1}\right)$ A. Köllicker: Entwicklungsgeschichte des Menschen und der höheren Thiere. L.eipzig 1876, p. 229. 
zuerst mit ganz schwachem Spiritus und so fort; eine besondere Färbung ist nicht nöthig. Solche Embryonen habe ich nun schon über 2 Jahre in Canadabalsam eingeschlossen und sie sind noch heut ganz vortrefflich. Weniger möchte ich die Ueberosmiumsäure für histologische Studien empfehlen, mir schien es immer, als ob sie doch die Gewebe ziemlich bedeutend verändert; deswegen habe ich eine Combination von Ueberosmiumsäure und Chromsäure angewendet, indem ich in ein Uhrschälchen voll weingelber Chromsäurelösung 3-5 Tropfen einer $1 / 2 \%$ Ueberosmiumsäurelösung zusetzte; doch mehr als die Chromsäure allein hat mir diese Mischung nicht genützt. Sonstige Erhä rtunsmittel zog ich nur ausnahmsweise zu Hilfe.

Für die ersten Entwicklungsstadien von Lacerta agilis und Tropidonotus natrix ist es ebenfalls nöthig, die trächtigen Thiere zu tödten und die Eileitereier unter Salzwasser oder gleich in Chromsäurelösung zu öffnen; sehr kleine Embryonen; bei denen man der Weichheit der Gewebe wegen auf eine Streckung von vornherein verzichten muss, lässt man am besten auf dem Dotter liegen; grössere schneidet man heraus, befreit sie vom Amnion und sucht sie durch Nadeln, von denen eine in die Schwanzspirale, die andre unter den Oberkiefer gesteckt wird, in einer mit Wachs ausgegossenen Präparirschale zu strecken. Bei Nattern muss man, um Drehungen des Körpers, welche bei Querschnitten störend wirken, zu vermeiden, die Bauchwand einschneiden oder dieselbe vorn am Hals mit der Pincette anfassen und unter leisem Zug abzutrennen suchen; meist gelingt dies leicht, doch mitunter fasst man den Darm mit an und reisst mit dessen Mesenterium streckweise auch die beiden Genitaldrüsen ab, was solche Embryonen zum Theil unbrauchbar macht - doch ich wusste mir nicht anders zu helfen.

Es gelang mir leicht, beide Thiere in Gefangenschaft zur Eiablage zu bringen; die Lacerta agilis hielt ich stets isolirt in kleineren mit Drahtgittern versehenen Käfigen theils der leichteren Fütterung der Thiere, theils der leichteren Uebersicht des Käfigs wegen; Lacerta agilis frisst nämlich gern ihre eigenen Eier und man würde, wenn man mehrere in einem Käfig halten und nicht bei Zeiten für die Sicherstellung der Eier sorgen würde, von den meisten Bruten sehr viel verlieren. Hat man dagegen nur ein Thier in einem Käfig, so begnügt sich dies mit einem Ei, das es, wie ich öfters sah, gleich nach dem Akt der Eiablage mit Behagen, ohne zu kauen, ganz hinunterschluckte. Nachdem ich diese Beobachtung des öfteren gemacht hatte, war es natürlich selbstredend, dass ich für Entfernung der Eier aus dem Käfig sorgte; ich brachte sie 
in flache Glasschalen auf feuchtes Moos und deckte sie mit Moos zu; für genügende Feuchtigkeit muss man sorgen, das Ei darf, wenn es sich normal entwickeln soll, keine Delle bekommen; oft wird eine solche, wenn man das Moos mit einer Spritzflasche anfeuchtet, wieder ausgeglichen und die Eier sehen prall aus; das Blut des Fruchthofes schimmert röthlich durch, und ist dies ein gutes Zeichen für normale Eier. Durchschnittlich legte bei mir jede Lacerta agilis 8-10 Eier, welche Zahl mit der von Leydig angegebenen übereinstimmt. Die Entwicklung bis zum Ausschlüpfen dauert mindestens $6-8$ Wochen; zum Ausschlüpfen selbst habe ich keine Eier gebracht, da ich die Embryonen vorher tödtete. Direktes Sonnenlicht ist selbstredend bei der Aufstellung der Brutkasten zu vermeiden, die Eier beginnen durch zu starke Wasserabgabe zu schrumpfen und sterben sehr leicht ab.

Die Natter legt 30-40 Eier auf einmal in Haufen unter Moos, Steine etc., die Eier kleben in Reihen oder grösseren Klumpen an einander, haben eine ziemliche harte pergamentartige Hülle und sind prall. Dass die Natter dasselbe Gelüst auf ihre Eier zeigt, wie die Lacerta agilis, habe ich nicht beobachtet, doch nahm ich auch ihre Eier aus dem Käfig und brachte sie im ersten Jahre meiner Untersuchungen, um sie möglichst vor den lästigen Pilzen unseres Institutes zu schützen, in den inneren Raum der sogenannten Fliegenfangapparate aus Glas, die ich auf Watte setzte. Um die nöthige Feuchtigkeit zu geben, stelle ich ein Uhrschälchen mit Wasser in die untre Oeffnung. So gelang es, die Eier, welche meist im Juli gelegt werden, lange Zeit am Leben zu erhalten, einen Theil derselben bis zum Ausschlüpfen zu bringen - Ende August etwa. Doch waren die Verluste immer noch gross und ich brachte. daher im nächsten Jahr - mit viel besserem Erfolg - die Eier in Blumentöpfe auf Moos, welche ich mit einem Drahtgitter bedeckte und in den Schlangenkäfig selbst stellte. In diesen herrscht ein eigenthümlicher Geruch, ein gewisser Grad von Feuchtigkeit selbst bei guter Ventilation, der mir für die Entwicklung der Eier nöthig zu sein schien; wie gesagt war diesmal der Erfolg ein viel besserer. Man hat es nun in der Hand, jeden Tag von dem Eierhaufen zwei oder mehr zu lösen, zu präpariren und so sich eine vollkommene Entwicklungsreihe herzustellen, ohne jede Lücke, wie es bei dem Hühnchen ebenfalls geschieht, oder wenigstens überall geschehen sollte.

Die weitere Verarbeitung des Materiales geschah durch Zerlegen in Schnittserien - eine fürchterliche Aufgabe, wenn i h nicht das Leyser'sche Mikrotom hätte benützen können, mit dessen Hilfe es weniger 
plagend ist, einen Embryo von etwa $80 \mathrm{~mm}$. in Schnitte von ${ }^{1 / 40} \mathrm{~mm}$. Dicke zu zerlegen, also in 3200 Schnitte! Sehr viel Erleichterung verschafft man sich, wenn man die Embryonen vor dem Schneiden durchfärbt; ich wandte dazu Carmin, Hämatoxylin und Pikrokarmin an. Das erstere versagt oft für die inneren Theile den Dienst, es dringt nicht immer durch, ich glaube dann nicht, wenn die Chromsäure nicht ganz ausgezogen ist; das Hämatoxylin färbt ganz präcis, doch habe ich leider die Erfahrung gemacht, dass es sich in Canadabalsam oder Damarlack nicht hält, die Schnitte verbleichen und zwar diejenigen zuerst, welche dem Rand des Deckglases am nächsten liegen, also für den Zutritt der Luft am leichtesten zugänglich sind - für Dauerpräparate ist es also nicht zu gebrauchen. Endlich das Pikrokarmin, dieses liefert die besten Resultate, so lange es noch nicht zu alt ist; zu seiner Darstellung verfuhr ich auf sehr einfache Weise; ich goss zu einer konzentrirten und filtrirten Carminlösung, deren Ammoniakgehalt an der Luft verdunstet war, konzentrirte Pikrinsäurelösung und warf auch noch etwas Pikrinsäure in Substanz hinein; nach einigen Tagen filtrirte ich und erhielt eine eigenthümlich gefärbte, dunkle Flüssigkeit, die ganz exakt die Kerne roth färbte, während die Zellsubstanz, Nerven, Fasern etc mehr gelblich blieben. Diese Lösung verdünte ich vor dem jedesmaligen Gebrauch mit dem vierfachen Volumen Wasser und liess die Embryonen zum Durchfärben 12-24 Stunden in ihr liegen. Auch für andre Thiere, namentlich Würmer, Mollusken haben wir ganz vortreffliche Resultate gesehen, so dass wir alle fast ausschliesslich damit arbeiten.

Bei der Menge von Querschnittserien, die ich im Laufe der Untersuchung fertigte, war es mir nöthig, um den Ueberblick nicht zu verlieren, Schemata zu entwerfen, die ich durch Einzeichnen der Querschnitte in carrirtes Papier, also in einem Längsbilde mir darstellte; für solche Schemata ist es nicht nöthig, jeden Querschnitt genau zu messen oder jeden genau zu zeichnen, ungefähr richtige Verhältnissgrössen genügen zu diesem Zweck.

In der Arbeit habe ich es unterlassen, jeden Fmbryo, von dem ich Angaben mache, dem Aeussern nach zu beschreiben; es hätte dies die Arbeit unnöthig schwer und schleppend gemacht, ohne dass der Nutzen eiu grosser ist; auch den Versuch, bei jedem Embryo ungefähr das gleiche alte und mehr bekannte Stadium des Hühnchens anzugeben, musste ich bald aufgeben, theils weil ich selbst in der Entwicklungsgeschichte des Hühnchens noch keine eignen, hierzu genügenden Erfahrungen besitze, theils, weil ein Vergleich schliesslich doch nicht gut 
wegen der Verschiedenheit der Thiere möglich war. Ich begnüge mich daher mit der Grössenangabe und mit dem Alter des Embryo's vom Tag der Eiablage an gerechnet; beide unterliegen aber Schwankungen und Fehlern, sind also nur als ungefähr richtig anzusehen.

Die Untersuchungen wurden insgesammt im hiesigen zoologischen Institut ausgeführt unter Benützung der Mittel, die demselben zu Gebote stehen und welche der Vorstand des Institutes, Prof. Semper, in liberalster Weise eine lange Zeit fast ausschliesslich für diese Arbeit verwenden liess; nur so war es möglich, ein Material zu sammeln, wie es für entwicklungsgeschichtliche Untersuchungen nöthig ist - möglichst ohne Lücken; doch nicht allein für Material, sondern auch für die fortwährende Anregung und Unterstützung bei der mitunter sehr schwierigen und ermüdenden Untersuchung bin ich meinem Lehrer zu grossem Dank verpflichtet. 


\section{Eigne Untersuchungen.}

\section{A. Segmentalorgane (Urniere, Wolff'scher Körper.)}

\section{Wolff'scher Gang.}

Das Erste, das von der Urniere auftritt, ist der Ausführungsgang derselben, der Wolff'sche Gang. Ueber die erste Entstehung desselben habe ich bei Reptilien wenig Untersuchungen angestellt, obgleich eine genaue Angabe darüber zur Klärung der so sehr differenten Ansichten über seine Bildung bei höheren Wirbelthieren, meist Hühnchen und Kaninchen, sehr erwünscht und nothwendig gewesen wäre. Doch bestehen bei dem frühen Auftreten des Urnierenganges grosse Schwierigkeiten für die Präparation des bereits gekrümmten Embryos, die bei der Kleinheit des Objekts ein Strecken desselben fast zur Unmöglichkeit machen, daher man bei Schnittserien immer nur einige brauchbare Schnitte erhält. Was ich hierbei nun bemerkt habe, ist kurz Folgendes: Bei einem kaum $5 \mathrm{~mm}$. langen Embryo von Lacerta agilis finde ich auf Querschnitten dicht unterhalb des Herzens den Wolff'schen Gang der Seitenplatte anliegend an einer Stelle, die weder zur Seitenplatte noch ganz zu den Ursegmenten gehört, sondern, nach aussen zum Ectoderm hin scharf und zwar halbkreisförmig begrenzt, zwischen beiden liegt, gegen die Mittellinie zu jedoch ohne bestimmte Grenze mit den Zellen der Seitenplatte in Verbindung steht; in der Mitte dieser sich nach aussen abschnürenden Zellenmasse ist ein Lumen schon ziemlich deutlich zu erkennen, von dem die Zellen nach dem Ectoderm zu radiär angeArbeiten a. d. zool,-zoot. Inst. Würzb, Bd. IV. 
ordnet sind, medial mehr regellos liegen. Die Stelle, an der hier der Gang liegt, entspricht vollkommen derjenigen, an der Waldeyer ${ }^{1}$ ) die Entstehung des Ganges beim Hühnchen beobachtet hat und die auch von späteren Autoren für das Hühnchen als die richtige angegeben worden ist; so schliesst sich in Bezug auf den Ort der Entstehung E. Gasser ${ }^{2}$ ) ganz an Waldeyer an; das nämliche thut A. Kölliker ${ }^{3}$ ) und ebenso Foster und Balfour, ${ }^{4}$ ) doch herrschen wegen der Bildung selbst noch Differenzen. Die neuesten Autoren scheinen immer mehr zu bestätigen, dass der Wolff'sche Gang solid angelegt wird und erst später ein Lumen bekommt, dass dieses letztere jedoch weder durch Umlegen eines soliden, langgestreckten Zellenkörpers an die Seitenplatte (Waldeyer), also durch Schluss einer Rinne, noch durch Ausstülpung vom Pleuroperitonealepithel (Romiti) sich bilde. Die letztere Ansicht hat die allerwenigste Wahrscheinlichkeit und eigentlich keinen genügenden Beweis durch ihren Urheber selbst gefunden; man vergleiche darüber, was z. B. Gasser 1. c. und Semper ${ }^{5}$ ) sagen, vor Allem aber Romiti's Arbeit selbst (Schultze's Archiv 1873), wo ich wie andere vergeblich nach überzeugenden Beweisen suche. Anch. Waldeyer's Ansicht ist bisher von keiner Seite bestätigt worden, während man sich die Entstehung derselben schon aus seinen Bildern, deren Richtigkeit anerkannt wird, erklären kann. Noch viel weniger überzengend ist die Herleitung der Epithelien des Woff'schen Ganges aus dem Ectoderm, wofür die in Bezug auf Anordnung der Zellen doch schematischen Figuren auf Taf. 10 (Waldeyer 1. c.) gar keinen Anhalt geben. Wir können also immerhin mit Sicherheit annehmen, dass der Wolff'sche Gang aus d em Mesoderm und zwar aus einem Zellstrang, der zwischen Ursegmenten und Seitenplatten liegt, entsteht, und später ein Lumen bekommt. Für dieselbe Art der Entstehung scheint mir auch meine Beobachtung bei Reptilien zu sprechen, doch kann ich vor der Hand einen sicheren Entscheid nicht geben, behalte mir aber vor, meine Untersuchungen über diesen wichtigen Punkt fortzusetzen und darüber zu berichten.

1) Eierstock und Ei p. 115 u. ff. tab. IV. fig. 37-43.

2) Sitzungsbericht der Gesellsch, z. Bef. d. ges. Naturwissensch. in Marburg 10, Febr. 1875. p. 21.

3) Entwicklungsgeschichte d. Mensch. u. d. höh, Thiere. 1876. p. 120 fig. 48.

$\left.{ }^{4}\right)$ Grundzüge der Entwicklungsgeschichte der Thiere. Deutsche Ausg. 1876. p, 72. fig. 20. p, 124, fig. 41 .

$\left.{ }^{5}\right)$ Das Urogenitalsystem der Plagiosiomen etc. Diese Arbeiten Bd. II. p. 403. 
Was nun das weitere Verhalten des Wolff'schen Ganges bei Reptilien anlangt, so stellt derselbe immer ein vorn blind geschlossenes Rohr dar, das hinten in die dorsale Wand der Cloake einmündet, während des grössten Theiles der Urniere auf deren dorsalen Fläche verläuft, hinten jedoch allmählig lateral und endlich ganz ventral von ihr zu liegen kommt. Dass der Gang vorn wirklich blind geschlossen ist, davon habe ich mich nicht nur durch die frische Untersuchung, sondern vor Allem durch das Abzeichnen der vordersten Querschnitte der Urniere überzeugen können: es zieht durch die Peritoneaihöhle bei älteren Embryonen ein Blatt, welches von der Aorta herkommend, schräg nach anssen sich an die Bauchwand ansetzt und die Peritonealhöhle in zwei Kammern theilt; in diesem Blatt, das sich erst später bildet, liegt das vordere Ende der Urniere und ihres Ausführungsganges; während nun der vor dem Anfang liegende Schnitt nur ein aus sternförmigen Zellen bestehendes Gewebe zeigt, tritt im nächsten plötzlich eine rundliche Scheibe polyedrischer Zellen auf, mit scharfen Zellgrenzen, gelblich gefärbtem und getrübtem Protoplasma und deutlichem, ovalem Kern; kein Spalt ist auch mit der stärksten Vergrösserung in dieser Scheibe zu erkennen, genau schliesst Zelle an Zelle; je nachdem der Schnitt nun gefallen ist, bemerkt man anch durch Heben und Senken des Tubus, dass diese Scheibe an der Peripherie dicker ist, als im Centrum, so dass man es also eigentlich mit einem Segment eines gebogenen Kanales zu thun hat, was denn durch den nächstfolgenden Schnitt auch bestätigt wird, indem nun 2 Kanäle auf dem Querschnitt erscheinen, welche durch eine Brücke von polyedrischen Zellen verbunden werden; im dritten Querschnitt sind dann meist die beiden Kanäle noch vorhanden, in den folgenden bleibt der eine, welcher am meisten dorsal liegt, immer zu erkennen, während sich zu dem anderen zahlreiche QuerLängs- und Schrägschnitte von meist dünneren Kanälchen gesellen. Hieraus geht hervor, dass der Wolfe'sche Gang umgekehrt U förmig beginnt, dass der eine Schenkel zur Urniere, der andere zum Ausführungsgang gehört.

Dieses Verhältniss konnte ich nicht nur für Lacerta agilis, sondern für die verschiedensten Entwicklungsstadien auch bei der Blindschleiche und der Natter konstatiren; der Wolff'sche Gang ist also bei Reptilien stets vorn geschlossen, kommunicirt hier nie mit der Leibeshöhle.

Seine weiteren Schicksale werde ich weiter unten besprechen. 


\section{Urniere, Segmentalorgane.}

Sehr bald nach dem Auftreten des Urnierenganges, wenn derselbe nach hinten zu noch nicht den Enddarm erreicht hat, findet man bereits vorn hinter dem Herzen die sich bildende Urniere. Zwischen der Reihe der Ursegmente und dem Pleuroperitonealepithel zieht von vorn nach hinten ein Strang indifferenten, aus Kernen und einer Zwischensubstanz bestehenden Gewebes, das scharf gegen das Peritoneum und auch gegen die Urwirbel abgesetzt ist; es geht ohne Grenze in das zellige Gewebe des Mesenteriums, um die Aorta etc. über und verwandelt sich bei der weiteren Entwicklung zum Theil in glatte Muskelzellen, zum Theil in gewöhnliches, ungeformtes Bindegewebe. Das Peritonealepithel ist auf der costalen Seite stark verdickt, ebenso an der Uebergangsstelle in das viscerale Blatt, wird jedoch hier mehr einschichtig, aus einer einfachen Lage meist klcinerer Kerne bestehend (cf. taf. V. fig. 1. P. ep., fig. 2., 11. etc.). Von ihm geht die Entwicklung der Urniere aus, zu der ich mich jetzt wende:

\section{a. bei Lacerta agilis.}

Wenn man einen jungen Embryo einem Eileiterei entnimmt und, frisch schon bei schwacher Vergrösserung in seitlicher Lage untersucht, so bemerkt man leicht neben der Reihe der Urwirbel nach der Bauchwand zu eine Reihe von rundlichen Bläschen, die vordersten als wirkliche Blasen, die hinteren als noch solide, aus Zellen bestehende Kugeln; die Anordnung ist eine völlig regelmässige und was ganz besonders hervorgehoben werden muss, die Zahl der Blasen stimmt in der Anlage vollkommen mit der Zahl der Urwirbel überein; nach vorn hört meist diese Uebereinstimmung auf, die Urwirbel werden grösser und auf eine gewisse Zahl derselben kommt eine grössere Zahl von Urnierenbläschen. Dieses Verhältniss bleibt sich bei jeder Behandlungsweise des Embryo gleich; ich habe auf taf. $\mathrm{V}$ in fig. 4 und 5 Sagittalschnitte von in ihrer natürlichen Lage gehärteten Embryonen der Lacerta agilis halbschematisch abgebildet; doch sind die Contouren des ganzen Bildes wie der Theile genau mit einem Zeichenprisma nach dem Original ausgeführt; die 10 Blasen (fig. 4. taf. V. Sg. bl.) liegen genau neben 10 Urwirbeln, je eine zu einem Wirbel gehörig; weiter nach vorn war schon eine Verschiebung der Theile eingetreten, welche 
Incongruenz bedingte. Sehr häufig erhält sich nun eine Zeit lang, wenigstens streckenweise diese segmentale Anordnung; in fig. 5 . taf. V. ist ein Sagittalschnitt von einer mehr nach vorn gelegenen Stelle der Urniere abgebildet, an der bereits Urnierenkanälchen (Ur. k.) und Malpighische Körperchen (M. K.) vorhanden sind; auch hier ist die regelmässige segmentweise Anordnung noch bei den 5 hintersten Urnierenbläschen (Sg. bl.) deutlich zu erkennen, während das sechste sich zwischen Urwirbel 5 u. 6 - von hinten gezählt - einschiebt. Selbst nach dem Aufhören der strengen Segmentirung, d. h. der der Zahl nach genauen Uebereinstimmung zwischen Urnierenbläschen und Urwirbeln bleibt die Urniere bis in das späte Embryonalleben gegliedert, wie dies in übereinstimmender Weise Lereboullet ${ }^{1}$ ) von Lacerta agilis und Rathke ${ }^{2}$ ) von Tropidonotus natrix berichtet haben; die Autoren sprechen zuerst von einer Reihe von Bläschen, später von Malpighischen Körperchen und wirklich gibt es kaum ein regelmässigeres und zierlicheres Bild als eine frische Urniere bei schwacher Vergrösserung betrachtet; medial liegen von vorn nach hinten in einer Reihe die röthlichen glomeruli, dann folgen die gelblichen, stark getrubten Urnierenkanälchen, welche in regelmässigen der Zahl nach mit der der glomeruli übereinstimmenden Sammelgängen, welche sich durch ein geringeres Lumen von den eigentlichen Drüsenkanälchen unterscheiden, in den Wolff'schen Gang einmünden. Später geht diese Regelmässigkeit verloren, indem oft 2 und 3 Malpighische Körperchen nebeneinanderliegen.

Bei der Betrachtung von Sagittalschnitten oder frischen Objekten ist es nicht möglich, sich über die Herkunft dieser Urnierenbläschen oder wie sie aus verschiedenen, weiter unten zu erörternden Gründen richtiger Segmentalbläschen genannt werden, zu vergewissern; dazu sind Querschnitte durch gehärtete und gestreckte Embryonen nöthig. Eine Untersuchung solcher Schnitte, wie sie in den fig. 1. u. 2. taf. V von Lacerta agilis abgebildet sind, ergibt nun Folgendes: seitlich neben der Aorta liegt ein kolbiger Zellenhaufen, der sich bei genauer Verfolgung der Schnittserie als ein kugliger, nach vorn und hinten scharf abgegrenzter Körper zu erkennen gibt und dessen Zellen direkt mit den Zellen des Peritonealepithels zusammenhängen; der zellige Körper selbst ist noch solid, an diesen schliesst sich ventral ein kurzer, hohler Stiel, dessen

1) Recherches sur le développement du lézard. Ann. d. sc. nat. Zool. tom. X VII. p. 145 u. taf. V, fig. 50.

2) Entwicklungsgeschichte der Natter. p. 47. 
Höhle direkt mit der Peritonealhöhle kommunicirt. Der in fig. 1. taf.V. abgebildete Schnitt stammt aus der hintersten Körpergegend eines schon ziemlich weit entwickelten, doch noch nicht abgelegten Embryos, der im vordersten Theil der Urniere bereits Malpighische Körperchen erkennen lässt; daher die Differenz in der Ausbildung der Theile zwischen diesem und dem in fig. 2. abgebildeten Schnitt, der einem viel jüngeren Thier zukommt, aus dem vorderen Theile herrührt und ein späteres Entwicklungsstadium der Urnierenbläschen darstellt. In fig. 2. taf. V. liegt zwischen Aorta und Wolff'schen Gang der Querschnitt einer grossen Blase, die als solche sich durch die Verfolgung der Schnittserie und durch die seitliche Ansicht (cf. taf. V. fig. 4.) zu erkennen gibt. Die sie konstituirenden Elemente sind cylinderförmige Zellen mit grossem Kern, sie gehen ventral in die kleineren Kerne des Peritoneums allmälig und ohne Grenze über; die Brücke ist allerdings sehr kurz, doch deutlich vorhanden; eine Kommunikation dieser Segmentalblase mit der Peritonealhöhle durch einen hohlen Kanal existirt auf diesem Stadium sicher nicht mehr; ich habe so viele Schnittserien und genau aufeinanderfolgende Entwicklungsistufen durchmustert, dass ich sagen muss, die Communikation besteht nur sehr kurze Zeit, ist überhaupt auf Schnitten nur selten zu finden; so wie in der soliden Zellenkugel (fig. 1. taf. V. Sg. bl.) eine Höhlung auftritt (fig. 2. Sg. bl.) ist auch die früher bestehende, hohle Einsenkung des Peritoneums geschlossen und die Höhlung der Segmentalblase ausser aller Verbindung mit der Bauchfellhöhle; nur die Wandung derselben hängt mit dem Epithel durch einen kurzen soliden Stiel zusammen.

Dass fig. 2. taf. V. wirklich ein vorgeschritteneres Stadium von fig. 1. darstellt, lehrt nicht allein die Verfolgung der Schnittserie von fig. 1. nach vorn zu, sondern auch die Vergleichung älterer Embryonen und die seitliche Ansicht (taf. V. fig. 4). In beiden Fällen finden wir nach vorn von deu soliden, dorsalwärts gehenden Knospen des Peritoneums rundliche oder ovale Blasen, welche eine Zeit lang mit den Peritonealzellen in Verbindung stehen, sich später aber von diesen abschnüren und weitere Umwandlungen erfahren.

Als solche ist zunächst die Bildung der Urnierenkanälchen zu beschreiben, von welchen ich gefunden halie, dass sie seitliche Sprossen der Segmentalbläscheu sind und sich erst sekundär mit dem Wolff'schen Gange in Verbindung setzen; nie habe ich weder am frischen Präparat noch an Querschnitten gesehen, dass der Urnierengang durch Sprossen sich daran betheiligt, sondern allein die Segmentalblase; diese liegt 
nämlich zuerst (fig. 2. taf. V.) sehr dicht am Wolff'schen Gange, wird jedoch meist später durch eine dünne Schicht noch indifferenter Kerne des Mosoderms von demselben getrennt; Querschnitte lassen dann einen kleinen, kuppenartigen Fortsatz der Segmentalblase erkennen, der nach dem Wolff'schen Gang zustrebt, diesen erreicht, ja sogar dessen Wandung etwas einstülpt, schliesslich aber mit ihm so verschmilzt, dass eine Trennung der beiderseitigen Zellen völlig unmöglich ist und man nicht direkt entscheiden kann, ob nicht aus der Grenzschicht von Zellen zwischen künftigem. Urnierenkanälchen und dem Wolff'schen Gang kurze Gänge, die späteren Sammelgänge hervorgehen.

Schon Lereboullet ${ }^{1}$ ) hat bei Lacerta agilis die Umwandlung der Bläschen in die Kanäle der Urniere beobachet, doch scheint aus seinen Worten hervorzugehen, dass er die ganze Blase in den Kanal sich verwandeln lässt, während ich das primäre Urnierenkanälchen als einen seitlichen Spross der Wandung der Segmentalblase erkannt habe.

Das Verbindungsstuick zwischen Segmentalbläschen und Wolff'schem Gang ist anfangs solid und grade gestreckt, krümmt sich jedoch sehr bald Sförmig, wobei auch die Segmentalblase ihre Lagerung ändert und sich statt der vorher inne gehabten Richtung mit dem grössten Durchmesser von rechts nach links nun schräg von oben nach unten stellt (ef. taf. V. fig. 3).

Auf diesem Stadium geht die Krümmung des Verbindungsstückes noch nicht über eine senkrecht durch die Körperaxe gelegte Ebene heraus; daher bekommt man auf Querschnitten dieses Bild sehr häufig (taf. V. fig. 3); später erheben sich einzelne Strecken über oder senken sich unter die ursprüngliche Ebene und es ist dann reiner Zufall, wenn man ein mittelgrosses Urnierenkanälchen von seinem Ursprung bis zur Einmündungsstelle auf einem Schnitt verfolgen kann; meist braucht man dazu noch mindestens den vorhergehenden und folgenden Schnitt (cf. taf. V. fig. 7), oft noch mehrere; doch wird man sich immer überzeugen, dass wenigstens bis zur Mitte des Embryonallebens hin ein jedes Malpighische Körperchen seinen eignen Urnierenkanal hat, der ohne mit andern in Verbindung zu treten, nach mannigfachen Windungen sịch ziemlich verschmälert und von der Mittellinie herkommend in den Wolff'schen Gang eintritt. Es ist dies ein Verhalten, das auch Lereboullet (l. c. tab. V. fig. 50) zur Darstellung bringt, er zeichnet den Wolff'schen Gang und an diesem zwei Urnierenkanälchen mit ihren

1) Rech. sur le dével, du lézard. I. c. p. 136. 
typischen Theilen, die, ohne eine Verbindung mit einander einzugehen, in den Wolff'schen Gang münden. Lereboullet ist durch Präparation zur Erkennung dieser Thatsachen gekommen, während ich es durch Querschnitte konstatirte. Auf der Höhe der Ausbildung der Urniere möchte ich mich weniger bestimmt für dies Abgeschlossensein der einzelnen Kanälchen aussprechen; bei den sehr zahlreichen Windungen, welche dieselben dann beschreiben, ist ein Verfolgen eines einzelnen Kanales nicht gut möglich; wenn man auch oft, namentlich bei Blindschleichen und Nattern 2, selbst 3 Malpighische Körperchen auf einem Schnitt erhält, so habe ich doch nie eine Theilung der Urnierenkanälchen beobachtet, so dass ich annehmen zu können glaube, dass das frühere Verhältniss des gesonderten Verlaufes des zu einem glomerulus gehörigen Urnierenkanälchen erhalten bleibt; wir können uns also schematisch die Urniere der Reptilien so denken, dass wir von dem hohlen Urnierengang ausgehend in direkt nach der Mittellinie zustrebende, regelmässig angeordnete, schmale Kanäle gelangen, die sich erweitern, sehr vielfach winden und schlingen und endlich an die zu beiden Seiten des Mesenteriums gelegenen Malpighischen Körperchen herantreten und hier den Gefässknäuel aufnehmen.

Dieser bildet sich nach meinen Beobachtungen auf folgende Weise: Nachdem das Lumen der Segmentalblase sich in das anfangs solide Urnierenkanälchen fortgesetzt und dieses in den Wolff'schen Gang durchgebrochen ist, stülpt sich die der Aorta zunächst gelegene Wand der Blase nach innen ein; ich habe nicht recht entscheiden können, ob diese Einstülpung eine Wucherung der Wandung nach innen, also solid ist und erst später hohl wird, oder von Anfang an eine echte Einstülpung darstellt; jedenfalls vermehrt sich die Zellenlage der Segmentalblase und begrenzt später einen in die Höhlung der Blase einspringenden Hohlraum (cf. taf. V. fig. 6), in dessen Innern Blutkörperchen und Zellen von zweifelhaftem Charakter liegen; sehr oft und wie ich glaube auf den jüngeren Stadien habe ich darin Blutkörperchen gesehen, ohne dass es mir bei Verfolgung der nächsten Schnitte möglich gewesen wäre, eine Verbindung dieser Einstülpung mit der benachbarten Aorte zu finden, wie sie in den weiter nach vorn liegenden, sich bildenden Malpighischen Körperchen da ist. Dies ist der Grund, warum ich mit Bornhaupt $^{1}$ ) zu der Annahme hinneige, dass die Blutkörperchen im

1) Untersuchungen über die Entwickelung des Urogenitalsystems beim Hühnchen. In.-Diss. Riga. 1867. p. 26. 
Innern der Einstülpung entstehen, sich vielleicht von der Wandung derselben abschnüren oder sich aus den noch indifferenten Zellen des Mesoderms entwickeln, cf. taf. V. fig. 6 u. 7 a. Diese Frage habe ich nicht weiter verfolgt, da sie mich zu weit von meinem Thema abgeführt hätte, ebenso wenig habe ich nach der weiteren Ausbildung des glomerulus, nach den vielfachen Schlingen desselben u. s. w. gesucht; mir kam es nur darauf an, zu zeigen, dass die Segmentalbläschen sich durch Wucherung oder Einstülpung des der Aorta zunächst gelegenen Theiles ihrer Wandung zu echten Malpighischen Körperchen umbilden, die ihr Blut direkt durch kurze Gefässstämmchen, welche natürlich ebenso regelmässig wie die Organe, zu denen sie führen, angeordnet sind, aus der Aorta erhalten (cf. taf. V. fig. 9). Der Verlauf der zuführenden Gefässe ist anfangs ein grader, erst später kommt das Körperchen tiefer zu liegen, wodurch die vasa afferentia einen schrägen von vorn nach hinten gehenden Verlauf erhalten. Ueber den Verbleib der austretenden Gefässe weiss ich Nichts anzugeben.

Die äussere Wandung des Malpighischen Körperchen besteht aus einer einschichtigen Lage platter kernhaltiger Zellen, die sich bei günstig geführtem Schnitt an die Zellenbekleidung des glomerulus unmittelbar anschliessen, wie sie ja in der That von demselben Substrat nämlich vom Peritoneum herstammen. Die den glomerulus bekleidenden Zellen gehen später ebenfalls in Plattenzellen mit polygonaler Begrenzung und deutlichem Kern über; wie sich zu ihnen das Gefässendothel verhält, ist mir unbekannt geblieben.

Das an den glumerulus sich anschliessende Urnierenkanälchen beginnt mit einer trichterförmigen Erweiterung, verengt sich jedoch sehr bald; die platten Zellen der'Wandung des Malpighi'schen Körperchens erheben sich und gehen allmählich in die einschichtige Cylinderzellenlage der Urnierenkanälchen über; die Abgangsstelle liegt allermeist an der lateralen Wandung des Körperchens. Es ist schon oben erwähnt worden, dass man an den Kanälchen zwei Theile unterscheiden kann: die dickeren (bei Lereboullet tubes ondulés oder sacs sécréteurs) sind die drüsigen Kanälchen und von einer einschichtigen Cylinderzellenlage ausgekleidet, deren Protoplasma durch zahllose kleinste Körnchen gelblich getrübt ist, was sich auch an mit Terpentin etc. behandelten Präparaten noch erhält. Schon seit langem ist bekannt, dass die Urnierenkanälchen bei den Reptilien flimmern, ${ }^{1}$ ) wovon man sich bei jedem

$\left.{ }^{1}\right)$ cf. Die Angaben von Remak in Frorieps neue Notizen. XXXV. 1845. p. 308 und 309 und Kölliker in Müll. Arch. für Anatomie und Physiologie 1845. p. 518-523. 
Irischen Präparat iiberzengen kann. So riel ich gesehen have, flimmern alle Kanälehen, mit Ausnahme ihres Anfangs- und Endstückes; die Cilien sind sehr lang und erhalten sich nicht in Chromsäurepräparaten, wesshalb sie auf meinen Zeichnungen durchgehends weggelassen sind. Im Wolff'schen Gang habe ich nie etwas von Flimmerung gesehen, ebensowenig in der Höhlung der Malpighischen Körperchen.

Die zweiten Theile der Urnierenkanälchen, die Sammelröhrchen oder Endröhrchen, unter welchen die einzelnen Enden der Urnierenkanälchen mit der Mündung in den. Wolff'schen Gang zu verstehen sind, tubes droits Lereboullet's, und welche - höchst wahrscheinlich - nicht mehrere Kanälchen aufnehmen, sind bedeutend dünner sowohl in ihrer Wandung als auch im Lumen, die Zellen sind kubisch, ohne körnige Trübung. Diese Sammelröhrchen treten alle von der Mittellinie herkommend in die mediale Wandung des Wolff'schen Ganges ein und verlaufen ziemlich oberflächlich auf der dorsalen Fläche der Urniere. Präparirt man eine solche heraus und betrachtet bei schwacher Vergrösserung ihre dorsale Fläche, so sieht man mehr lateral den Wolff'schen Gang, von diesem ausgehend ganz regelmässig die Endröhrchen wie Spangen die Urniere umfassend, um sich an der medialen Fläche derselben in die Tiefe zu senken; namentlich bei Schlangenembryonen ist dies sehr deutlich zu erkennen.

\section{b. bei Anguis fragilis.}

Da die Entwicklung der Segmentalorgane bei den einzelnen Familien der Reptilien wenig Differenzen bietet, vielmehr sich eng an das bei Lacerta agilis erkannte anschliesst, so werde ich im Nachfolgenden nur einige abweicheude Punkte anführen, um Wiederholungen zu vermeiden.

Auch bei unsrer Blindschleiche werden die Segmentalorgane in Form von kleinen Bläschen angelegt, welche ebenfalls in der ersten Zeit ihres Bestehens streng segmental angeordnet sind, um dann wie bei den Eidechsen in einfacher Gliederung zu verbleiben.

Die Segmentalblase (cf. Taf. V, Fig. $11 \mathrm{u.12}$ ) ist kleiner als bei den Eidechsen (ich werde weiter unten eine vergleichende Tabelle der Masse geben) und aus mehr Zellen zusammengesetzt; in Fig. 12, Taf. V, welche ein etwas früheres Stadium als Fig. 11 darstellt, ist der Schnitt etwas schräg geführt; wir sehen einerseits (Sg.-bl.) die Blase mitten durchgetroffen, ihre ventrale Fläche in Verbindung mit dem Peritonealepithel; auf der andern Seite ist ihr vorderes oder hinteres 
Deckstück in den Schnitt gefallen und gegen das Peritoneum scharf abgegrenzt. Die Blase grenzt lateral an den Wolffschen Gang, den sie etwas eindrückt, medial an die Aorta. In dem älteren Stadium Fig. 11 erfolgt kurz vor der Bildung der Urnierenkanälchen eine Drehnng der Blase, sie neigt ihre frühere dorsale Fläche gegen den Wolffschen Gang zu, von dem sie etwas abgerückt erscheint und entsendet gegen diesen einen kleinen Fortsatz, den ersten Anfang des Segmentalkanälchens. Dieses verbindet sich sehr bald mit dem Ausführungsgang (Fig. 11, Ur.-k.) und macht dann dieselben Umwandlungen durch, wie sie bei der Eidechse beschrieben worden sind. Auffallend ist, dass die solide Verbindung der Segmentalblase mit dem Peritonealepithel so lange bestehen bleibt und bei der Drehung der Blase in einen förmlichen Stiel (Sg.-g. Fig. 11) ausgezogen erscheint; selbst wenn die Abschnürung stattgefunden hat, bemerkt man noch an der ventralen Fläche der Blase ein kleines Häufchen von Zellen, welches ich als den Rest dieses Stieles deute (cf. Fig. 11, Taf, V rechterseits).

Mit der Drehung der Blase scheint sich auch das Lumen derselben zu verkleinern, später bei der Bildung der Malpighischen Körperchen wird es wieder grösser; es entsprechen die hierbei beobachteten Bilder ziemlich genau den in Fig. 6-8, Taf. V wiedergegebenen Entwicklungsstadien bei Lacerta agilis; die glomeruli gehen anch bei der Blindschleiche aus einer Einstülpung der medialen Wand der Segmentalblase hervor und erhalten ihr Blut durch kleine Zweige direkt aus der Aorta.

Auf der Höhe der Ausbildung der Urniere kann man Kanälchen von zweierlei Dicke erkennen, die dickeren, die sich unmittelbar an die glomeruli anschliessen und in dem Stroma der Urniere zahlreiche Windungen, jedoch keine beobachteten Theilungen beschreiben, haben ein stark getrübtes, einschichtiges Flimmerepithel, während die schwächeren aus der Tiefe an die dorsale Fläche der Segmentalorgane tretend, ein niedrigeres Epithel besitzen, das nicht mehr zu flimmern scheint; sie dringen alle in regelmässigen Abständen in die mediale Fläche des Wolffschen Ganges ein und verhalten sich wie bei den Eidechsen.

\section{c. bei Tropidonotus natrix.}

Die Embryonen unserer Ringelnatter würden sich wegen der Länge der Segmentalorgane und der dadurch bedingten sehr verschiedenen Ausbildung der einzelnen Abschnitte derselben am besten zu ihrem Studium eignen, wenn nicht gerade diese Länge eine ganz besondere Anforderung 
an unsere Geduld beim Anfertigen von Schnittserien stellte; freilich ist dann auch eine solche Serie ganz besonders lehrreich und für die andern Organe ebenfalls brauchbar.

Bei einem Embryo von $13^{\mathrm{mm}}$. Länge (Scheitel bis After) konnte ich zuerst an Querschnitten das Vorhandensein von Segmentalblasen und die Verbindung des Epithels derselben mit dem Peritonealepithel aufs Deutlichste nachweisen und verschiedenen Beobachtern demonstriren. Die Blasen liegen an der gewöhnlichen Stelle (cf. Fig. 13, Taf. VII) zwischen Wolff'schen Gang und Aorta einerseits und Urwirbel und Peritonealepithel andrerseits; sie sind ziemlich klein, rundlich, etwas in die Breite gestreckt. Die Abschnürung findet früh statt. Die Zahl der letzten, also jüngsten Blasen stimmt immer genau mit der Zahl der zugehörigen Urwirbel überein; ich habe mich davon bei frischer Untersuchung der hintersten Enden der Segmentalorgane, die nicht heraus- . präparirt waren, oft genug überzeugt; die Theile sind so durchsichtig, dass man ziemlich starke Vergrösserungen anwenden kann und nicht zu Aufhellungsmitteln, die vielleicht quellend auf manche Theile einwirken könnten, seine Zuflucht zu nehmen braucht; ich untersuchte in $1 / 2-1 \%$ Kochsalzlösung oder auch in Eiweiss von Nattereiern; döch auch Sagittalschnitte von in Chromsäure und Alkohol gehärteten Embryonen zeigen dasselbe Verhältniss, das jedoch vorübergehend ist; auf späteren Stadien erscheint die Reihe der Urnierenkanälchen gegenüber derjenigen der Körpersegmente zusammengerückt, was jedoch Folge eines stärkeren Wachsthums der letzteren ist. Rathke giebt in seiner Entwicklungsgeschichte der Natter p. 47 ausdrücklich an, dass die Zahl der Bläschen oder Beutelchen, wie er die Segmentalblasen nennt, nicht genau mit der Zahl der Urwirbel übereinstimme; ich kann mir diese Angabe nicht recht erklären, da ich stets eine streng segmentweise Anordnung der jüngsten Segmentalbläschen erkenne, wovon auch Semper, noch ehe ich meine Untersuchung begann, sich überzeugt hatte, indem er (Urogenitalsystem der Plagiostomen p. 414) sagt: „bei Reptilier ist es ungemein leicht, sich davon zu überzeugen, dass in der That jedem Urwirbel auch eine Blase entspricht... “. Ich kann nur annehmen, dass Rathke nicht die jüngsten Bläschen gesehen hat, sondern weiter vorn zählte, wo ja in der That eine Inkongruenz in der Zahl besteht, die hintersten 10-15 Bläschen sind immer segmental angeordnet.

Wenn man sich die Mühe giebt aus Embryonen von abgelegten Eiern etwa 13-16 Tage nach der Ablage die Urniere herauszupräpariren, so wird man bei schwacher Vergrösserung an dem hinteren Ende 
derselben bemerken, dass am Wolffschen Gang in bestimmten regelmässigen Entfernungen Knäuel von Kanälchen hängen, die nicht unter einander in Verbindung stehen; es sind dies die hintersten Abschnitte der Urniere aus je einem Segmentalorgan bestehend; der Abstand zwischen zwei Knäulen betrug bei einem Embryo vom 13. Tage nach der Eiablage $0,339 \mathrm{~mm}$. Ich halte das mit für eine Stütze meiner oben bei der Urniere der Eidechse ausgesprochenen Ansicht, dass der zu einem Malpighischen Körperchen gehörige Kanal nicht mit dem davor oder dahinter liegenden communicirt, dass vielmehr die Urniere aus einer regelmässig hinter einander liegenden Reihe von einzelnen, abgeschlossenen, schlauchförmigen Drüsen, den Segmentalorganen besteht.

\section{d. bei anderen Schlangen.}

Es war mir noch möglich ganz junge Embryonen von Callopeltis A esculapii und einer unbestimmten $\mathrm{Z}$ am e $\mathrm{n}$ is art aus Italien, welche bei einem hiesigen Naturalienhändler in der Gefangenschaft abgelegt hatte, zu untersuchen.

Die Embryonen der Aeskulapschlange hatten eine Länge von 11 bis $13^{\mathrm{mm}}$. und boten noch frühe Entwicklungsstadien der Segmentalorgane dar; die vordersten hatten sich bereits vom Peritoneum abgeschnürt und standen durch solide, strangförmige Sprossen mit dem Wolff'schen Gang in Verbindung; nach hinten fand ich sie in der ersten Bildung als kleine, am Peritoneum hängende Blasen, die sich allmählich nach vorn vergrösserten; nie habe ich bei Schlangen die Bildung eines eigentlichen Trichters, wie bei den Eidechsen beobachtet, auch nicht die Andeutung eines feinen Spaltes, doch mag vielleicht die Behandlungsweise in dieser Beziehung ändernd eingewirkt haben.

Von den Embryonen der Zamenis sp.? konnte ich nur ganz hinten zwei noch mit dem Peritoneum in Verbindung stehende Segmentalblasen erkennen; weiter nach vorn die Bildung von Kanälchen als laterale Sprossen dieser Blasen und endlich etwa von der Mitte ab die völlig ausgebildete Urniere, welche kein abweichendes Verhalten bot.

Im Anschluss hieran gebe ich eine vergleichende Tabelle für die Masse der einzelnen Theile der Segmentalorgane bei den untersuchten Embryonen, wobei ich bemüht war, möglichst entsprechende Stadien zu wählen, doch ist natürlich dem subjectiven Ermessen grosser Spielraum gelassen. 


\section{Wolff"scher Gang.}

\begin{tabular}{|c|c|c|c|c|c|c|c|c|}
\hline Masse in $\mathrm{mm}$. & \multicolumn{2}{|c|}{$\begin{array}{l}\text { Grösster } \\
\text { Durchm. }\end{array}$} & \multicolumn{2}{|c|}{$\begin{array}{l}\text { Kleinster } \\
\text { Durchm. }\end{array}$} & \multicolumn{2}{|c|}{$\begin{array}{l}\text { Höhe des } \\
\text { Epithels. }\end{array}$} & Kerne. & \\
\hline \multirow{3}{*}{$\begin{array}{l}\text { 1. hald nach seiner } \\
\text { Entstehung. }\end{array}$} & \multicolumn{2}{|c|}{0,039} & \multicolumn{2}{|c|}{0,035} & \multicolumn{2}{|c|}{0,014} & 0,010 & Trop. natr. \\
\hline & \multicolumn{2}{|c|}{0,055} & \multicolumn{2}{|c|}{0,035} & \multicolumn{2}{|c|}{0,016} & 0,008 & Coron. laevis. \\
\hline & \multicolumn{2}{|c|}{0,065} & \multicolumn{2}{|c|}{0,025} & \multicolumn{2}{|c|}{0,009} & 0,008 & Anguis frag. \\
\hline $\begin{array}{l}\text { vorn } \\
\text { hinten }\end{array}$ & \multicolumn{2}{|c|}{$\begin{array}{l}0,023 \\
0,080\end{array}$} & \multicolumn{2}{|c|}{$\begin{array}{l}0,019 \\
0,023\end{array}$} & \multicolumn{2}{|c|}{0,009} & 0,008 & Lac. agilis \\
\hline \multirow{5}{*}{$\begin{array}{l}\text { 2. aus der Mitte des } \\
\text { Embryonallebens. }\end{array}$} & \multirow{4}{*}{\multicolumn{2}{|c|}{$\begin{array}{l}0093 \\
0,072 \\
0,089 \\
0,071\end{array}$}} & \multirow{4}{*}{\multicolumn{2}{|c|}{$\begin{array}{c}0,093 \\
0,069 \\
0,062 \\
0,024-0,053\end{array}$}} & \multirow{4}{*}{\multicolumn{2}{|c|}{\begin{tabular}{|c}
0,012 \\
0,012 \\
0,017 \\
0,021 \\
Breite 0,008 \\
\end{tabular}}} & 0,008 & Tropid. natr. \\
\hline & & & & & & & 0,008 & Coron. laev. \\
\hline & & & & & & & 0,009 & Anguis frag. \\
\hline & & & & & & & 0,007 & Lac. agil. \\
\hline & M. & W. & M. & W. & M. & W. & & \\
\hline \multirow{4}{*}{$\begin{array}{l}\text { 3. kurz vor dem Aus- } \\
\text { schlüpfen. }\end{array}$} & 0,069 & 0,064 & 0,061 & 0,053 & 0,016 & 0,016 & 0,007 & Trop. natr. \\
\hline & $?$ & ? & $?$ & $?$ & ? & ? & ? & Coron. laev. \\
\hline & 0,091 & 0,089 & 0,065 & 0,053 & $\begin{array}{ccc}0 & 0 & 10 \\
0,0 & 0 & 17\end{array}$ & 0,014 & 0,008 & Anguis frag. \\
\hline & 0,141 & 0,135 & 0,113 & 0,113 & 0,020 & 0,020 & 0,010 & Lac. agil. \\
\hline
\end{tabular}

Segmentalblase.

\begin{tabular}{l||c|c|c|c|c}
\hline & $\begin{array}{c}\text { Grösster } \\
\text { Durchmesser. }\end{array}$ & $\begin{array}{c}\text { Kleinster } \\
\text { Durchmesser. }\end{array}$ & $\begin{array}{c}\text { Höhe des } \\
\text { Epithels. }\end{array}$ & $\begin{array}{c}\text { Breite der } \\
\text { Zellen. }\end{array}$ & Kerne. \\
\hline Tropid. natr. & 0,084 & 0,046 & $0,014-0,017$ & - & 0,008 \\
Anguis frag. & 0,103 & 0,065 & 0,022 & - & $0,008-0,014$ \\
Lac. agilis & 0,112 & 0,060 & $0,019-0,024$ & $0,008-0,01$ & 0,008
\end{tabular}




\section{Urnierenkanälchen.}

a) secernirender Abschnitt.

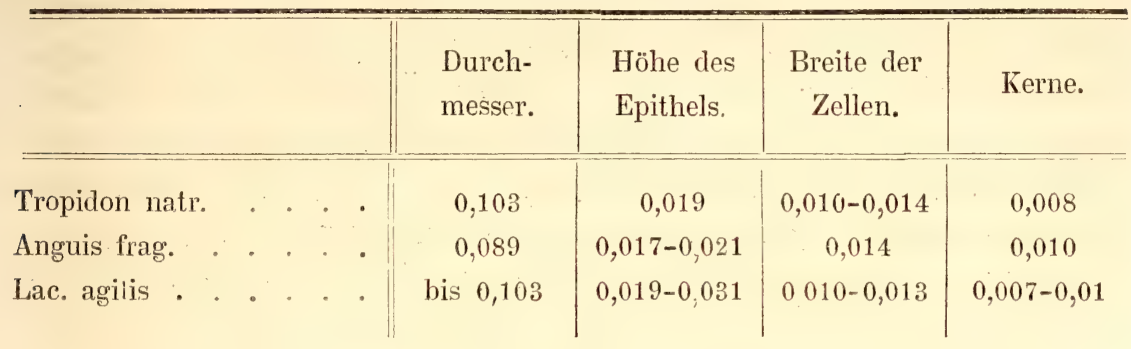

b) leitender Abschnitt.

\begin{tabular}{ll||c|c|c|c}
\hline & & $\begin{array}{c}\text { Durch- } \\
\text { messer. }\end{array}$ & $\begin{array}{c}\text { Höhe des } \\
\text { Epithels. }\end{array}$ & $\begin{array}{c}\text { Breite der } \\
\text { Zellen. }\end{array}$ & Kerne. \\
\hline Tropidon. natr. . . . . . & 0,039 & 0,014 & 0,010 & 0,007 \\
Anguis frag. . . . . . & 0,035 & 0,010 & 0,009 & 0,008 \\
Lac. agil. . . . . . . & 0,035 & 0,008 & 0,005 & $0,004-0,006$
\end{tabular}

\section{Die ausgebildete Urniere.}

Was nun die Verhältnisse der ausgebildeten Urniere anlangt, so habe ich über diesen Punkt die wenigsten Untersuchungen angestellt, weil mich andere Organe viel zu sehr fesselten; es ist auch kaum anzunehmen, dass hier irgend welche besondere Differenzen vorkämen, die nicht bereits oben ihre Erledigung gefunden hätten. Wegen der äussern Formverhältnisse verweise ich auf die ziemlich ausführliche Darstellung Rathke's ${ }^{1}$ ), die jedoch hauptsächlich nur spätere Stadien berücksichtigt und eine Reihe von Fragen, die heute von der grössten Bedeutung sind, naturgemäss gar nicht berührt. Was jedoch von mir angegeben wurde, befindet sich meist in Uebereinstimmung mit den Darstellungen Rathke's. Hervorheben muss ich noch mit Rathke die Lage der Malpighi'schen Körperchen oder "Blutdrüsen der Urniere"; "alle haben ihre Lage sehr

1) Entwicklungsgeschichte der Natter p. 154 etc. Königsberg 1839. 
oberflächlich an der nach innen gekehrten Seite der genannten Eingeweide (Urnieren), befinden sich in einiger Entfernung von dem untern Rande derselben, stehen dicht gedrängt beisammen und setzen ursprünglich eine einfache Reihe zusammen; nachher aber, wenn sie sich vergrössern und vermehren, verschieben sie sich, besonders im mittleren Theil des Organes..." Was hier von den Segmentalorganen der Natter gesagt ist, gilt auch für die andern untersuchten Reptilien. Die später auftretende grössere Zahl der glomeruli, durch welche das Verlorengehen der Regelmässigkeit bedingt wird, muss als eine Theilung der ursprünglich aus den Segmentalblasen hervorgegangenen glomeruli aufgefasst werden, zu welcher Deutung auch J. W. Spengel ${ }^{1}$ ) für die Amphibien gekommen ist, ohne übrigens die Möglichkeit einer späteren, sekundären Einstülpung des Peritonealepithels ausschliessen zu können, da die Entwickelung von diesem Autor bis dahin noch nicht zur Genüge untersucht war. Ich habe auf diesen Punkt bei Reptilien geachtet und kann eine sekundäre Einstülpung ausschliessen, so dass kaum ein anderer Weg zur Erklärung übrig bleibt als der der Theilung, wofür ich auch einige Beobachtungen anführen zu können glaube, die ich bei Natterembryonen gemacht habe; ich sah nämlich oft genug sehr langgestreckte Malpighi'sche Körperchen, fernerhin auch solche, in denen der glomerulus in zwei Hälften zerfiel und selbst die Kapsel, der Theilung der glomeruli entsprechend, eine seichte Furche zeigte. Da ich nun auf älteren Stadien statt eines Malpighi'schen Körperchens in einer Ebene zwei fand, mitunter auch mehr, so glaube ich nicht fehl zu gehen, wenn ich die erwähnten Beobachtungen kombinirend eine Theilung und dadurch bedingte Vermehrung der Körperchen annehme. Wie weit die Theilung in das Segmentalkanälchen hineingeht, kann ich nicht angeben, da Schnittserien hierzu ungünstig sind. Mit der Vermehrung der Körperchen wird selbstredend auch die Gefässvertheilung eine andere, so lass an einem der Aorta entspringenden Gefäss mehrere glomeruli ansitzen und schliesslich eine Traubenform entsteht, wie sie Rathke (Natter tab. III. fig. 15 und 16) abbildet.

Die regressive Metamorphose der Urniere kann ich erst bei Behandlung der ausführenden Geschlechtswege besprechen.

1) Das Urogenitalsystem der Amphibien. Diese Arbeiten Bd. III. Heft 1. 


\section{B. Geschlechtsorgane.}

\section{Indifferentes Stadium.}

\section{a. Bei Lacerta agilis und Anguis fragilis.}

Mit diesem Namen bezeichne ich jenen Znstand der ersten Anlage der Keimdrüsen, in welchem es noch nicht möglich ist, das künftige Geschlecht des Embryo zu erkennen; in diesem Stadium lassen auch äussere Charaktere, die später auf den ersten Blick Männchen und Weibchen leicht unterscheidbar machen, völlig im Stich, da sie noch einander ganz gleich sind; ich meine hauptsächlich die Penispapillen, die bei beiden Geschlechtern angelegt werden, ungefähr von der Mitte des embryonalen Lebens an beim Männchen sehr an Grösse zunehmen und dadurch ein gutes Merkmal des männlichen Geschlechts sind.

Die ersten Spuren der Geschlechtsorgane gehen sehr weit zurück und fallen zeitlich fast genau mit der ersten Entstehung der Segmentalorgane zusammen; da wo nämlich das Peritonealepithel, welehes die Segmentalorgane (Urnierenfalte, Keimwall der Autoren) überzieht, in das Epithel anf der Darmfaserplatte iibergeht, also am Beginne des Mesenteriums des Darmes sicht man schon bei Embryonen von 8-9 $\mathrm{mm}$. (Anguis fragilis. ef. taf. V. fig. 11 u. 12. Ur. f.) in dem meist etwas verdickten Epithel einzelne grosse Zellen liegen, die von gewöhnlichen Peritonealzellen begrenzt sind. Die Thatsache, dass man bei einigem Suchen leicht Uebergánge zwisehen den Peritonealzellen, die übrigens nur Kerne in einer ganz geringen Nenge Protoplasma sind, und den vergrösserten, echten Zellen mit Zellmembran, Protoplasma und Kern findet, deutet darauf hin, dass hier durch besondere Wachsthumsvorgänge eine Ansammlung von Protoplasma um einen Kern in erhöhtem Masse stattgefunden hat, der völlig gleichwerthig den Peritonealzellenkernen ist. Solche vergrösserte Peritonealzellen bezeichnet man als Ureier, welchen Namen ich von jetzt ab ebenfalls gebranchen werde, während ich die allerdings bis jetzt noch nicht erhobene Stelle des Peritonenms, welche die Ureier birgt, nach dem Vorgang Anderer als Ureierfalte bezeichne. Dieselbe erstreckt sich nicht in der ganzen Länge der Peritonealhöhle jederseits neben dem Mesenterium, sondern beginnt hinter dem Anfang der Segmentalorgane etwa am hinteren Ende der Leber 
(in späteren Stadien) und reicht zuerst bis an das hintere Ende der Segmentalorgane, d. h. soweit die Leibeshöhle sich erstreckt.

Anfangs ist die Zahl der Ureier eine sehr kleine, so dass sie sich anf Schnittserien leicht zählen lässt; später wird sie beträchtlicher und damit beginnen auch weitergehende Veränderungen, die das Entstehen einer wirklichen Falte zur Folge haben. Es erhebt sich das Bindegewebe unterhalb der Aorta in einer Längsleiste, welche jederseits vom Mesenterium von vorn nach hinten zieht, von Anfang an jedoch mehr eine langgestreckte Spindelform annimmt, indem die Verdickung in der Mitte am stärksten, nach vorn ziemlich jäh, nach hinten ganz allmählich abnimmt. Was die Breite der Verdickung anlangt, so ist dieselbe ebenfalls in der Mitte am stärksten und wird nach vorn und hinten schmäler. Schon von Anfang an macht sich, wie überhaupt in den paarigen Organen der Leibeshöhle eine Asymmetrie in der Höhe bemerklich, die durch das ganze Leben sich erhält; zuerst sind die Differenzen minimale, 1-3 Querschnitte von $1 / 40^{\mathrm{mm}}$. Dicke betragend, welche man versucht sein könnte, auf Rechnung einer etwas schiefen Schnittführung zu setzen, doch spricht die Constanz der Erscheinung dagegen.

Die histologische Zusammensetzung der Ureierfalte, die, wie ich hervorheben muss, bei jedem Embryo gefunden wurde, also die Anlage für den Hoden und den Eierstock darstellt, ist folgende: man unterscheidet an ihr ein inneres Stroma, welches aus Bindegewebskernen von $0,004-0,009^{\mathrm{mm}}$. Grösse besteht und ohne Grenze in das kleinzellige Gewebe zwischen den Segmentalkanälchen, im Mesenterium etc. übergeht, und ein dieses Stroma überziehendes Epithel mit Ureiern $=$ Ureierpolster oder Ureierlager. I)ieses ist die unmittelbare Fortsetzung des Peritonealepithels, hier nur in der Weise modificirt, dass es verdickt erscheint und ein Theil seiner Zellen sich zu Ureiern umwandelt. In den ersten Stadien (cf. Taf. VII, Fig. 1, 2, 3, Ur. f. Lacerta agilis) ist die Grenze zwischen Peritonealepithel und Stromazellen keine bestimmte, doch fand ich im Pikrokarmin ein ganz vortreffliches Mittel zur Unterscheidung beider, indem mit diesem Reagens sich gewisse Kerne stärker färben; hierzı gehören auch die Kerne der Peritonealzellen, die fast immer dunkler gefärl,t waren als die Kerne der darüberliegenden Stromazellen; mit Absicht habe ich diese dunklere Färbung auch in der Zeichnung durch den dunkleren Ton auszudrücken gesucht, um meine Präparate möglichst genau wiederzugeben. Ohne diese Reaktion wäre es z. B. gar nicht möglich zu entscheiden, wie viel von den auf Taf. VII Fig 1 bei Ur. f. um das Urei liegenden Kernen zum Epithel oder zum 
Bindegewebe gehörten, da ja die Kerne einander völlig gleichen; wir sehen, dass in diesem Stadium die Ureier noch zwischen den Peritonealzellen liegen, dass sie jedoch später mit der Bildung der Ureierfalte (cf. Taf. VII. Fig. 3. Ur. f.) in das Stroma selbst zu liegen kommen, also dorthin eingewandert sind, ohne von den Peritonealzellen, wie es scheint einige mitzunehmen.

Die hier geschilderten Verhältnisse habe ich hauptsächlich an Embryonen von Lacerta agilis und von Anguis fragilis studirt, während mir von Tropidonotus natrix und Coronclla laevis nicht so zusammenhängende Stadien zu Gebote stehen. Jedoch finde ich auch bei diesen die erste Spur der Geschlechtsdrüse in vergrösserten Peritonealzellen, in Ureiern, die jedoch - namentlich habe ich dies an Embryonen von der Natter gesehen - bei einem Embryo nicht dieselbe Grösse erreichen wie bei einem gleichalten zweiten; ich glaube aus noch später miłzutheilenden Gründen, dass bei der Natter sich schon so früh der Geschlechtsunterschied kenntlich macht, indem es nämlich auch beim Männchen wohl zur Ausbildung der Ureier kommt, diese jedoch von Anfang an etwas kleiner als beim Weibchen bleiben, als Ureier aber durch ihre Grösse und vor allem durch die nach aussen begrenzte Protoplasmaschicht gegenüber den Peritonealzellen kenntlich sind.

Bei einem Blindschleichenembryo von $8-9^{\mathrm{mm}}$. Körperlänge finde ich die Ureier im Durchschnitt $0,017-0,021 \mathrm{~mm}$. gross; die Kerne $=$ $0,010-0,012^{\mathrm{mm}}$.; wïhrend die Kerne der dazugehörigen Peritonealzellen höchstens $0,008^{\mathrm{mm}}$. gross sind; bei einem Embryo von Lacerta agilis, der einen Tag nach der Eiablage dem Ei entnommen und getöltet wurde,

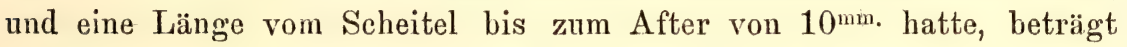
die Grösse der Ureier nur 0,017 mm., der Eikerne 0,008 mmi; die Peritonealzellenkerne haben eine Grösse von $0,00 \tilde{z}-0,007^{\mathrm{mm}}$, während die ganze Epithelverdickung auf der Geschlechts- oder Ureierfalte 0,017_-0,016 beträgt, woraus sich ergiebt, dass 2 , höchstens 3 Kerne des Peritoneums übereinanderlagern; Stellen, in denen Ureier enthalten sind, sind natürlich dicker; die Geschlechtsfalte hat in diesem Stadium eine Höhe bis $0,035^{\mathrm{mm}}$. und eine Breite von $0,050^{\mathrm{mm}}$. Diese letzteren Masse sind natürlich je nach der Stelle, der sie entnommen sind, sehr verschieden.

Aus den mitgetheilten Zahlen erkennen wir, dass erstens der Kern der Peritonealzellen bei der Umwandlung in ein Urei ziemlich bedeutend wächst und dass zweitens die zugehörige Protoplasmamenge, die für einen Kern der Peritonealzellen bei der dichten Aneinanderlagerung derselben sehr gering ist, ebenfalls ganz beträchtlich zunimmt. 
Die nächsten auffallenden Veränderungen in der an Grösse zunehmenden Geschlechtsdrüse bei Lacerta agilis und Anguis fragilis bestehen im Auftreten eigenthümlicher, mehr blattartiger Zellenbalken, die mehr oder minder breit von der Basis der Geschlechtsfalte her in das Stroma der Geschlechtsdrüse eindringen. Sie bestehen aus dicht an einander gelagerten, ovalen Kernen von 0,004-0,006 mm. Grösse, die sich etwas in Gestalt und Grösse von den Kernen des Peritonealephitels unterseheiden und anch durch ihre Tinktion im Pikrokarmin insoferne hervorstechen, als sie in der Intensität der Färbung ungefähr die Mitte halten zwischen Peritonealzellen und Stromazellen; es ist auch dies versucht worden, in dem Ton der Figuren wiederzugeben; jedoch nur bei besonders gelungenen Präparaten, für deren Herstellıng sich keine bestimmte Regel aufstellen lässt, ist diese Verschiedenheit in der Tinction bemerkbar, sehr häufig ist kein Färbungsunterschied zwischen den Stromazellen und den Zellen der eingewucherten Balken zu sehen oder derselbe ist sehr minimal. Jedenfalls ist namentlich auf späteren Stadien eine mehr oder weniger scharfe Grenze zwischen den Zellenbalken und dem umgebenden Gewebe vorhanden; am wenigsten ist dieselbe bei Lacerta agilis ausgesprochen (ef. taf. VII. fig. 4), wo es bei der in Anwendung gebrachten Behandlungsweise nicht möglich war, auf Querschnitten überall eine zarte Linie als Begrenzung der in Rede stehenden Zellenbalken zu erkennen, während dies andererseits bei Anguis fragilis (ef. taf. VII. fig. 7 und 8.) leichter ist. Es scheint, als ob auch hier nicht zu vermeidende Differenzen in der Behandlungsweise von Einfuss sind; vielleicht liegt das aber auch im Oljekt selbst, denn Embryonen von Platydactylus facetanus, die auf dieselbe Weise behandelt waren, gaben mir noch giinstigere Bilder und waren auch für die Erkenntniss der Herkunft dieser Zellstränge von Bedeutung; leider fehlen mir, da ich im Herbst 1876 zu spät nach den Balearen kam, jüngere Stadien, doch ist das jüngste, beobachtete von $11 \mathrm{~mm}$. Lünge in der Ausbildung der Geschlechtsorgane noch soweit zurück, dass es für die Auffassung der Zellstränge massgebend sein kann. Man erkennt an einem Querschnitt etwa aus der Mitte des Körpers auf's Dentlichste den Zusammenhang der die Zellenbalken konstituirenden Elemente mit den Zellen der äussern Wand der Malpighi'schen Körperchen (cf. taf. VIII. fig. 1. Sg. str.) Wenn man nun damit die Thatsache, dass bei jüngeren Embryonen von Lacerta agilis und Anguis fragilis die Zellenbalken zuerst an der Basis der Geschlechtsdrüse auftreten und später erst in derselben liegen, in Verbindung bringt, so scheint mir kein $Z_{w}$ eifel 
dariber obzuwaten, dass die Zellenbalken Sp rossen eines Theiles der äussern Wand der Malpighischen Körperchen sind. Nachder ich dies beim Gecko gefunden hatte, konnte ich dasselbe Verhalten auch bei Lacerta und Anguis konstatiren; ich habe schon oben hervorgehoben, dass die Malpighischen Körperchen, welche aus den ursprünglichen Segmentalblasen hervorgegangen sind, in einer Reihe von vorn nach hinten angeordnet sind und zwar an der Basis der Geschlechtsfalte liegen oder wenigstens in deren unmittelbaren Nähe nach aussen von ihnen (cf. taf. V. fig. 10. gl. taf. VII. fig. 4. 7. 8. gl. etc.). Diejenige Stelle der Wandung, welche unmittelbar nach der Geschlechtsfalte zu gerichtet ist, ist es nun, welche sich verdickt und einen Strang entsendet, der in die Geschlechtsdriise eintritt und allmählig bis an die untere Fläche derselben, bis unter den verdickten Epithelbelag derselben vordringt (ef. taf. VII. fig. 4.); bei a ist die Verbindung mit dem äussern Epithel des Malpighischen Körperchens M K., dessen glomerulus nicht gezeichnet ist; der Strang macht hier, um in die Geschlechtsclrüse zu gelangen, ein Knie, wie auch bei Anguis fragilis (fig. 7 und 8 derselben Tafel) und beim Gecko (taf. VIII. fig. 1.). Dieser einfache Verlauf macht bald einem gewundenen Platz, der betreffende Spross macht mehrere Windungen, er theilt sich mehrmals und entsendet auch nach vorn und hinten einen Fortsatz, der sich, wie es scheint, mit dem nächst höheren oder tieferen verbindet. Da diese Zellenbalken von den Segmentalblasen abstammen. so werde ich dieselben von nun an Segmentalstränge nennen, obgleich sie der Zahl nach nicht den Körpersegmenten, wohl aber den aus den Segmentalbläschen herrorgegangenen Malpighischen Körperchen entsprechen. Um über die Form des Netzes, welches an der Geschlechtsclrise durch die Segmentalstränge gebildet wird, mehr Klarheit als es durch Betrachtung von Quersehnittserien mögiich ist, zu gewinnen, zeichnete ich mehrere Querschnittserien von Embryonen von Anguis fragilis in der seitlichen Ansicht in carrirtes Papier und erhielt so folgendes Bild: An der Basis der Geschlechtsdrüse, aber noch im Wolfischen Körper gelegen zieht von vorn nach hinten ein blattartiger Strang von Zellen; der selbst in 2-5 Einzelstränge zerfällt, die sich bald wieder vereinigen, um wieder auseinanderzufahren und so fort, der also vielfach von langgestreckten, schmalen Spalten durchbrochen ist und nun in einzelnen, mehr oder weniger zusammenhängenden Partien von unregelmässiger Gestalt in die Geschlechtsurüse eindringt. Auf der entgegengesetzten Seite besteht die Verbindung: mit den Malpighischen Körperchen und zwar derart, dass von jedem 
Körperchen im Bereich der Geschlechtsfalte ein Fortsatz zu dem Hauptzellenstrange hinläuft, der den letzteren nach ganz kurzem Ver'auf trifft; es liegen oft nur 2-4 Kerne zwischen der Wand des Körperchens und dem von vorn nach hinten ziehenden Hauptstrang, der aus der Vereinigung der Einzelstränge entstanden ist; man muss bedenken, dass die Malpighischen Körperchen sehr dicht über einandor stehen, dass also der Raum zwischen den zuerst gesonderten Segmentalsträngen ein sehr kleiner ist und nur wenige Zellen dazu gehören, um eine Verbindung der gesonderten Segmentalstränge unter einander in der Richtung von vorn nach hinten $\mathrm{zu}$ ermöglichen und durch weitere Theilung das Netzwerk von Zellensträngen an der Basis der Geschlechtsdrüse, unseren „Hauptzellstrang" zu bilden.

Richten wir nun unser Augenmerk auf die freie Fläche der in die Geschlechtsdrüse eingewucherten Segmentalstränge, so sind auch hier ganz eigenthümliche Verhältnisse zu beobachten: es erreichen nämlich die Segmentalstränge - oder Blätter das verdickte Peritonealepithel, das zwischen seinen gewöhnlichen Elementen die Ureier enthält, und verbinden sich mit demselben so innig, dass die vorher bestehende scharfe Grenze des Epithels gegen das Stroma und gegen die Stränge vollständig verschwindet; von den wuchernden Strängen wird das Stroma fast an der ganzen ventralen Fläche der Geschlechtsdrüse verdrängt und macht Zellen Platz, welche in unmittelbarem Zusammenhang einerseits mit dem verdickten Epithel, andrerseits mit den eingewucherten Strängen steht. Mit andern Worten: es beginnt ein Durchwachsungsprozess der beiden Gewebe, den man aber nach den späteren Stadien besser als eine Einwanderung von Elementen des Keimepithels in die Segmentalstränge bezeiclınet.

Man sieht nämlich später innerhalb der Segmentalstränge grosse Zellen liegen, die vollkommen in Gestalt und Grösse, in der Reaktion gegen Pikrokarmin den Ureiern gleichen. Uebergangsstadien von den Elementen der Segmentalstränge zu diesen Ureiern findet man nicht, wohl aber den Weg, auf dem sie in die Stränge hineingelangt sind, resp. hineingelangen; es ist dies erstens die Berührungs- und Verwachsungsstelle der ventralen Flächen der Segmentalstränge mit dem verdickten Peritonealepithel und zweitens scheint auch die Möglichkeit zu bestehen, dass Elemente des Ureierpolsters durch das Stroma hindurch an jeder anderen Stelle in die Stränge, soweit letztere in der Geschlechtsdrüse liegen, eindringen können. Was den ersteren Weg anlangt, so wird ein Blick z. B. auf Fig. 8, Taf. VII wohl keinen Zweifel über denselben aufkommen lassen, der Segmentalstrang ist an seinem ventralen Theil 
kolbig verdickt und hat sich mit dem Ureierpolster derart innig verbunden, dass man nicht mehr sagen kann, wohin die Kerne an der Verbindungsstelle gehören, ob zum Peritonealepithel oder zu den Segmentalsträngen, während die Ureier in Vordringen in den Strang begriffen sind. Dasselbe Verhältniss findet man fast auf allen Schnitten dieses Stadiums, sowohl bei der Bindschleiche als auch bei der Eidechse z. B. Fig. 5 u. 6 auf Taf. VII. Hier ist mehr zufällig die Verbindung auf ein e Reihe von Kernen beschränkt, bei dieser aber selbst lässt die Reaktion des betreffenden, sonst gelungenen Präparates gegen Pikrokarmin im Stich, die Intensität der Färbung nimmt nämlich allmählich gegen die Zellstränge zu, auf dem Verbindungswege ab und die Ungewissheit über die Zugehörigkeit der betreffenden Kerne bleibt bestehen. Dass jedoch die Ureier auf diesem Wege einwandern, scheint mir ganz sicher zu sein, wie viel aber von den Peritonealzellen mit daran betheiligt sind und ob überhaupt, ist zweifelhaft.

Der zweite Weg führt durch das Stroma ohne eine direkte Verbindung zwischen den Strängen und dem Ureierlager; man sieht nämlich sehr oft die Ureier im Stroma selbst liegen, einmal dicht unter dem Epithel, dann wieder näher an den Strängen selbst und es dürfte wohl anzunehmen sein, dass sie in die Stränge auch eindringen, sonst wäre es unverstäudlich, wie solche Bilder zu deuten seien und ferner, wie diejenigen Ureier, we'che an den seitlichen Flächen des Ureierlagers entstehen, in die Stränge gelangen, da man keine Bilder erhält, welche etwa auf ein Verschieben und Hindrängen nach der ventralen Fläche der Geschlechtsdrüse zu zu beziehen sein, wo die Einwanderung nach obigem wirklich stattfindet. Da ich nun hierbei niemals gesehen habe, dass das Urei mit einer Gruppe von Peritonealzellen in das Stroma tritt, vielmehr immer allein liegt, so ist es mir sehr wahrscheinlich, dass auch bei dem Durchwachsungsprozess an der ventralen Fläche der Geschlechtsdrüse von den Peritonealzellen nur wenige mit den Ureiern in die Segmentalstränge aufgenommen werden, doch lässt sich wenigstens vorläufig eine Entscheidung absolut nicht geben.

Hiermit hat das indifferente Stadium der Geschlechtsdrüse sein Ende erreicht, es beginnen sowohl in derselben als auch an andern Körperstellen Veränderungen, welche das Erkennen des Geschlechts ermöglichen, diese sollen uns jedoch erst beschäftigen, nachdem ich das entsprechende Stadium bei den Schlangen abgehandelt habe; vorher gebe ich noch einige Bemerkungen über die Zeit, in der die eben beschriebenen Bildungen auftreten. 
Dieselbe lässt sich nun nicht so genau begrenzen, wie wir dies in den entwicklungsgeschichtlichen Angaben vom Hühnchen und sellsst vom Kaninchen gewöhnt sind, weil erstens Tag und Stunde der erfolgten Begattung unbekannt sind, zweitens ein grosser Theil der Entwicklung oder die ganze im Eileiter abläuft, die bei keiner bestimmten Grenze aufhört und drittens die Wittermngsverhältnisse und noch manehes andere von gewissem Einfluss sind; ich labe oft die Erfahrung gemacht, dass, wenn zwei Eidechsen, die unter denselben Bedingungen in Gefangensehaft gehalten wurden, an einem Tage die Eier ablegten, die Untersuchnng eine grosse Differenz in der Ausbildung der Embryonen zeigte, eine Differenz, die bis auf 17 Tage stieg, so dass ich Entwicklungsstadien, die ich bei einem frisch abgelegten Embryo traf, bei einem anderen, der am selben Tage von einer audern Mutter abgelegt war, erst 17 Tage nach der Eiablage fand; so sehr waren die beiden Bruten verschieden. In fig. 4. taf. VII. ist ein Querschnitt von einem Embryo von Lacerta agilis abgebildet, der am 17. Tage nach der Eiablage dem Ei entnommen und präparirt wurde; dasselbe Stadium finde ich bei einem Embryo einer andern Brut bereits am ersten Tago nach der Eiablage; ich darf hier an eine zufällige Angabe Bidder's ${ }^{1}$ ) erinnern, nach welcher Lacerta agilis um Dorpat Eier legt, aus denen wie bei unserer Blindschleiche sofort die Jungen aus. kriechen; vielleicht ist es dort der kurze, nicht genügend warme Sommer, der das Thier zwingt, seine eigne Körperwärme zum Ausbrüten der Eier anzuwenden, um Nachkommenschaft zu erzielen. Dem entsprechend ist anch bei uns die Zeit, welche von der Eiablage bis zum Anskriechen der Jungen verfliesst, eine sehr variable aber zum mindesten - nach meinen Frfahrungen - 6 bis 8 Wochen betragende. Zeitangaben haben also keinen sehr brauchbaren Werth für einen Nachuntersucher, aber auch die Grössen sind schwankend und wenig zuverlässig: der Embryo liegt immer stark gekrümmt und muss, um gemessen und in Schnittserien zerlegt werden zu könnem, erst gestreckt werden, wobei man sich natürlich auf die Streckung des Rumpfes beschränkt; hicrlei sind jedoch Dehnungen und in Folge dessen Differenzen von mehreren Millimetern nicht ganz zu vermeiden. Dazu kommt noch, dass wirklich Grössenunterschiede zwischen Embryonen derselben Brut, zur selben Stunde getödtet vorhanden sind, die oft recht beträchtlich sind. Wir müssen uns also an anatomische Charaktere halten, die mir konstanter zu sein

1) Anatom. und listol. Untersuchurgen über die männl. Geschlechts- und Harnwerkzeuge der nackten Amphibien. Dorbat 1846. p. 67. 
scheinen, übrigens wird man, wie bei den Segmentalorganen, selbst auf späteren Stadien die Anfänge immer noch an den hintersten Theilen finden, da die Entwicklung wie bei den Segmentalorganen von vorn nach hinten fortschreitet, ja sogar hinten bei den Geschlechtsdrüsen auf einer gewissen, frühen Stufe stehen bleilt und endlich degenerirt.

Die hier geschilderte Entwicklung spielt sich bei Lacerta agilis ungefähr zwischen dem 2. und 20. Tage nach der Eiablage ab, so zwar, dass man am sichersten diese Stadien um den 10. Tag herum findet; was die Grösse anlangt, so sind Embryonen von 10-13 mm. Länge, gemessen vom Scheitel bis After am giinstigsten; bei Anguis fragilis Grössen von etwa 14 bis höchstens $20 \mathrm{~mm}$., ebenfalls vom Schcitel bis zum After. Auch die Länge der Penispapillen ist massgebend: sind bei mehreren Embryonen derselben Brut diese gleich gross, so hat auch eine Differenzirung in der Geschlechtsdrïse noch nicht stattgefunden.

\section{b. Bei Tropidonotus natrix.}

Die bei Anguis fragilis und Lacerta agilis geschilderten Verhältnisse treten auch bei den Schlangen auf, doch in etwas modifieirter Weise, welche eine besondere Beschreibung nöthig machen; als Repräsentant wurde hauptsächlich unsere Ringelnatter studirt, da Embryonen dieser aus späteren Entwicklungsstufen leicht zu beschaffen waren.

Die ersten Entwicklungsvorgänge schliessen sich auf's engste den früher bekannt gewordenen bei Anguis und Lacerta an, es kommt auch zuerst zur Bildung einer Verdickung des Peritonealepithels, von dem sich einzelne Elemente zu Ureiern vergrössern. Hierauf erhebt sich die ganze Stelle in Form eines sehr langen, spindelförmigen Körpers und wird als feiner, weisser Streif auf den Segmentalorganen, zu beiden Seiten des Mesenteriums liegend, für das blosse Auge sichtbar. Diese Eihebung wird von Bindegewebszellen gebildet, die innerhalb der Masse des Wolff'schen Körpers gelegen bereits feine Fasern entsenden, in der Geschlechtsdrüse aber noch aus Kernen bestehen, um die sich das Protoplasma noch nicht zellig abgegrenzt hat; das Peritonealepithel ist wenig verdickt, die Ureier verhältnissmässig klein und spärlich.

Es ist anch hicr nochmals daran zu erinnern, dass die Malpighischen Körperchen in einer regelmässigen Reihe von vorn nach hinten an der 
Basis der Geschlechtsdrüse liegen. Sie sind es, an welchen die folgenden Prozesse zu beobachten sind.

Wir finden zuerst eine Verdickung an der äussern Wand der Malpighischen Körperchen (cf. taf. VIII. fig. 8. Sg. str.), die in dem gezeichneten Falle $0,010 \mathrm{~mm}$. beträgt; dieselbe ist von Anf́ang an gegen die Geschlechtsdrüse zu gerichtet und entsendet auch sehr bald nach hinten einen kleinen Fortsatz, so dass wir also in der Seitenansicht am Malpighischen Körperchen einen kleinen schwach gebogenen Haken sehen, der mit dem senkrechten Schenkel zuerst ventral nach der Geschlechtsdrüse zu strebt, dann sich horizontal resp. caudal umbiegt und blind endigt. Dies wiederholt sich im Bereich der Keimdrüse bei allen Malpighi'schen Körperchen, jedoch nicht gleichzeitig, da ja vorn die Segmentalstränge zuerst auftreten und während sich die hinteren bilden, sellust weitere Umbildungen erfahren. Diese bestehen in einer bedentenden Zunahme der Verdickung an der äussern Wand des Malpighi'schen Körpercheus und in der Entstehung eines Lumens in dem Segmentalstrang, wodurch derselbe zu einein kurzen, vorn und hinten geschlossenen Kanal wird; um das Lumen ordnen sich die Kerne, indem sie mehr Spindelform annehmen, radienartig (ef taf. VIII. fig. 11. Sg. str.). Noch immer ist die Verbindung mit dem Epithel des Malpighi'schen Körperchens sehr deutlich und erhält sich anch noch längere Zeit. Die Masse für die Verdickungen u. s. w. sind folgende:

Verdickting wie sie fig. 8. taf. VIII. entspricht: $=0,023 \mathrm{~mm} \cdot$ breit, $0,010^{\mathrm{mm}}$. hoch. Zellkerne in derselben $=0,006-008 \mathrm{~mm}$.

Verdickung wie siefig. 10 taf.VIII. entspricht: $=0,021 \mathrm{~mm}$. breit, $0,020^{\mathrm{mm}}$. hoch Zellkerne in derselben $=0,006 \mathrm{~mm}$.

Verdickung entsprechend fig. 11 taf. VIII. $=0,021 \mathrm{~mm} \cdot$ breit, $0,021 \mathrm{~mm} \cdot$ hoch.

Zellkerne in derselben $=0,006 \mathrm{~mm}$.

Durchmesser des Lumens $=0,005-007 \mathrm{~mm}$.

Gehen wir nun einen Schritt weiter, so finden wir ein weiteres Vordringen des Kanales in die Geschlechtsdrüse hinein, deren Stroma sich in einer ganz eigenthümlichen Weise modificirt; die Kerne vergrössern sich nämlich sehr bedentend von $0,006 \mathrm{~mm}$. auf $0,012 \mathrm{~mm}$. und darüber, und bei vielen grenzt sich eine Protoplasmaschicht als äusserer Ring ab; das Peritonealepithel ist verdickt, namentlich an der ventralen Fläche der Keimdrüse, Ureier sind spärlich. In dem Segmentalstrang (taf. VIII. fig. 12. a) haben die Kerne noch mehr Spindelform angenommen und stehen zum Theil sehr dicht gedrängt; ihre Länge beträgt 
bis $0,012 \mathrm{~mm}$. Das Lumen des Kanales ist in unsrer Figur gegen die Höhlung des Malpighi'schen Körperchen abgeschlossen; doch habe ich sehr oft beim Durchmustern von Querschnittserien Objekte gesehen, bei denen auf's deutlichste eine Communikation stattfand, so dass ich sie als eine Zeit lang bestehend annehmen muss. Beobachtung nur dieses Stadiums würde das Ganze nur als eine Ausstülpung der Wandung des Körperchens erscheinen lassen, eine Annahme, die nach dem Vorhergehenden durchaus nicht gerechtfertigt erscheint, vielmehr ist der Bildungsgang ein solcher, dass zuerst durch Wucherung der Zellen an einer bestimmten Stelle der Wandung der Malpighi'schen Körperchen, welche stets gegen die Geschleclitsdrüse zu gerichtet ist, eine kappenartige Verdickung entsteht, die sich mit der Spitze krümmend nach hinten schlägt; erst sekundär entsteht in diesem Zellenhaufen eine Höhlung, die dann nach dem Malpighi'schen Körperchen zu durchbricht.

Hiermit hat das indifferente Stadium bei der Natter schon ein Ende erreicht, also noch bevor die den Segmentalsträngen von Lacerta und Anguis entsprechenden Theile in die Geschlechtsdruise hinein gewuchert sind und sich mit dem verdickten Epithel, dem Ureierlager verbunden haben. Nach dem Mitgetheilten besteht eine Differenz zwischen Schlangen einerseits und Eidechsen, Blindschleichen andrerseits; ich habe von den letzteren so viele Embryonen aus dem auch äusserlich indifferenten Stadium untersucht und überall die Verbindung der Segmentalstränge mit dem Ureierlager gefunden, dass ich kaum annehmen kann, ich hätte znfällig nur kïnftige Männchen geschnitten, während bei den Schlangen, noch ehe die Segmentalstränge so weit ausgebildet sind, dass sie an das Ureierlager reichen können, die Differenzirung der Geschlechter eintritt.

\section{Ausbildung der männlichen und weiblichen Keimdrüisen.}

\section{a. Hoden.}

Ich habe hier noch von den Schlangen (Natter) bis zu jenem Stadium nachzutragen, in welchem die Segmentalstränge das Ureierlager erreichen, um von da ausgehend die weitere Ausbildung des Hodens zu besprechen, soweit dieselbe überhaupt von mir in das Bereich der Untersuchung gezogen wurde. 
Wenn man sich eine Querschnittserie von eincm Natterembryo vom 18. - 20. Tage nach der Eiablage in carrirtes Papier einzeichnet, um über die Gestalt und Anordnung der Segmentalstränge an der Basis der Geschlechtshrüse eine Anschauung zu erhalten, die sich durch Sagittalschnitte nicht gewinnen lässt, so bekommt man ein ähnliches Bild, wie ich es von der Blindschleiche beschrieben habe, nur habe ich nicht entscheiden können, ob wir entsprechend dem. Hauptzellstrang der Blindschleiche auch bei der Natter einen von vorn nach hinten verlaufenden Hauptkanal haben; in der ersten Zeit ist es sicher kein einheitlicher Kanal; derselbe besteht vielmehr aus einzelnen, allerdings in einer Längsreihe angeordneten Stücken, die jedoch später so nahe an einander rücken, dass dadurch auf Querschnitten das Bild eines Lärgskanales selbstredend nur im Bereich der Keimdruise entsteht; zu diesem entsendet nun jedes Malpighische Körperchen einen Fortsatz und andererseits dringen Kanälchen in die Keimdrüse ein, die nun zum Hoden wird. In fig. 13. taf. VIII. ist ein solcher Kanal dargestellt, der direkt als Sprosse des auf dem Querschnitt getroffenen Hauptkanales, der unmittelbar dem Malpighi'schen Körperchen anliegt, erscheint, wohl auch unzweifelhaft als solcher aufzufassen ist; diese ersten Hodenkanälchen, um deren Kerue sich das Protoplasma zellig abzugrenzen beginnt, dringen im weiteren Wachsthum bis an das Ureierlager vor und verbinden sich mit demselben (taf. VIII. fig. 14.). Dass hier eine Aufnahme von Peritonealzellen mit wenigen Ureiern in die Hodenkanälchen stattfindet, scheint mir nicht $\mathrm{zu}$ bezWeifeln zu sein; ich sah auch an einem allerdings jüngeren Embryo, als er in fig. 14 dargestellt ist, vom 10. Tage nach der Eiablage, dass zwischen dem Hauptkanal und dem Epithel ein Strang ausgespannt war, der nur aus 4 Zellen bestand: am Hauptkanal lag ein Urei, halb zwischen die Zellen des Kanales aufgenommen, dann folgten 2 Zellen, die wie Peritonealzellen aussahen und endlich wieder ein Urei; solche Bilder habe ich oft in meinen provisorischen Notizen mir abgebildet, wodurch also auch für die Natter die Möglichkeit des Eindringens von zelligen Elementen des Ureierlagers auf zwei Wegen vorhanden wäre. Die Natter ist in dieser Beziehung ein ungünstiges Objekt, da der Hoden sehr langgestrezkt ist, die Ureier am künftigen Hoden sehr klein bleiben, schon sehr früh einzuwandern und sich zu verändern scheinen. Desshalb unterbreche ich hier die Darstellung bei der Natter und wende mich zu günstigeren Thieren, den Eidechsen und nächsten Verwandten.

Während von Anfang an bei der Natter die Segmentalstränge Kanäle 
darstellen, treten Höhlungen bei den Echsen und Schleichen crst sekmndär auf, womit die Differenzirung der Geschlechter gegeben ist, weil nämlich nur beim Hoden dieser Vorgang auftritt. Leydig ${ }^{1}$ ) hat im Hoden nengeborener Individuen von Lacerta vivipara cinen urspriinglich gleichmässig zelligen Körper gesehen, welcher in die späteren Samenkanäle durch Abscheidung von Bindesubsłanz zerfällt, so dass geschlängelte Cylinder entstehen; Leylig denkt sich den Zellkörper durch Einwuchern von Bindegewebe in bestimmt abgegrenzte und geformte Theile zerlegt werdend, welche später ein Lumen bekommen. Iaceita vivipara konnte ich nicht untersuchen, doch lässt sich diese Beobachtung ganz mit den meinigen an Lacerta agilis vereinigen: der solide Zellkörper im Hoden ist der Complex der in den Hoden eingewucherten Segmentalstränge, welche auf der Schnittserie auch bei Lacerta agilis und Anguis fragilis stets vorhanden ist, also auch einen Zellkörper darstellt, der jedoch anf der einen Seite, ventral zum grössten Theil mit dem Ureierlager, auf der andern Seite, dorsal durch Zellstränge im Mesorchinm mit dem Malpighischen Körperchen in Verbindung steht. In diesem Zellkörper grenzen sich nun im Hoden wirklich gewundene Cylinder ab, indem das spärliche Bindegewebe in die Substanz hineinwuchert; sie stehen mitnnter noch mit dem Peritonealepithel in Verbindung, meist jodoch sind sie davon abgeschnürt und durch Bindegewebe getrennt. In diesen Cylindern treten hierauf Höhlungen auf, welche den Eindruck machen, als ob sie durch Auseinanderweichen der die Cylinder zusammensetzenden Zellen entstanden seien; man sieht das Protoplasma in Zacken, welche mitunter eine Brücke zwischen den Wandungen bilden, in das Innere hineinragen. Dabei beginnen sich die Kerne radiär zu stellen und es treten auch feine Linien zwischen je zweien als Zellbegrenzungen auf. Die Vermehrung der ursprünglich soliden Kanäle schreitet immer fort, bis die ganze Driise von kleinen Schläuchen erfült ist, zwischen deren ursprünglichen Zellen noch sehr gut die Ureier als grosse Zelleu mit grossem, gekörnten Kern zu erkennen sind. Mit dem zunehmenden Wachsthum der Drüse nimmt successive das Ureierlager des Hodens ab, so dass schliesslich Nichts als ein einfacher, seröser Ueberzug übrig bleibt. Dieses trifft man bereits bei jungen Thieren gleich nach dem Ausschlüpfen aus dem Ei (ef. taf. VII. fig. 12.).

Es frägt sich nun erstens, wohin kommen die Ureier and zweitens was wird in der weiteren Entwickelung aus ihnen. Die erste Frage ist

1) Deutsche Saurier. p. 132. 
wohl kur dahin zu beantworten, dass die Ureier in die Hodenkanälchen aufgenommen werden, auch wenn sich die innige Verbindung zwischen Segmentalsträngen und Ureierpolster gelöst hat. In der That findet man anfangs eine Menge Ureier im Stroma, während sie später in demselben nicht mohr vorkommen, vielleicht geht auch ein Theil derselben zu Grunde.

Was die andere Frage nach dem endlichen Schicksal der in die Hodenkanälchen gelangten Ureier anlangt, so scheint mir dieselbe atifs innigste mit der Spermatozoenbildung zusammenzuhängen, einen Punkt, den ich nur kursorisch in das Bereich meiner Untersuchung gezogen habe; doch will ich einige Beobachtungen darüber mittheilen. Ich wähle dazu den Hoden von Platydactylus facetanus und gehe von dem Qnerschnitt des Hodens eines Thieres, welches noch im ersten Sommer steht, aus: Wir finden da (taf. VIII. fig. 3.) die Hodenkanälchen umgeben von einer feinen doppelt konturirten Membran, auf welche nach inuen zuerst eine Lage von kleinen, stark getrübten Kernen in mehr homogenem Protoplasma folgt; diese Lage bildet eine sehr dünne Schicht. Dann kommen nach innen zahlreiche, grosse Zellen von übrigens ziemlich variabler Grösse, deren ganze Gestalt, Grösse und Eigenschaften des Kernes auffallend an Ureier erinnern und wohl kaum anders denn als Ureier zu denten sind, da es mir gelungen ist, diese Zellen vom ersten Auftreten im Peritonealepithel bis nach dem Einwandern in die Hodenkanälchen zu verfolgen. Ich gebe in Tafel VIII. fig. 7. einen Querschnitt einiger Hodenkanälchen eines im vorhergehenden Jahre geborenen, im April des nächsten Jahres getödteten Thieres von Lacerta agilis, in dem ebenfalls eine grosse Zahl von Ureiern neben kleineren Zellen vorhanden sind; in einem Zwischenstadium von derselben Spezies, aber noch einem Embryo von $12 \mathrm{~mm}$. Länge, vom Scheitel bis zum After gemessen, finden wir neben verhältnissmässig zahlreichen kleinen und mittelgrossen Zellen eine Anzahl von grossen Zellen, die den in diesem Stadium noch vorhandenen Ureiern im Ureierlager aufs genaueste gleichen (cf. taf. VII. fig. 10) und auch solche sind. Dasselbe sieht man bei frisch ausgeschlüpften männlichen Blindschleichen (taf. VII. fig. 12.) - alle diese grossen Zellen halte ich für eingewanderte Ureier und möchte zu der Annahme, dass sie mit der Spermatozoenbildung in Zusammenhang stehen, noch Folgendes anführen: sie fehlen nämlich denjenigen Kanälchen, welche einfache Leiter des Sekretes sind und die an der Basis des Hodens und im Mesenterium desselben liegen, eine Thatsache, die mir nicht zufäliig zu sein scheint. 
Bei einem ausgewachsenen Geckomännchen finde ich die Hodenkanälchen aus drei Theilen bestehend (cf. taf. VIII. fig. 4): zu äusserst eine feine Membran, dann folgt eine Lage stark getrübter, kubischer Zellen und endlich die dicke Schicht der Spermatoblasten, von denen die äussersten noch am ähnlichsten den Ureiern, wenn auch kleiner als diese sind; nach dem Lumen $\mathrm{zu}$ werden sie noch kleiner, stark lichtbrechende Körperchen, die Köpfe der Spermatozoen treten in ihnen auf und endlich ganz im Lumen finden wir schon freie Spermatozoen.

Ganz ähnliche Verhältnisse habe ich auch an verschieden alten Hoden von Lacerta agilis beobachten können, Beobachtungen, welche nach Herstellung der Tafeln gemacht wurden und daher nicht mehr bildlich dargestellt werden konnten. Bereits erwähnt ist, dass man im Hoden von einjährigen Eidechsen neben kleinen Zellen, die mehr regellos stehen (cf. taf. VIII. fig. 7), grosse Zellen mit stark granulirtem Kern findet, die ich als Ureier ansehe; im Sommer, wenn die Spermatozoenbildung beginnt, was sich auch durch den Wechsel des Farbenkleides kund gibt, ist das Bild ein ganz anderes; statt der kaum mehr als eine Lage bildenden Ureier haben wir eine 6-8fache Lange von Zellen, die meist radiär angeordnet und kleiner als die ersteren sind; doch glaube ich mich nicht zu täuschen, wenn ich sie als Thellungsprodukte der Ureier betrachte. Aus ihnen entwickeln sich die Spermatozoen, von denen immer mehrere in einer Zelle entstehen.

So liickenhaft nun anch das hier Mitgetheilte ist, so glaubte ich doch selbst das Wenige veröffentlichen zu sollen, um andere Untersucher auf die Frage nach der Herkunft der grossen Zellen (Ureier) im Hoden und ihre Funktion auch bei andern Wirbelthieren aufmerksam zu machen; vor kurzem hat la Valette St. George Untersuchnngen uiber die Spermatozoenbildung bei Amphibien ${ }^{1}$ ) publicirt, wobei ebenfalls grosse ureierähnliche Zellen eine Rolle spielen; leider gibt la Valette Nichts über den Ursprung dieser Zellen an, sagt aber ausdrücklich (p. 811), dass bei allen Wirbelthieren solche Zellen zuerst im Hoden auftreten und zu Spermatoblasten würden.

Ueber die Herkunft der eigenthümlichen, gelben Zellen zwischen den Hodenkanälchen der Eidechsen, auf welche Wagner, Leydig und Andere aufmerksam machen, und die sich leicht in jedem Zerzupfungspräparate nachweisen lassen, konnte ich mir keine bestimmte Ansicht bilden.

1) Ueb. d. Genese d. Samenkörper. M. Schultze's Arch. f. mikr. Anatom. Bd. XI'. 
Noch während des embryonalen Lebens wird die durch die Segmentalstränge hergestellte Verbindung der Hodenkanälchen mit den Malpighi'schen Körperchen ganz gelöst; diese Verhindungsstücke in dem Mesorchium erscheinen meist solid, dermchren sich gar nicht, sondern schwinden immer mehr. Die Verbindung, welche also ursprünglich zwischen Hoden und Segmentalorganen bestanden - seine Hauptbestan:ltheile sind förmlich aus den letzteren heransgewachsen, - verschwindet dadurch, dass noch im Verlauf des ersten Lebensjahres die Segmentalstränge, welche von den Malpighi'schen Körperchen zum Zellstrang oder Zellkörper im Hoden und später zu den Hodenkanälchen führten, resorbirt werden - vielleicht mit Ausnahme der vordersten zwei oder drei, welche sich zu den wenigen Ausführungsgängen des Reptilienhodens umwandeln, die wie bekannt, vorn am Hoden austreten und in den Nebenhoden münden.

\section{b. Ovarium.}

Wir verliessen das Ovarium auf dem Stadium, in welchem es völlig dem jungen Hoden gleicht und hatten Gelegenheit, zu bemerken, dass ein Unterschied zwischen Schlangen und Eidechsen vorhanden sei, indem es nämlich bei den ersteren nicht zu einer Verbindung zwischen Segmentalsträngen und Ureierlager kommt; sondern es bleiben, während dieselbe beim Männchen eintritt, die Stränge beim Weibchen klein und an der Basis der Geschlechtsfalte liegen (cf. taf. VIII. fig. 14. Sg. str.) Von Eidechsen und Blindschleichen habe ich, wie bereits erwähnt, so zahlreiche Embryonen untersucht, und keinen Unterschied in der Ausbildung der Geschlechtsdrüse bis zu einem gewissen Stadium gefunden, dass ich mich berechtigt halte, anzunehmen, es finde bei beiden Geschlechtern eine Verbindung zwischen Segmentalstrïngen und Ureierlager statt, die beim Männchen den Schwund des Ureierlagers in Folge des Einwanderns des grössten Theiles seiner Elemente in die Segmentalstrïnge bedingt, während beim iVeibchen im weiteren Verlanf der Entwicklung es zur Lösung der Verbindung, zur Degeneration der Segmentalstränge und zur Follikelbildung vom Ureierlager ans kommt.

Betrachten wir zuerst die Segmentalstränge, so finde ich bei älteren weiblichen Embryonen dieselben als rundliche Haufen von kleinen Zellen, die sich noch immer etwas dunkler färben, an der Basis des Orariums liegen (ef. taf. VII. fig. 9 und 11. Sg. str.) Den Zeit- 
punkt des völligen Verschwindens der Segmentalstränge konnte ich nicht genau bestimmen, da der erste Winterschlaf dazwischen fällt und ich während desselben keine Thiere untersuchen konnte; genug - bei jungen, einjährigen Eidechsen und Blindschleichen, bei welch letzteren ich bald nach dem Ausschlüpfen noch die in Frage stehenden Gebilde (taf. VII. fig. 11) erkennen konnte, war es mir nicht möglich, auf Schnittserien irgend etwas zu finden, was ich der Lage und dem Bau nach mit den Resten der Segmentalstränge hätte in Beziehung bringen können, ebensowenig gelang mir dies bei Tropidonotus natrix und Coronella laevis. Man wird sich hierbei vielleicht an die Zellenhaufen erinnern, welche Waldeyer ${ }^{1}$ ) in dem spärlichen Stroma des Ovariums von Lacerta agilis gefunden hat; diese könnte man vielleicht als Reste der Segmentalstränge auffassen und sie dadurch erklären; mir ist es jedoch wahrscheinlicher, dass Waldeyer die kleineren, von ziemlich grossen Zellen ausgekleideten Lymphräume als die Zellenhaufen angesehen hat; auf Querschnitten kann ich solche Bildungen nicht sehen, wohl aber die zuerst von Leydig erkannten Lymphräume. Uebrigens wäre es möglich, dass doch bei einigen Thieren solche Reste vorkämen; es ist bekannt, dass solche Organe, welche der regressiven Metamorphose unterworfen sind, ungemein leicht und oft individuell variiren. Wir haben also die Segmentalstränge beim Weibchen der untersuchten Reptilien als das Homologon des Hodens zu betrachten, das eine Zeit lang neben dem Ovarium bestehen bleibt, jedoch schon nach dem ersten Jahre völlig(?) resorbirt ist.

Das Stroma des embryonalen. Ovariums besteht aus einem Gewebe von ziemlich grossen, kernhaltigen Zellen, die ohne Zwischensubstanz aneinander gelagert sind und vereinzelte Gefässe enthalten; sie gehen ohne bestimmte Grenze an der Basis des Ovariums in echte Bindegewebszellen über und sind $\mathrm{mir}$ in der. Geschlechtsdrüse schon vorher legegnet; z. B. taf. VII. fig. 5 lässt als Stroma sehr grosse Kerne erkennen, während weiter vorn Bindegewebszellen vorhanden sind; auch bei der Natter (taf. VIII. fig. 12) sehen wir ähnliche Zellen das Stroma bilden und bemerken, dass schon 4 Tage später (fig. 13) die Zellen sich zum grössten Theil in spindelförmige Bindegewebszellen umgewandelt haben $d$. h. beim Hoden, während in demselben Alter beim Weibchen sie in der Mitte des Ovariums zusammengehäuft liegen und nach aussen zu allmählich in Bindegewebszellen übergehen. Auch in Fig. 16. taf. VIII.

1) Eierstock und Ei. p. 69. 
vom Ovarium eines Natterembryo finde ich das Stroma aus denselben Zellen bestehend, während sich in der Grundsubstanz eine feine Faserung bemerklich macht; ich glaube es also hier mit einem jungen Bindegewebe zu thun zu haben, das sich später wirklich in ein fibrilläres Bindegewebe, aber meist mit grösserem Reichthum an Zellen umwandelt. Die eigenthümlichen Zeichnungen im Stroma in fig. 9. taf. VII. halte ich für Kunstprodukte, einmal sind sie so unregelmässig, dass man gar Nichts mit ihnen anfangen kann und dann sind sie nicht konstant, obgleich die Embryonen auf dieselbe Weise behandelt wurden.

Vom Ureierlager ist bereits durch Leydig ${ }^{1}$ ) bekannt, dass dasselbe in zwei spindelförmigen Körpern (Keimwülste, Keimstätte) bei der Eidechse vorhanden ist. Ich stimme diesem vollkommen bei, es gilt auch für die Blindschleiche; der früher einfache, verdickte Peritonealïberzug, der in gleichmässiger Weise das Ovarium überkleidete, hat sich mehr auf die beiden Seitentheile des Organes zurückgezogen, während die ventrale Fläche nur von dem einfachen Peritoneum bedeckt ist, das sich aber unmittelbar jederseits in das Ureierlager fortsetzt und endlich am Mesovarium ohne erkennbare Grenze in das Peritoneum übergeht. Das Ureierlager fasse ich nur als eine Verdickung des Peritonealepithels auf, von dem einzelne Elemente durch stärkeres Wachsthum die Ureier bilden; Leydig lässt die Keimstätte in einem feinen, bindegewebigen Fachwerk die künftigen Eier enthalten und vom Peritoneum überzogen sein; der Unterschied in unsrer Angabe erklärt sich meines Erachtens leicht aus der verschiedenen Art der Untersuchung, Leydig brachte die Theile im ganzen unter das Mikroskop, ohne Schnitte anzufertigen und hat ein in diesem Stadium unter dem Ureierlager liegendes bindegewebiges Fachwerk als auf gleicher Höhe mit dem ersteren gehalten und die oberste Lage von Zellen für das Peritoneum genommen, was freilich ganz richtig ist, nur gehören eben, wie Querschnitte lehren, die darunter liegenden Zellen mit den Ureiern ebenfalls zum Peritoneum, es ist eine lokale Wucherung desselben. Von feinen bindegewebigen Fasein, die eine Abtheilung der ursprünglich zelligen Anlage innerhalb des Ureierlagers in Follikel bedingen, habe ich Nichts wahrgenommen, vielmehr finden sich feinfasrige Züge von Bindegewebe, welche ein Maschenwerk von lymphatischen Räumen abgrenzen, wie es Leydig angibt (1. c.), dorsal vom Ureierlager, im Stroma und bilden das letztere; der Leydig'schen Schilderung habe ich Nichts hinzuzufügen,

1) Die deutschen Saurier. p. 131. tab. XI, fig. 133. 
als dass diese Räume von Bindegewebszügen mit vielen, grossen Bindegewebszellen begrenzt werden.

Solche Züge jungen Bindegewebes grenzen auch an das Ureierlager (cf. taf. VI. fig. 13-17); sie sind Träger von Blutgefässen und einzelnen Pigmentzellen und bilden, wie Leydig zuerst angibt und ich nur bestätigen kann, die äussere Wandung der Eifollikel.

Bei den so sehr auseinandergehenden Angaben über die E i follikel bildung bei Wirbelthieren, war eine Untersuchung bei den Reptilien besonders geboten, von denen nur sporadische Mittheilungen bei der einmal fast sprüchwörtlich gewordenen Uebereinstimmung zwischen Reptilien und Vögeln vorhanden sind. Um mich möglichst vor Täuschung zu schützen, habe ich sehr verschiedene Altersstufen und verschiedene Reptilien untersucht, doch im Wesentlichen überall dasselbe gefunden.

Wenn Waldeyer ${ }^{1}$ ) sagt, „bei erwachsenen Eidechsen fand ich keine Spur einer Follikelbildung vom Epithel aus", so hat er damit nur für gewisse Jahreszeiten und vielleicht auch für solche Thiere Recht, die $\mathrm{zu}$ alt sind und dem baldigen Tode verfallen. Ich muss angeben, dass ich kein Ovarium gesehen habe, das mir nicht Eifollikelbildungsstadien auf Querschnitten ergeben hätte - auch von ganz ausgewachsenen Thieren, nur muss man eben im Frühjahr und Sommer untersuchen.

Von jedem der beiden Ureierlager auf jedem Ovarium, die sich bei älteren Eidechsen auf das hintere Ende des Ovariums beschränken geht die Eifollikelbildung aus und zwar, wie es scheint, an einer bestimmten Linie, die ungefähr die Mitte des Ureierlagers, aber an der gegen das Bindegewebe grenzenden Schicht, bezeichnet und parallel der Wirbelsäule verläuft. In taf. VIII. fig. 6. habe ich halbschematisch einen Querschnitt vom Ovarium einer einjährigen Eidechse, die im Mai getödtet wurde, abgebildet; das Ovarium hängt an dem noch funktionirenden Wolff'schen Körper, der durch den glomerulus (gl.) und den Wolff'schen Gang hezeichnet ist; neben ihm liegt die Nebenniere (Nn.). Zu beiden Seiten des Mesovariums finden wir das Ureierlager (Ur. f.) und in jedem einen sich bildenden Follikel; das Ureierlager ist in seiner Mitte gegen das Stroma hin ausgebuchtet, diese Verdickung zieht fast ununterbrochen von vorn nach hinten, soweit überhaupt das Ureierlager reicht und stellt diejenige Linie dar, in der die Follikelbildung vor sich geht.

1) Eierstock und Ei. p. 69 . 
Von den Ureiern, die ziemlich regellos in der Ureierfalte zerstrent sind, gelangt immer eins in diese Hervortreibung, so dass an einem konstruirten Längsschnitt immer eine Reihe derselben über einander liegt; dieses Urei vergrössert sich etwas cf. z. B. fig. 16. taf. VI., um dasselbe ordnen sich noch innerhalb des Ureierlagers die klein gebliebenen Peritonealzellen radienartig in einer ein- oder mehrfachen Schicht an und grenzen sich nun durch eine feine linie, die ich immer zuerst an der ventralen Fläche des jungen Follikels bemerke, von den umgebenden Zellen ab. In den Zellen des Follikels beginnen nun auch schon Veränderungen, wie sie als bleibender Zustand zuerst von Eimer ${ }^{1}$ ) für die Follikelepithelien des Reptilieneies dargestellt wurden; das Protoplasma scheidet nämlich bei Lacerta agilis (cf. fig. 13. taf. VI.) kleine Körnchen aus, die sich in Menge bei den ausgebildeten Epithelien finden. Damit ist nun eigentlich der Follikel fertig und liegt noch innerhalb des Ureierlagers, aus dem er jedoch herausrückt, indem er das dorsal vor ihm liegende Bindegewebe kappenartig um sich herumstülpt, von diesem gleichsam umfangen und völlig von seinem Entstehungsort abgeschnürt wird. Ein solches Durchtrittsstadium ist in taf. VI. fig. 15. von einem erwachsenen Thier von Anguis fragilis abgebildet; wir sehen die Follikelepithelien in Zusammenhang mit den Zellen des Ureierlagers an der ventralen Fläche des jungen Follikels. Ganz kurz vor der Untersuchung des betreffcnden Thieres abgeschnürte Follikel sind in den Figuren 13 und 14 derselben Tafel dargestellt, der Follikel ist von einer dünnen Schicht Bindegewebes umgeben und grenzt an der einen Seite, ventral, an den sich bildenden, nächsten Follikel, auf der andern - dorsal - an den nächst älteren; dieser wiederum liegt zwischen dem nächst jüngeren und dem nächst älteren und so fort bis der älteste ganz ventral liegt un zu erkennen ist.

Durch diese Art der Follikelbildung an einer bestimmten Linie wird also die Anordnung der Eier eine ganz regelmässige, sie bilden auf dem Querschnitt einen mehr oder minder regelmässigen Kranz, cf. taf. VIII. fig. 6 von Lacerta agilis; derselbe besteht aus zwei korrespondirenden Hälften, die man dadurch erhält, dass man parallel der Mittellinie des Körpers das Ovarium halbirt; am meisten dorsal am Mesovarium liegt auf jeder Hälfte eines Ovariums das Ureierlager, dann folgen Schritt für

1) Untersuchungen über die Eier der Reptilien I. II. M. Schultzes Arch, für mikr. Anatomie. Bd. VIII. 1872. p. 216-243 u 397-434. 
Schritt die Follikel, die jüngsten am Ureierlager, die ältesten am weitesten von ihm entfernt. Die Richtung im Wachsthum ist in fig. 6. taf. VIII. durch die Pfeile angedeutet.

Da der Zuwachs jedoch nicht in einem Punkte, sondern in einer Linie stattfindet, so erhalten wir demgemäss, wenn man das ganze Ovarium in Betracht zieht, zwei korrespondirende Hälften als zwei etwas gekrümmte Blätter, indem die Eier wenigstens eine Zeitlang ziemlich genau entsprechend in Reihen angeordnet sind, die ältesten ventral in die Leibeshöhle vorspringend, die jüngsten dorsal am Ureierlager.

Diese Anordnung erhält sich jedoch in ihrer Regelmässigkeit nicht durch das ganze Leben, durch die kolossale Vergrösserung, welche die Eier im weiteren Wachsthum erfahren, müssen Verschiebungen eintreten; diese bedingen es dann, dass die ältesten Eier erwachsener Thiere zwar immer noch ventral liegen, jedoch über das eigentliche Ureierlager hinaus gelangt sind und zwar nach vorn; wir haben am erwachsenen Ovarium die Eier nicht mehr in parallelen Linien vom Ureierlager ausgehend angeordnet, sondern in Ringen, die von dem nach hinten liegenden Ureierlager radiär ausstrahlen; der hinterste liegt ungefähr in der Höhe des Organes, die anderen mehr nach vorn gelegenen erheben sich in einem bestimmten Winkel. Aber auch diese Anordnung ist nur eine mehr schematische, die zu Stande kommen müsste, wenn das Wachsthum in gleicher Weise in beiden Ureierlagern vor sich ginge, dies ist jedoch namentlich bei älteren Ovarien nicht der Fall; es fallen einzelne Follikel aus, werden gar nicht gebildet, andre scheinen früh zu degeneriren und endlich kommt die uiberwiegende Grösse der ausgewachsenen Follikel über die jungen in Betracht, eine Differenz, die, wie es mir scheint, nicht ganz durch die radiäre Anordnung und die Grösse der dadurch entstehenden Winkel kompensirt wird. Jedenfalls passt das Schema auf junge Ovarien und ist mit einiger Modification auf ältere anwendbar.

Schon unter den Sauriern ist eine Ausnahme von dem hier geschilderten Verhalten zu erwähnen, es sind das die Geckotiden, von denen ich Platydactylus facetanus von den Balearen untersuchen konnte; bei diesem finde ich auf einem Ovarium immer nur ein Ureierlager, in demselben die Ureier aber so vertheilt, dass mir das ganze als gleichwerthig den getrennten Ureierlagern der Eidechsen erscheint, die ja, wie aus der Entwicklung bekannt ist, aus einem Lager entstehen; es scheint also beim Gecko der embryonale Typus beibehalten zu sein. Die 
Ureier liegen rechts und links von der Mittellinie ihrer gemoinsamen Keimstätte, an demjenigen Theil des Ureierlagers, der in das gewöhnliche Peritoneum übergeht. Die grössten Ureier trifft man am nächsten der Mittellinie und scheinen mir von beiden Seiten abwechselnd gegen denjenigen Punkt des Ureierlagers vorzurïcken, an dem die Follikelbildung stattfindet. Diese geht nun in derselben Weise vor sich, wie bei der Eidechse und der Blindschleiche: es schliesst sich noch innerhalb des Ureierlagers eine gewisse Menge von Peritonealzellen an das $\mathrm{Ei}$ an, grenzt sich von den umliegenden Zellen ab und wird zum Follikelepithel, wie dies in fig. 14. taf. IV. dargestellt ist. Unterhalb des Ureierlagers finde ich viele Iymphräume, die von Bindegewebsbalken begrenzt werden und innen von einem hier kleinzelligen Epithel ausgekleidet sind. Dieselben Räume sind auch für Lacerta agilis durch Leydig (deutsche Saurier) beschrieben worden, wo sie in der That vorhanden sind, doch konnte ich mich weder bei Lacerta noch beim Gecko überzeugen, dass die Follikel, wie es Leydig annimmt, in diese Lymph. räume hineingelangen; ich habe nie gesehen, dass die letzteren sich gegen die Ureierlager öffnen und dort etwa den jungen Follikel aufnehmen; immer finde ich dies Ureierlager von den Lymphräumen getrennt durch eine mehr oder weniger dicke, aber immer vorhandene Lage von jungem zellenreichen Bindegewebe, das erst durchbrochen werden müsste; jedoch sehe ich Nichts, was hierauf schliessen lässt.

Was nun den Bau des Follikels bei Geckotiden anlangt, so besitzen wir durch Eimer ${ }^{1}$ ) so hinreichende Angaben, dass ich denselben Nichts hinzuzusetzen wüsste; höchstens würde ich die Funktion der grossen Follikelzellen als einzellige Drüsen mehr betonen; nach dem, was ich davon gesehen habe, kann man sich grade beim Gecko hiervon überzeugen, wie es Eimer auch darstellt.

Zwischen den Drüsenzellen des Follikels liegen noch eine Auzahl kleiner Zellen, von denen bei Lacerta agilis Waldeyer ${ }^{2}$ ) angiebt, dass sie während des Lebens unregelmässig vertheilt seien, nach dem Tode jedoch an die äussere Wand des Follikels gelangen. Für Lacerta konnte ich mich von diesem Verhalten nicht recht überzeugen, ich sehe auch an Schnitten kleine Zellen unter den Drüsenzellen vertheilt, wenn freilich die grösste Zahl derselben an der Peripherie angeordnet ist; wie

1) Ueber den Bau der Reptilieneier I. II. M. Schultze's Arch. f. mikr. Anat. Bd. VIII.

2) Eierstock und Ei. p. 70. 
Waldeyer dazu kommt, hier eine Wanderung snzunehmen, weiss ich nicht, auch ist mir nicht klar, wie er sich überzengt hat, dass im Leben diese Wanderzellen unter den andern liegen und endlich beim Tode alle nach aussen kriechen. In fig. 17. taf. IV. habe ich einen jungen Follikel von Anguis fragilis im Querschnitt abgebildet, aus dem Nichts für die Waldeyer'sche Annahme zu entnehmen ist; ebensowenig finde ich bei älteren Follikeln.

Beim Gecko bilden diese kleinen Zellen eine regelmässig vorhandene und auf Querschnitten wie Flächenansichten nachzaweisende, einfache Schicht an der äussern Wand der Follikel, als Grenze gegen das Bindegewebe; es ist die Frage, ob diese Zellen zum Follikelepithel gchören und identisch sind mit den andern, kleinen Zellen zwischen den einzelligen Drüsen. Ich sehe nämlich öfters, dass bei Querschnitten die bindegewebige Lage sich von den Follikelzellen trennt und dass dann diese einfache Schicht kleiner Zellen nicht an den Follikelzellen hängen bleibt, sondern am Bindegewebe, also jedenfalls mit diesem in engerer Verbindung stehen muss; wie man darüber einen Entscheid geben soll weiss ich nicht recht, doch könnte man vielleicht an jene Ansicht denken, welche in der Histologie die endothelartigen Zellen gewisser Membranen nicht als echte Epithelien ansieht, die aus dem Ecto- oder Entoderm stammen, sondern als eine nur epithelähuliche Grenzschicht, die zum Bindegewebe gehört und von diesem abstammt. Dieses Verhältniss muss ich unentschieden lassen.

Das beschriebene einfache Ureierlager vom Gecko, in dem allerdings eine Sonderung in zwei seitliche Bildungsstätten der Ureier ein. getreten ist, bedingt eine andere Art der Anordnung der Eier im Ovarium als ich sie bei Eidechsen angab. Nach vorn und nach hinten nehmen die Ureier die ganze Ureierfalte ein und nur in der breiteren Mitte liegen sie an den Seiten; die Follikelbildung geschieht ebenfalls in einer Linie, doch da eben nur eine Anwachslinie an jedem Ovarium vorhanden ist; so bekommen wir keine aus zwei entsprechenden Hälften bestehende Kette von Eiern, sondern nur eine; allerdings liegt auch hier das älteste Ei am meisten ventral und dann schliessen sich die jüngeren an. - In einer kürzlich erschienenen Arbeit ${ }^{1}$ ) hatte ich Gelegenheit, von der geringen Zahl der vom Gecko abgelegten Eier zu sprechen, in jełem Ovarium reift nämlich nur ein Ei und jeder Eileiter nimmt immer nur ein Ei zur ersten Entwicklung auf; desshalb findet man auch immer

$\left.{ }^{1}\right)$ Lacerta Lilfordi und Lacerta muralis, Diese Arbeiten Bd. IV. Heft 1. 
nur zwei Eier von Platydactylus zusammen abgelegt, nie mehr, selten jedoch nur eins; das ganze Ovarium ist auch bedeutend kleiner, als das unserer Lacerten, doch habe ich eine besonders geringe Ausbildung des Ureierlagers nicht bemerkt; in demselben liegen, namentlich vorn und hinten, die Ureier ebenso zahlreich, als bei unsern Eidechsen; wir müssen daher annehmen, dass die Follikelbildung langsam vor sich geht, in bedeutend geringerer Zahl als bei den Eidechsen stattfindet, von denen ich übrigens bei Lacerta muralis und Lacerta Lilfordi mittheile, dass ihre Ovarien ebenfalls sehr klein sind und nur wenig Eier reifen. Dasselbe findet auch bei Lacerta faraglionensis Bedr. statt; ich erhielt trächtige Weibchen dieser interessanten Form durch Herrn Dr. Fraisse, der sie selbst auf dem Faraglione sammeln liess und mir lebend in Gazebeuteln von dort mitbrachte; ein Theil der Weibchen hat bis jetzt abgelegt, immer fand ich nur zwei - leider unbefruchtete Eier zusammen und kann bei den noch trächtigen Exemplaren nicht mehr als zwei Eier durch die Bauchdecken hindurch sehen und fühlen; das Ovarium ist auch bei dieser Raçe auffallend klein.

Endlich habe ich noch ebenfalls durch Herrn Dr. Fraisse eine Anzahl lebender Exemplare des seltenen Phyllodactylus europaeus Gené aus Italien erhalten und zwar von der Insel Tinetto; mir war dies doppelt angenehm, da ich durch deren Untersuchung die Angaben Wiedersheim's ${ }^{1}$ ) prüfen konnte, die, wenn sie sich bestätigten, das allgemeinste Interesse beanspruchen durften. Wiedersheim sagt (l. c. p. 511), dass das Reifen der Eier und zwar nur eines einzigen auf der einen Seite stattfindet, links häufiger als rechts; als Grund gibt W. an, dass das einzige reifende $\mathrm{Ei}$ sich zu einer solch monströsen Grösse entwickelt, dass man annehmen kann, es absorbire die Kraft des kleinen Organismus in ihrem ganzen Umfang, abgesehen davon, dass ein zweites Ei in dem Leibesraum absolut keinen Platz mehr finden würde. Dies wird nun allerdings durch die fig. 8 auf taf. XVIII. und fig. 13 taf. XIX. bestätigt; leider finde ich keine Angabe darüber, ob die beiden Zeichnungen von demselben Thier stammen, was zur Beurtheilung des Falles immerhin wichtig wäre, da ich nach meinen Erfahrungen annehmen muss, dass es Wiedersheim wirklich mit einem Monstrum, mit

1) Zur Anatomie und Physiologie des Phyllodactylus europaeus mit besonderer Berücksichtigung des Aquaeductus vestibuli der Ascalaboten im Allgemeinen; zugleich ein zweiter Beitrag zur Inselfauna des Mittelmeeres. Morphol. Jahrb. I. Bd. 1876. p. 495--534. 
einem pathologischen Prozess zu thun hatte; ich finde nämlich bei sieben „hochträchtigen Weibchen des Phyllodactylus", die in meinem Besitz sind, jedes mit zwei Eiern schwanger, in jedem Eileiter befindet sich ein Ei, woron ich mich leicht durch die anatomische Untersuchung als auch dadurch ïberzeugte, dass ich erstens durch die Bauchdecken jederseits der Mittellinie je ein Ei sehen konnte und zweitens bei der erfolgten Ablage stets zwei Eier nebeneinander liegend fand. Ich habe nur ein Weibchen in den Händen gehabt, das nur ein reifes $\mathrm{Ei}$ in dem einen Eileiter enthielt und erkläre mir also die citirten Abbildungen als von einem kranken Thier herrührend, bei dem es W. selbst "bcinahe unerklärlich schien", wie das Ei die enge Cloakenspalte sollte passiren können, das Ei übertrifft nämlich im Durchmesser die Cloakenspalte fast um das Vierfache; die Spalte könnte man sich vielleicht dehnbar denken, doch der Beckenkanal ist es sicher in diesem Masse nicht. Das Mass dieses monströsen Eies gibt W. auf 11-12 mm. in der grössten Länge, 8-9 mm. in der grössten Breite an; während ich dies schreilue liegen mir 4 abgelegte Eier von Phyllodactylus vor, von denen das kleinste einen Längsdurchmesser von $9 \mathrm{~mm}$, und einen Breitendurchmesser von $7 \mathrm{~mm}$. besitzt, während das grösste $10 \mathrm{~mm}$. lang und nur $6 \mathrm{~mm}$. breit ist: das sind Differenzen von $2-3 \mathrm{~mm}$., welche immerhin einen bedeutenden Unterschied im Kubikinhalte der Eier bedingen.

Was nun endlich die einseitige Funktion des Ovariums bei Phyllodactylus, "welche an die Vögel erinnert", anlangt, so hat sich, wie ich glaube, Wiedersheim durch das nicht gleichzeitige Reifen der Eier und jenes monströse Ei täuschen lassen; ich habe nämlich gesehen, dass nicht blos bei Phyllodactylus, sondern auch bei unsern Eidechsen auf einem gewissen Stadium in dem einen Eierstock die Eier, welche bei der nächsten Brunst abgesetzt werden sollen, etwas weiter entwickelt sind als in dem andern; diese Ungleichheit der Ausbildung wird jedoch wieder eingeholt und ist kurz vor der Loslösung der Eier aus dem Ovarium nicht mehr zu beobachten; diese Asymmetrie in der physiologischen Leistung ist nicht überall gleich stark ausgesprochen oder erscheint es uns wenigstens nicht, da wir in unserm Falle keine anderen Kriterien dafür haben, als die Grösse der Eier, die nun, wie ich in Uebereinstimmung mit Wiedersheim angeben muss, in einem gewissen Stadium zwischen rechts und links variirt.

Uebrigens wirft auch Wiedersheim die Frage auf, ob die Verminlerung der Fruchtbarkeit nicht mit den klimatischen Verhältnissen des Südens zusammenhängt. Trotz dieser geringen Fruchtbarkeit sind 
nach allen Berichterstattern z. B. die Individuen von Lacerta muralis sehr häufig, sind, wie ich selbst weiss, die Gecko's (Platydactylus facetanus) auf Menorka so gemein, dass man kaum einen Stein findet, unter dem nicht ein Gecko sässe; ebenso zahlreich ist auf der ganz kleinen Isla del Ayre die Lacerta Lilfordi und solche Beispiele gibt es genug, so dass trotz der verminderten Fruchtbarkeit eine Vermehrung resultirt, die an Individuenzahl wohl die Individuen verwandter Thiere in unsern Breiten übertrifft. Dies kann man mit klimatischen Verhältnissen des Siidens in Verbindung bringen, die dort weit weniger als bei uns auf das Einzelthier einwirken und so den Procentsatz der vor der Zeit sterbenden Thiere auf ein Geringes herabsetzen; oder man kann hierzu noch ein Fehlen von Nachstellungen annelımen, das sicherlich auf der Isla del Ayre und dem Faraglionefelsen vorhanden ist. Es ist hier jedoch nicht der Ort, diese Frage weiter zu diskutiren.

Bei den Schlangen bleibt das einfache Ureierlager durch das ganze Leben bestehen, während bei Lacerta agilis und Anguis fragilis schon während des embryonalen Lebens eine Zweitheilung des ursprünglich einfachen Ureierlagers eintritt, wie die figg. 9 und 11 auf taf. VII. zeigen. Man könnte die Doppelspindelform des Ureierlagers bei den beiden letztgenannten Reptilien vielleicht mit der Kürze des Ovariums in Zusammenhang bringen, welche selbst wieder durch die Kürze des Körpers bedingt wird. Die Produktion der Eier findet hier neben einander, weniger hintereinander statt; auch das Ovarium der Blindschleiche ist klein, zusammengedrängt, das der Schlangen aber sehr langgestreckt, ein Ei hinter dem anderen gelagert. Nur die jüngsten Eier resp. Follikel liegen neben den ganz grossen, aber anch wieder unter einander eine Längsreihe bildend. Aus der fig. 5. taf. VIII. ist das desswegen nicht genau ersichtlich, weil das Ovarium durch die ältesten Follikel sehr in Falten gelegt ist und die ursprünglichen Verhältnisse dadurch verwischt sind. Doch lehrt schon die Vertheilung der jüngeren Follikel, dass die Bildung derselben am ganzen Ovarium stattfinden muss und ihre Anorduung in einer Längsreihe deutet darauf, dass nur ein Ureierlager, nur eine Keimstätte für sie vorhanden ist. Schon fig. 15 nnd 16 auf taf. VIII. zeigen dies eine Ureierlager eines Natterembryos auf der ventralen Fläche des Ovariums, dieses kommt dann, wenn die ersten Follikel im Laufe des ersten Lebensjahres gebildet werden, ganz nahe an das Mesovarium zu liegen, woranf uns schon die Lage der jüngsten Follikel an alten Ovarien hindeutet. Durch ältere und jüngere Ovarien habe ich Schnittserien angefertigt und diese haben mir ergeben, dass 
wirklich ein kleines Ureierlager neben dem Mesovarium als eine Verdickung des Epithels gelegen ist, von wo aus sich die Follikel ventralwärts bilden. Schon bei Thieren, die nach dem ersten Winterschlaf im Mai untersucht wurden, scheint mir das Ureierlager, das bei etwa 90 facher Vergrösserung kaum zu erkennen ist und auf einem Schnitt 1-2 Ureier, oft gar keine enthält, unterbrochen zu sein; jedenfalls wird die Epithelverdickung oft so dünn, dass man sie kaum als solche ansprechen kann. In noch viel ausgesprochenerem Masse ist dies bei alten Ovarien der Fall, das ursprünglich kontinuirliche, bandförmige Ureierlager ist mit dem weiteren Wachsthum des Ovariums in einzelne, langgestreckte Inseln aufgelöst, die allmälig aus demselben Substrat, dem Peritonealepithel hervortauchen und eine Längsreihe neben dem Mesovarium bilden.

Endlich komme ich zu dem Binnenepithel der Reptilieneier, dessen Existenz bekauntlich zuerst von Clark $^{1}$ ) bei Schildkröten behauptet wurde; schon Gegenbauer ${ }^{2}$ ) widerspricht diesem nicht allein für Schildkröten (Emys europaea), sondern auch für Alligator lucius, Lacerta agilis und Tropidonotus natrix; 11 Jahre später berichtet Eimer ${ }^{3}$ ) aufs Nene von dem Vorhandensein eines Binnenepithels oder einer Embryonalmembran, was wieder von Ludwig ${ }^{4}$ ) den heftigsten Widerspruch erfuhr, der sich ebensowenig wie Gegenbaur von dem fraglichen Epithel überzeugen konnte. Ludwig diskutirt auch die Beweise, welche von Clark und Eimer für das Binnenepithel beigebracht worden sind, ohne jedoch völlige Beweiskraft in den Angaben Beider anzuerkennen. Ich hatte Gelegenheit, bei meinen Untersuchungen über das Ovarium der Reptilien - fast möchte ich sagen, zahllose Querschnitte von Reptilieneiern aus allen Stadien und von sehr verschiedenen Thieren zu durchmustern, ohne dass ich auch nur irgend Etwas gefunden hätte, welches mir die Behauptung Eimers zu rechtfertigen schien; ich habe die Eier frisch und gehärtet untersucht, aber immer mit demselben negativen Resultat und halte auch dafür, dass sich Eimer und Clark getäuscht haben.

1) Embryology of the Turtle in L. Agassiz contrib. to the nat. hist of the Unitad States of America. Vol. Il. Boston. 1857. p. 486 etc.

$\left.{ }^{2}\right)$ Wirbelthiereier mit partieller Furchung. Müll. Arch. 1861. p. 510.

$\left.{ }^{3}\right)$ Untersuchungen über die Eier der Reptilien. I. II. Arch. f. mikr. Anat. VIII. 1872. p. 409 etc.

$\left.{ }^{4}\right)$ Ueber die Eibildung im Thierreiche. Diese Arbeiten Bd. I. 1874. p. 445 etc. 


\section{Ausfïlurende Geschlechtswege}

\section{Samenleiter.}

Hier berichten alle Autoren übereinstimmend und richtig, dass der Wolff'sche Gang im männlichen Geschlecht zum Samenleiter wird, eine Funktion, die er in allen Wirbelthierklassen übernimmt. Ich habe an dieser Stelle neben einigen Angaben über den Bau des ausgebilleten Organes noch einige Mittheilungen über die Metamorphose der Segmentalorgane, Urniere und deren Reste beim Weibchen zu machen.

Es ist bekannt und jede Untersuchung unsrer Reptilien lehrt es, dass nach dem Ausschlüpfen aus dem Ei die Segmentalorgane noch den Raum von dem vordern Ende der Geschlechtstheile bis über den Anfang der bleibenden Nieren einnehmen und dergestalt noch in Gemeinschaft mit den Nieren funktioniren; wir finden noch Malpighische Körperchen, Flimmerung in den Kanälchen und ein Sekret, das sich durch den Wolff'schen Gang gemeinschaftlich mit dem Sekret der Nieren durch den Harnleiter in die Cloake ergiesst. Wesentlich dasselbe Verhältniss bleibt noch bis zum ersten Winterschlaf bestehen, zwar scheint eine Reduktion des Organes einzutreten, doch ist dieselbe nur scheinbar, das Thier wächst, die Segmentalorgane jedoch nicht mehr. Nach dem ersten Winterschlaf finde ich in demselben Raum zwischen Hoden und Nieren wie ein Band eine grauweisse Masse ausgestreckt, die aus einem Hauptkanal und zahlreichen, vielfach gewundenen Kanälchen besteht; die Flimmerung ist noch erhalten und ist nach dem Hauptkanal zu gerichtet, dem Wolff'schen Gang bei beiden Geschlechtern; auch die glomeruli sind noch ganz deutlich in einer Längsreihe an der medialen Fläche der Segmentalorgane zu erkennen; selbst im Wolff'schen Gang finde ich bei einigen Präparaten ein Secret, das Organ funktionirt also noch. Trotzdem ist eine sichtliche Redultion eingetreten, die Zahl der glomeruli hat abgenommen, ich zähle (bei Lacerta agilis Männohen im Anfang Mai getödtet) 17 glomeruli auf der rechten, 21 auf der linken, bei einem Weibchen, zur selben Zeit getödtet, 25 resp. 27 glomeruli; die Urnierenkanälchen sind viel geringer an Zahl geworden und verlaufen nun mehr gestreckt in grossen Schleifen von vorn nach hinten. Auch macht sich schon ein Unterschied bemerklich je nachdem man ein Weibchen oder Männchen untersucht; bei dem letzteren nämlich 
bildet der Wolff'sche Körper ein vorn etwas dick angeschwollenes, hinter dem Hoden bandartig werdendes Organ und läuft in ununterbrochener Continuität auí der ventralen Fläche der Nieren bis zur Cloake, nach hinten, etwa im vorderen Drittel der Nieren seine Kanälchen verlierend; beim Weibchen tritt dagegen eine Zerreissung in mehrere Portionen ein, die hintereinander liegen und zum Theil noch miteinander durch ein Kanälchen verbunden sind; das vordere Ende des Organs ist kaum gegen das hintere verdickt, die vorhandene Verdickung rührt von dem goldgelben Körper her, der in früherer Zeit als Nebennicre aufgefasst, in neuerer Zeit jedoch als ein Rest des Wolff'schen Körpers gedeutet und beim Männchen als Paradidymis, Giralde'sches Organ, gelber Rest des Wolff'schen Körpers (Leydig), beim Weibchen Paroophoron (Waldeyer), Parovarium (His) genannt wurde. Zu dieser Auffassung führten lediglich topographische Gründe und die rerkehrte Nomenklatur der sogenannten "vergleichenden Anatomie," welche die Namen für Organe niederer Thiere von den höheren und höchsten entlehnte, unbekümmert darum, ob eine Parallele durch die Entwicklung nachzuweisen war oder nicht. Nirgends finde ich den durch die Entwicklung erbrachten Beweis, dass der goldgelbe Körper wirklich ein Rest der Segmentalorgane, des Wolff'schen Körpers ist, es genügte dieselbe Lage, wie sie bei höheren Wirbelthieren Paradidymis und Parovarium haben, um bei den Eidechsen und Schlangen (dasselbe gilt für die übrigen Reptilien) ein Organ mit demselben Namen zu belegen; wie unrecht dies war, davon habe ich mich durch die Verfolgung der Entwicklungsgeschichte des goldgelben Körpers überzeugt, worüber ich in einer besonderen Arbeit demnächst berichten werde; hier sei nur so viel im Voraus mitgetheilt, dass der goldgelbe Körper sowohl dem Bau als der Entwicklung nach Nichts mit den Segmentalorganen zu thun hat und dass daher obige ihm von neueren Autoren beigelegte Namen als irrig zu bezeichnen und zu streichen sind. Den Beweis für diese Ansicht bringe ich demnächst.

Der Wolff'sche Gang ist bei beiden Geschlechtern (Lacerta agilis) ziemlich gleich stark im Mai nach dem ersten Winterschlaf ausgebildet: der Durchmesser beträgt bei einem Männchen 0,073 mm., das Lumen $0,045 \mathrm{~mm}$.; beim Weibchen, das gleich gross war und zur selben Zeit getöltet wurde, hat der erstere 0,057-0,068 mm., das Lumen 0,039 mm., eine Differenz ist also vorhanden und, wenn Messungen an 3 Pärchen massgebend sein können, auch konstant. 
Auf welche Weise der Schwund der glomeruli und der Kanälchen vor sich geht, habe ich nicht in allen Stadien verfolgen können, doch sprechen manche Punkte für eine fettige Degeneration mit nachfolgender Resorption der Epithelien; ich erinnere dabei an die Figur 131 auf tab. X von Leydig's "deutsche Saurier", die von einem neugeborenen Jungen von Lacerta vivipara herrührt und bei der man die dunkel gehaltenen Kanälchen des Wolf'schen Körpers kaum anders denn als in Fettmetamorphose begriffen deuten kann, umsoweniger anders, wenn ich noch bemerke, dass man beim Behandeln solcher Präparate mit Terpentin und Harzen diese Kanälchen fasst völlig aufhellt, wodurch die Natur der Trübung als fettige wohl erwiesen ist; eine Aufhellung mit Essigsäure gelingt am frischen Präparat nicht. Diese Degeneration beginnt schon im Embryonalleben am vordersten Theil der Segmentalorgane, wodurch das vorderste Ende der Urniere allmählich in gleiche Höhe mit den Geschlechtsorganen herabrückt.

Endlich verschwinden im Verlaufe des zweiten Lebensjahres bei beiden Geschlechtern (Lacerta agilis) die glomeruli und der grösste Theil der Urnierenkanälchen; es bleibt dann beim Männchen der zum Samenleiter gewordene Wolff'sche Gang übrig, der sich vielfach schlängelt, stärker wird und sich mit einer beträchtliehen Lage von Bindegewebe und glatten Muskelfasern umgiebt; vorn in der Höhe des Hodens bildet er den sogenannten Nebenhoden, in dem man auf dem Querschnitt sowohl stärkere als zahlreiche dünnere Kanälchen erkennen kann, die Leydig ${ }^{1}$ ) als verschieden dicke Abschnitte eines und desselben Kanales auffasst, einer Auffassung, der ich nicht ganz beistimmen kann.

Mir liegt eine aus der ersten Zeit meiner Untersuchungen stammende Schnittreihe des Hodens und Nebenhodens von Lacerta agilis, die während der Brunstzeit getödtet wurde, vor, bei welcher ich mich von dem Uebergang der dicken in die dünneren Schläuche nicht überzengen kann; ferner ist das Sperma nur in den dicken Theilen oder vielmehr in dem dicken Samenleiter enthalten und in den dünnen auch nicht ein Spermatozoe; dies scheint mir sehr gegen eine bestehende Communikation des eigentlichen Samenleiters mit den feineren Kanälchen zu sprechen. Hierzu kommt nun noch die Vertheilung dieser letzteren, welche selır an das Verhältniss der Urnierenkanälchen zum Wolff'schen Gang erinnert; ich finde auf allen Querschnitten die kleinen Kanälchen lateral

1) Leydig. Deutsche Saurier p. 141 u. tab. X. fig. $128^{2}$. 
vom Samenleiter angeordnet, am stärksten an der medialen Fläche desselben, da wo der goldgelbe Körper liegt, angehäuft. Beide Partien der dünnen Kanäle stehen nun durch einzelne Kanälchen, welche auf der ventralen Fläche des Samenleiters quer verlaufen, mit einander in Verbindung. Wenn ich ventral sage, so ist dies nicht ganz korrekt, insofern nämlich die früher ventrale Fläche sehr oft gegen den Hoden zu gewendet ist. Bei diesem Verhalten kann ich mich des Eindrucks nicht entwehren, als ob der sich zum Samenleiter entwickelnde Wolff'sche Gang, der an Masse zunimmt und sich vielfach windet, den Rest der Segmentalorgane, der ja ventral von ihm liegt, zur Seite gedrängt habe, gleich als wenn er durch seine Masse förmlich in diese eingesunken sei und für die kleinen Kanäle nur an seiner medialen und lateralen Seite Platz gelassen hätte. Wie früher so liegt auch jetzt der Samenleiter (Wolff'scher Gang) dorsal, die Urniere, jetzt Nebenkanälchen aber ventral.

Wie sehr der Wolff'sche Gang an Masse zunimmt, mögen einige Zahlen zeigen; in dem geschwellten Nebenhoden beträgt der Durchmesser des Samenleiters 0,288 mm., die Wandung misst 0,084 mm., das Lumen $0,120 \mathrm{~mm}$.; dagegen beträgt der Durchmesser der Nebenkanälchen $0,056 \mathrm{~mm}$., ihr Lumen nur $0,016 \mathrm{~mm}$; sie sind von einem einschichtigen Flimmerepithel ausgekleidet und beweisen auch durch dieses ihre Herkunft von den Urnierenkanälchen. Als solche haben sie wenigstens früher in Verbindung mit dem Wolff'schen Gang gestanden; ob sie es beim ausgebildeten Nebenhoden noch thun, habe ich nicht feststellen können, doch scheint das erhaltene Lumen und die Flimmerung in den feineren Kanälen eine noch bestehende Communication derselben mit dem Samenleiter wahrscheinlich zu machen. Jedenfalls aber kann man die dünnen und dickeren Karäle nicht als verschieden dicke Abschnitte eires und desselben Kanales betrachten.

Wir haben schon oben bemerkt, dass beim Weibchen (Lac. agilis) die Urniere nach dem ersten Winterschlaf anfängt, in mehrere Stücke zu zerfallen, die nun ebenfalls der fettigen Degeneration und Resorption bis auf kleine Reste unterliegen. Diese sind in ihrer Form, Zahl und Anordnung sehr variabel und selbst bei demselben Thier rechts und links verschieden; sie liegen stets in einer Reihe zwischen Eileiter und der Mittellinie, dem früheren Verlauf der Urniere entsprechend und zeichnen sich durch ihre graugelbliche bis bräunliche Fürbung ans; es sind unregelmässige $0,5-1 \mathrm{~mm}$. und darüber grosse, langgestreckte Körperchen, neben denen mitunter eine grosse Zahl von mikroskopisch 
kleinen Resten der Segmentalorgane in Form von rundlichen, mit einem Plattenepithel ausgekleideten Cysten vorhanden ist; auch diese sind sehr variabel sowohl im Auftreten als in Grösse und Gestalt; sie enthalten meist einen Hohlraum, in dem oft Concremente liegen oder sind namentlich die kleineren nur Zellenhaufen. Fast ausnahmslos sind die Epithelien der Cysten sowohl wie der grösseren, graugelben Reste fettig degenerirt. Präparate über diese Theile stellte ich mir sehr einfach dadurch her, dass ich den betreffenden Thieren den Bauch aufschnitt, die Gedärme entfernte und nun das Präparat etwa $1 / 2$ Stunde in $1 / 2 \%$ Chromsäurelösung liegen liess; dann behandelte ich mit Spiritus bis zum absoluten Alkohol im Verlauf von $24-48$ Stunden; präparirte das Peritoneum zwischen Ovarium und Niere heraus, entwässerte in Terpentin und schloss das ausgebreitete Bauchfell in Lack ein. Durch diese Behandlungsmethode werden natürlich die Epithelien anfgehellt, wodurch die Reste des Wolff'schen Körpers auch eine andere Farbe erhalten. Mitunter fand ich nun beim Durchmustern solcher Präparate noch einen früheren Zustand erhalten, indem ich kleine Kanälchen antraf, welche in einen kurzen, stärkeren Längskanal seitlich einmündeten, es ist dies der Wolff'sche Gang resp. ein Stück desselben mit einigen Stücken von Urnierenkanälchen. Für isolirte, abgeschnürte Stücke der letzteren, vielleicht auch des Wolff'schen Ganges selbst halte ich die beschriebenen Cysten, von denen man einige wohl in den meisten Präparaten antreffen wird. Alles zusammen - mit Ausnahme des goldgelben Körpers, neben dem man auf Querschnitten besonders bei jüngeren Thieren noch Kanälchen der Segmentalorgane sieht_- muss dem Nebenhoden des Männchens parallelisirt und Epoophor on Nebeneierstock benannt werden, so wenig passend diese Namen, die von höheren Wirbelthieren stammen, in unseım Falle auch sein mögen; ein Paroophoron oder Parovarium können wir bei den Reptilien nicht anerkennen, so wenig wie beim Männchen die Paradidymis; was bis jetzt dafür gehalten wurde und damit z. B. in Leydig's deutschen Sauriern bezeichnet wurde, ist der goldgelbe Körper, der in gar keiner Beziehung zum Urogenitalsystem steht.

Was nun dieselben Theile bei Anguis fragilis anlangt, so kann ich mich kürzer fassen, da der Prozess der Umwandlung und der Resorption der Segmentalorgane auf dieselbe Weise wie bei der Eidechse vor sich geht; beim Mänchen entsteht der Nebenhoden aus dem Wolff"schen Körper, beim Weibchen der durch Leydig uns näher beschriebene Nebeneierstock (Deutsche Saurier p. 149). 
Leydig sagt vom Nebenhoden der Blindschleiche (1. c. p. 152), derselbe sei sehr entwickelt, wenn man jedoch seine Figur 118. tab. IX. männliche Geschlechtsorgane von Anguis fragilis mit Figur 124. tab. X. dieselben Organe von Lacerta agilis vergleicht, so wird man zugeben, dass die Nebenhoden (g. resp. f) bei der letzteren stärker entwickelt ist, was selbst während der Brunstzeit, in welcher die Theile eine Schwellung erfahren, der Fall ist. Auch beim Nebenhoden der Blindschleiche kann man übrigens zweierlei starke Kanälchen, die überall wie bei Lacerta agilis flimmern, unterscheiden.

Der Nebeneierstock Epoophoron enthält bei Anguis fragilis noch mehr Theile vom Wolff'schen Körper, indem sowohl der Ausführungsgang als auch Urnierenkanälchen wenigstens zum Theil erhalten sind, cf. Leydig deutsche Saurier tab. IX. fig. 112. 1. u. 2. Buchstabe c; b ist der goldgelbe Körper, der keine Beziehung zu den Geschlechtsorganen hat und bei der Blindschleiche langgestreckt erscheint.

Wenn man das Peritoneum zwischen Ovarium und Eileiter in der bei Lacerta agilis erwähnten Weise behandelt und bei etwa 120 facher Vergrösserung durchmustert, so wird man einen Kanal, der von vorn nach hinten verläuft und etwa in der Höhe des Ovariums oft mit einer Cyste beginnt, leicht bemerken können; seine epithelige Auskleidung unterscheidet ihn leicht von gleich verlaufenden Gefässen, wie Leydig bemerkt: von diesem Kanal gehen eine grosse Zahl blind endigender Zellstränge seitlich ab, an denen Leydig noch Malpighische Gefässknäuel gesehen hat; ganz unregelmässig sind die Stränge, die oft noch ein Lumen enthalten, angeordnet; zwischen ihnen findet man noch zahlreiche abgeschnürte Stücke als rundliche oder längliche Zellenhaufen, die von einer kernführenden Membran umgeben sind und den Gang bis weit nach hinten, über den goldgelben Körper hinaus, begleiten. Leydig konnte den Kanal nicht bis zu seinem hintren Ende verfolgen, was freilich bei dem massenhaften schwarzen Pigment sehr schwer ist; doch glaube ich mich bei einem Präparat überzeugt zu haben, dass derselbe etwa im vorderen Drittel der bleibenden Niere blind endet, also nicht mehr die Cloake erreicht; auch auf Querschnitten konnte ich ihn nicht weiter verfolgen.

Von den Schlangen wissen wir durch die Untersuchungen Rathke's schon seit langem, dass der Nebenhoden aus dem Wolff'schen Körper hervorgeht; Rathke schliesst jedoch seine Untersuchungen mit dem neugeborenen Thier ab, es fehlen daher Angaben über die Reste der Segmentalorgane, namentlich beim Weibchen, über das ich hier noch 
einiges zu berichten habe. Diese bestehen nämlich bei allen untersuchten Spezies (Tropidonotus natrix, Coronella laevis, Callopeltis Aesculapii, Zamenis sp.? und Pelias berus) aus einem langen, von vorn nach hinten verlaufenden Kanal, der blind in der Höhe des Ovarium beginnt und sich weit nach hinten verfolgen lässt. Dieser Kanal hebt sich schon für das völlig unbewaffnete Auge auf dem durchsichtigen Peritoneum durch seine weissliche Farbe $a b$; noch deutlicher erkennt man ihn, wenn man ein frisch getödtetes, erwachsenes Weibchen aufschneidet und grade gestreckt, die Bauchdecken aus einander geschlagen in Chromsäurelösung etwa 1 Stunde liegen lässt und dann in Spiritus untersucht; nach einem solchen Präparat ist die fig. 5 auf taf. VIII von meinem Freund J. v. Kennel gezeichnet worden. Durch die Chromsäure gerinnen nämlich die Epithelien dieses Kanales und heben denselben im durchsichtigen Peritoneum als feinen, weissen, vielfach gewundenen Streif ab, der aber in seinem Verlauf stets die Richtung von vorn nach hinten beibebält. In seinem vordersten Ende liegt der Kanal auf dem langgestreckten goldgelben Körper, dicht neben dem Ursprung des Mesovariums, verläuft dann viel näher dem Darm als dem Eileiter gelegen neben einem kleinen Gefäss, sich in kleinen Biegungen schlängelnd und kommt an die äussere Seite der Niere zu liegen, von wo an ich ihn weiter durch Querschnitte nach hinten bis zur Einmündung des Harnleiters in die Cloake verfolgen konnte; es ist mir nach mehreren Präparaten sehr wahrscheinlich, dass er gemeinschaftlich mit diesem in die Cloake einmündet, doch habe ich die Verbindung nie so deutlich gesehen, dass ich sie ohne Zweifel hätte demonstriren können.

Wenn man Stück für Stück des Peritoneums als mikroskopisches Präparat behandelt, so gelingt es bei jedem Thier, einzelne, blind auslaufende und mannigfach gewundene Kanälchen nachzuweisen, welche in den Hauptkanal einmünden; dieser hat eine äussere, bindegewebige Hülle mit Muskelfasern gemengt, ist von einem einschichtigen Pflasterepithel ausgekleidet und, wie bemerkt, so stark, dass man ihn ohne Mühe mit blossem Auge erkennen kann.

Es scheint mir gar keinem Zweifel zu unterliegen, dass wir es hier mit dem in toto erhaltenen Wolff'schen Gang zu thun haben, der dem Gartner'schen Kanal bei einigen Säugern zu parallelisiren ist, während man die wenigen Kanälchen Nebeneierstock benennen kann.

Es schwinden also bei den Schlangen die Urnierenkanälchen fast ganz, der Wolff'sche Kanal bleibt jedoch vollständig erhalten; bei der Blindschleiche haben wir den grössten Theil des Kanales und eine ziem- 
liche Anzahl von Urnierenkanälchen und endlich bei der Eidechse sind vom Wolff'schen Gang nur einzelne abgeschnürte Stückchen nachzuweisen, während der grösste Theil der vorhandenen Kanälchen, Zellhaufen und Cysten wohl als Reste der Urnierenkanälchen aufzufassen ist. Ueberall funktioniren die Segmentalorgane bis ins zweite Lebensjahr hinein, von da an beginnen die Rückbildungen, die bei den untersuchten Repräsentanten der verschiedenen Gruppen verschieden weit gehen.

Ueber Reste des Wolff'schen Ganges, die ich bei weiblichen Geckotiden gefunden habe, wurde ich weiter unten handeln.

\section{Eileiter.}

Von besonderer Wichtigkeit erschien wegen der Angaben Sempers über die Entwicklung des Eileiters bei Haien eine genaue Untersuchung der Entwicklung desselben Organes bei den niederster, jetzt lebenden Amnioten, die mir, so einfach auch die Resultate sind, besondere Mühe gekostet hat, da ein ganz anderes Resultat als das mitzutheilende erwartet wurde.

Die Entwicklung der Tube habe ich bei Lacerta agilis, Anguis fragilis und Tropidonotus natrix in allen Phasen verfolgt und bei Coronella laevis und Callopeltis Aesculapii kontrolirt, ohne besondere Differenzen aufzufinden; ich beschränke mich daher, im Anschluss an meine Figuren auf taf. VI. die Entwicklung bei Anguis fragilis zu schildern und werde am Schluss noch einige Angaben über die andern Thiere machen.

Es ist nöthig, anf die Topographie des vordersten Theiles der Leibeshöhle einen Blick zu werfen, weil an diesen der erste Anfang. der Tube sich knüpft. Die Leibeshöhle Jäuft nach vorn in zwei durch eine bindegewebige Brücke getrennte Zipfel aus, die mehr nach vorn, als es fig. 1. taf. VI darstellt, noch weiter von einander entfernt liegen und schliesslich ganz schmal und spaltenförmig werden; die Höhle ist natürlich von dem Peritonealepithel ausgekleidet, das an einer Stelle und zwar an der pleura costalis, kurz vor dem Uebergang dieser in die pleura viseeralis auf der bindegewebigen Brücke eine mir völlig unverständliche Verdickung zeigt; in diesem Winkel liegen sehr oft die beiden Blätter so eng aneinander, dass von einem Spalt Nichts zu sehen ist. Eigentlich sind drei Brïcken vorhanden; die mittlere, unpaare von der ventralen Fläche der Aorta ausgehend, umschliesst den Oesophagus 
und die beiden, blindsackförmigen Lungenanlagen, ventral von dem ersteren gelegen; die beiden seitlichen, paarigen, welche auf derselben Höhe verschieden stark ausgebildet sind, treten schräg von der Mittellinie nach Aussen, verbinden das Bindegewebe um die Aorta mit dem Herzen und enthalten weiter hinten die Segmentalorgane (cf. fig. 2 taf. VI.) Mit dem Abrücken dieses Blattes von der ventralen Körperwand - in fig. 1 taf. VI. auf der linken Körperseite bei P. h. - treten die beiden Zipfel der Leibeshöhle zusammen; in sie ragt nun (fig. 2) die stark aufgetriebene Urnierenfalte hinein, welches Verhältniss bis nach hinten erhalten bleibt.

Die Abrissstelle der Urnierenfalte bildet den Ausgangspunkt für die Entstehung des Eileiters, zuerst des Tubentrichters; man findet nämlich an dieser Stelle (cf. fig. 4 u. 5. taf. VI.) das Peritonealepithel besonders verdickt und eine kleine, langgestreckte Erhebnng überziehend, die sich auf den Segmentalorganen gebildet hat. Im vordersten Theil liegt diese Erhebung, die ich die Tubenfalte nenne, (cf. fig. 10 taf. VI.) fast ganz ventral, rückt dann allmählich in einer Viertel Spiraltour um die ganze Urnierenfalte herum, so dass sie endlich ganz dorsal, doch immer in die Bauchhöhle hineinragend, zu liegen kommt; von hier ab - es geschieht das noch im vordern Drittel der Leibeshöhle - ist die Tubenfalte, deren Bildung ich bei verschieden alten Embryonen als von vorn nach hinten fortschreitend verfolgen konnte, an den Verlauf des Wolff'schen Ganges geknüpft und begleitet diesen im ganzen Bereich der Leibeshöhle bis hinten. Vom Wolff'schen Gang habe ich Eingangs meiner Arbeit erwähnt, dass dieser am hintern Körperende seine dorsale Lage aufgilt und allmählig ganz ventral zu liegen kommt und dann in die Cloake einmündet. Denselben Verlauf nimmt hinten die Tubenfalte, sie rückt ebenfalls ventral, hört jedoch selbstredend mit der Bauchhöhle auf. Ihre Bildung geht von vorn nach hinten vor ${ }^{*}$ sich und der Tubenbildung stets voraus.

Diese entsteht nämlich, wie schon erwähnt, da, wo die Urnierenfalte (fig. 1. taf. VI. Ur. f.) von der ventralen Körperfläche rückt, durch Einstülpung eines ganz umschriebenen Stückchens des Peritonalepithel nach innen in die Substanz der Urnierenfalte hinein. Auf Querschnitten, die halbschematisch, jedoch mit genauer Einhaltung der Grössenverhältnisse und der Conturen in fig. 1-3 auf taf. VI. von Anguis fragilis dargestellt sind, finde ich Folgendes: Nachdem die Segmentalorgane in der Urnierenfalte aufgetreten sind und die Tubenfalte eine auf dem Qnerschnitt stempelförmige Erhöhung gebildet hat, dessen Epithel stark 
verdickt ist, beginnt das letztere nach innen in die Tubenfalte hinein sich einzustülpen (fig. $2 \mathrm{~Tb}$. und fig. 6 und 7); diese Einstülpung kommt auf den nächsten Schnitten (fig. 3 rechterseits) tiefer in die Tubenfalten und schnïrt sich endlich als Kanal von dem äussern, verdickten Epithel $a b$; fig. 8 taf. VI lässt die Tubenfalte erkennen, deren verdicktes Epithel durch einen kurzen Gang mit dem Querschnitt eines Längskanaies in Verbindung steht, selbst aber nach hinten abgeschlossen ist; der Längskanal reicht noch einige Querschnitte von $1 / 40 \mathrm{~mm}$. Dicke weiter nach hinten und geht dann in einen soliden Zellstrang, dessen Zellen radienartig angeordnet sind, über (cf. fig. $9 \mathrm{~Tb}$ ); es ist ganz sicher, dass hinter der Einstülpung eine Verbindung des Peritonalepithels mit dem Kanal oder dem Zellstrange nicht stattfindet, stets sind beide scharf von einander getrennt. Auch der Zellenstrang ist in diesem Stadium nur auf einigen Schritten zu verfolgen, und endet dann; in der Tubenfalte, die hinter dem Ende des Zellstranges ihre grösste Höhe stets erreicht (fig. 10), liegt dann wieder das gewöhnliche Bindegewebe, welches sowohl den Wolff'schen Gang, als auch die Kanälchen der Segmentalorgane umgibt. Auf das Ende des Tubenzellstranges habe ich mein besonderes Augenmerk gerichtet, um hier die Waldeyer'sche Ansicht von der Tubenentstehuug bestätigt $\mathrm{zu}$ finden oder nicht, ich sah nie eine Verbindung zwischen Peritonealepithel und der wachsenden Tube, wie sie Waldeyer ${ }^{1}$ ) beim Hühnchen gesehen hahen will; mitunter bekommt man allerdings solche Bilder, erstens bei Schrägschnitten und dann bei Embryonen oder an solchen Stellen derselben, die mit der Pincette gequetscht worden sind, es legt sich dann das Epithel der Tubenfalte so dicht an das Epithel der Urnierenfalte an, dass man ganz ähnliche Bilder bekommt, wie sie Waldeyer zeichnet, die ich also nicht läugne; nur halte ich sie für Kunstprodukte, es ist mir auch nie gelungen, das hinterste Ende der entstehenden Tube da zu sehen, wo es nach der Waldeyer'schen Ansicht liegen müsste, ich sehe es stets in der Tubenfalte gelegen; nicht an dem Winkel, den die Tubenfalte mit der Urnierenobewläche bildet.

Diese Entwicklung habe ich an Blindschleichenembryonen von 14 bis $16 \mathrm{~mm}$. Länge, vom Scheitel bis zum After gemessen, verfolgt; als die jüngsten Stadien bekam ich beim Construiren der Schemata fuir die Tuben-Entwicklung, wie ich zwei derselben in fig. 11 und 12 taf. VI publicire, Bilder, welche die Tube in ihrem ersten Anfang darstellen

1) Eierstock und Ei. taf. V. Abbild. 50. 
und in dieser Vergrösserung und Zeichnungsweise wie mit dem Finger in das Peritonealepithel hineingedrückt erscheinen; dann kommen Schemata, die der fig. 11 entsprechen, wo wir das dunkel gehaltene Peritonealepithel sich an einer Stelle in einen kleinen Blindsack sich einstülpen sehen, der mit der Peritonealhöhle durch einen Spalt kommunicirt und nach hinten einen kurzen Zellenstrang angefügt hat. In einem späteren Stadium, wie es einer Länge von 17-18 mm. entspricht, ist der Blindsack lang ausgezogen, ebenfalls nach hinten mit einem Zellstrange in Verbindung. Dieser ist das hinterwärts wachsende Ende der Tube; die Wachsthumsrichtung ist in beiden Figuren durch Pfeile angedeutet. So geht das nun fort, bis die Tube die Cloake erreicht, immer unter Voransendung des Zellenstranges in die Tubenfalte hinein; hinten durchbohrt sie seitlich und ganz wenig nach vorn vom Wolf"schen Gang die Wand der Cloake, aber nur beim Weibchen - ich brauche wohl nicht hervorzuheben, dass die Tube bei beiden Geschlechtern gebildet wird - , beim Männchen endet sie dicht vor der Cloake blind nnd scheint sich nie mit derselben zu verbinden.

Nach meiner Darstellung entsteht die Tube also vom Peritonealepithel, durch Einstülpung desselben an einer ganz bestimmten Stelle, welche da liegt, wo die Urnierenfalte von der ventralen Körperfläche wegtritt, wo also die erstere im Ganzen einen Peritonealüberzug erhält; der so entstandene Blindsack wächst nun nach hinten in eine vorher gebildete leistenförmige Erhebung hinein bis zur Cloake, obne dass sich dabei andere Elemente des Peritoneums als die zuerst eingestülpten betheiligen.

Zu ganz demselben Resultat bin ich für Lacerte agilis, Tropidonotus natrix und Coronella laevis gekommen; der Ort, die Art der Entstehung und die weitere Ausbildung sind ganz gleich bei den untersuchten Reptilien; auch hier wächst die Tube in eine vorher gebildete Falte, die sich mit Ausnahme des vordersten Abschnittes an den Verlauf des Wolff'schen Ganges anschliesst, hinein.

Bei Lacerta agilis finde ich den ersten Anfang der Ênstülpung bei Embryonen vom 18. und 19. Tage nach der Eiablage, zu einer Zeit, in der die Urniere völlig ausgebildet ist und sich nach hinten von ihr schon ein Zellenstrang, die Anlage der Niere gebildet hat, in welche der Harnleiter eingewuchert ist; in der Geschlechtsdrüse ist die Einwanderung der Ureier in die Segmentalstränge in vollem Gange. Auch bei Lacerta agilis habe ich nicht gesehen, dass das hintere Ende der Tube beim Männchen in die Cloake eindringt. 
Das Wachsthum geht ziemlich langsam vorwärts: am 18. Tage nach der Eiablage entsteht die Tube, am 26. Tage nach derselben ist sie noch nicht über die Körperhälfte hinausgekommen und erst bei Embryonen, die ganz kurz vor dem Ausschlüpfen stehen mussten, deren Alter ich jedoch nicht angeben kann, da ich sie im Freien gefundenen Eiern entnahm, hatte die Tube beim Weibchen die Cloake erreicht, während beim Männchen bereits die Resorption begann.

Bei der Natter wird die Tube schon zu einer Zeit gebildet, während welcher das Ei sich noch im Eileiter des Mutterthieres befindet; der kleinste Embryo, der mir die Tube als kurzen nur auf wenigen Schnitten vorhandenen Blindsack zeigt, hat vom Scheitel bis zum After, im gestreckten Zustande gemessen, eine Länge von $39 \mathrm{~mm}$., das Wachsthum bis zur Cloake danert bis ungefähr zum 14. Tage nach der Eiablage und dann beginnt beim Männchen die Resorption und zwar, wie schon Rathke ganz richtig angibt, von hinten her.

Man findet am frischen Objekt, in $1 / 2-1 \%$ Kochsalzlösung untersucht, bei männlichen Embryonen zwischen dem hintern noch mit Lumen versehenen Ende der Tube und der Cloake einen körnigen Strang, der sich unmittelbar an die Tube ansetzt, ebenso breit ist wie diese und bis zur Cloake reicht; dieser körnige Strang vergrössert sich nun, je ältere Embryonen man untersucht, immer mehr nach vorn; indem die Tube selbst immer kürzer wird. Schliesslich reicht die körnige Degene$r_{a t i o n}$ der Tube bis zum vorderen Ende und scheint bei Schlangen auch dieses zu befallen, während bei der Iacerta agilis und der Blindschleiche dasselbe erhalten bleibt und zu einem von Leydig entdèckten Rest nach vorn vom Nebenhoden gelegen, sich umwandelt Ich habe denselben nicht in allen untersuchten Thieren auffinden können, während ich anderseits auf Schnittserien mich überzeugen konnte, dass auch im Verlauf der früheren Tube beim Männchen einzelne Stäcke in Form von länglichen Säckchen erhalten bleiben; diese Reste fand ich bei einigen Embryonen von Lacerta agilis und Tropidonotus natrix, welche kurz vor dem Ausschlüpfen standen; bei älteren Thieren konnte ich davon Nichts bemerken.

Bei der Umwandlung zum bleibenden Eileiter handelt es sich um die Ausbildung von zablreichen Drüsen in der Schleimhaut und um das Entstehen einer starken Muskellage; der ausgebildete Eileiter, der in seinem grössten Theile mehr als Uterus funktionirt, stellt einen bandförmigen Kanal dar, welcher vorn etwa in der Höhe des hinteren Endes der Leber mit einem grossen, vielfach eingeschnittenen Trichter in die 
Leibeshöhle ausmündet. An der Einmündungsstelle in die Cloake ist namentlich bei den Schlangen eine ganz besonders starke Anhäufung von glatten Muskelfasern zu erwähnen, welche ein kurzes, an der Cloake sitzendes Rohr darstellen, das den Eileiter aufnimmt. An der lateralen Kante der Tube verläuft ein ziemlich starkes, muskulöses Band von vorn nach hinten, welches, da es bedeutend kürzer als der Eileiter ist, bedingt, dass derselbe im nicht trächtigen Zustande in zahlreiche Querfalten gelegt ist. Befinden sich Eier im Eileiter, welche immer mit ihrem Längsdurchmesser parallel der Mittellinie liegen, so entsteht eine reine Kammernng des Eileiters, es bildet sich um jedes Ei eine so gut wie völlig abgeschlossene Tasche; die Wand des Eileiters wird an diesen Stellen sehr stark ausgedehnt, unterhalb und oberhalb eines jeden Eies liegt ein kurzes Stückchen intakten Eileiters, dessen Wände ganz zusammen liegen. Das muskulöse Band an der lateralen Kante des Eileiters ist zwar verstrichen, doch trotz der Ausdehnung als weisslicher Streif zu erkennen.

Bei den beiden Geckotiden, welche ich untersuchen konnte, ist die Kammerung des Eileiters ein bleibender Zustand, auch im nicht schwangeren Zustande vorhanden; wir finden sowohl bei Platydactylus facetanus als bei Phyllodactylus europaeus an den Trichter sich anschliessen? einen kurzen, etwas eingekerbten und gefalteten Kanal, der bald in eine platte Tasche (cf. fig. 1 taf. X) übergeht - jederseits nur in eine; dann folgt wiederum bei Platydactylus der Eileiter in der gewöhnlichen Form bis zur Einmündung in die Cloake; diesen Zustand konnte ich schon bei jungen, wenige Wochen alten Platydactylus facetanus von Menorka erkennen, indem der Eileiter an der späteren Stelle der Tasche spindelförmig aufgetrieben erschien. Die Tasche funktionirt als Uterus, in ihr wird ein Ei bis zu einem gewissen Zustand der Ausbildung beherbergt. Da bei beiden Thieren der Eileiter weniger bekannt, zum Theil sogar verkannt ist, möge es mir gestattet sein, über den eigentlichen Rahmen dieser Arbeit hinaus einige Angaben zu machen.

Ich beginne mit dem Eileiter von Platydactylus facetanus, welcher noch in der Höhe des hinteren Endes der Leber mit einem etwa $3=4 \mathrm{~mm}$. langen Spalt seinen Anfang nimmt; die Ränder dieses erscheinen fast ganz glatt, ganz seichte Einkerbungen kann ich allerdings an meinen Präparaten erkennen, doch sind dieselben lange nicht so tief, wie sie $\mathrm{z}$. B. Leydig ${ }^{1}$ ) von Lacerta vivipara abbildet; ob

1) Deutsche Saurier. tab. IX. fig. 116. 
Flimmerung an diesen Theilen vorhanden ist, weiss ich nicht. Von dem Spalt, der einen Theil des freien Randes einer weiter vorn beginnenden Bauchfellfalte einnimmt, geht ein sich etwas verjüngender platter Kanal nach der Mittellinie zu und krümmt sich in sanftem Bogen - lateral konkav - nach hinten, um nach kurzem Verlauf in die bereits erwähnte Tasche überzugehen, deren Wände im nicht schwangeren Zustande fast vollständig einander berühren; der Eileiter verengert sich vor der Tasche auf 1-1, כ mm., während der grösste Querdurchmesser der Tasche $5 \mathrm{~mm}$. beträgt. Das Lumen ist im Ganzen hinter dem Trichter spaltförmig, wird mehr nach hinten oval und endlich vor der Tasche, dem physiologischen Uterus, rund; schon ron Anfang an springen in das Iumen hinein eine Anzahl von Falten, die nach hinten immer zahlreicher werden und das Lumen sehr beschränken. Hinter der Tasche, welche ziemlich nahe der Mittellinie auf dem vorderen Ende der Niere liegt, folgt wiederum ein platter Kanal, der nach hinten, wo er die Cloakenwand erreicht, stark muskulös und cylindrisch wird; er durchbohrt die Cloake, ragt jedoch nach innen konvergirend mit einem kurzen an der Spitze durchbohrten Stück in die Höhlung der Cloake hinein, mündet also auf einer Papille aus.

Dies lässt sich Alles mit blossem Auge konstatiren; betrachtet man Querschnitte des Eileiters, so findet man denselben aus mehreren Lagen zusammengesetzt: zu äusserst liegt der Peritonealüberzug, der nur diejenige Stelle freilässt, wo das Mesenterium des Oviduct von demselben abtritt, es ist dies die mediale, schmale Fläche; dann folgen zwei Lagen glatter Muskelfasern, eine äussere longitudinale und innere cirkuläre Schicht, hierauf nach innen die submucosa mit zahlreichen, bis auf die Muskellage reichenden, schlauchförmigen Drüsen und endlich zu innerst die mit einem Cylinderepithel ausgekleidete Schleimhaut, deren Falten ich schon erwähnt habe. Die gesammte Dicke der Wandung beträgt allerhöchstens $0,75 \mathrm{~mm}$., meist nur $0,5 \mathrm{~mm}$; fast zwei Drittel der Wandung nimmt die Drüsenschicht ein, die aus zahllosen, nur wenig verzweigten, schlauchförmigen Drüsen zusammengesetzt ist; sie beginnen schon dicht hinter dem Trichter, dort etwas spärlicher und häufen sich am meisten in der Tasche. Ihre Funktion ist mir unbekannt, doch ist es sehr wahrscheinlich, dass sie mit der Bildung der harten Eischale in Beziehung stehen; das einfache Cylinderepithel der Schleimhaut kann man doch kaum dafür verantwortlich machen.

Der weitere Verfolg einer Schnittserie, die ich mit Erhaltung der Darmwand durch das hintere Ende des Urogenitalsystems eines weib- 
lichen Gecko anlegte - hauptsächlich mit Rücksicht auf Phyllodactylus und die Angaben Wiedersheims über dieses Thier, hat mich ein interessantes Verhältniss von Cloake und Eileiter bei Platydactylus facetanus auffinden lassen, welches mir bei der anatomischen Präparation entgangen war! der Eileiter liegt in dem hinter der Tasche folgenden Theil zwischen der dorsalen Wand der Cloake und der ventralen Fläche der Niere, mit der letzteren durch ein schmales Mesenterium verbunden. Von der Darmwand ist der Eileiter nicht ganz getrennt, sondern durch Bindegewebe an dieselbe angeheftet, wohl ist aber die Muskulatur des Eileiters völlig gesondert von der Muskulatur des Darms, zwischen beiden erstreckt sich ein, wie es scheint, lymphatischer Hohlraum. Nach hinten wird der Eileiter auf dem Querschnitt oval, seine Schleimhaut springt in vielen Falten in das Lumen hervor und misst im Durchmesser 0,509 mm., mit der Muskulatur etwa $0,738 \mathrm{~mm}$.; plötzlich verbreitert sich auf dem Querschnitt die Muskulatur des Eileiters an seiner ventralen Fläche und im nächsten Schnitt tritt unabhängig von der Schleimhaut des Eileiters der Querschnitt einer rinnenförmig gebogenen Drüse auf, die in der ventralen Muskellage des Eileiters eingebettet ist und diesen letzteren wie eine nicht ganz geschlossene Spange umfängt; ich unterscheide an der Drüse, die ich wegen ihrer Lage als Tubenoder Eileiterdrüse bezeichnen will, den rinnenförmigen Ausführungsgang, der ganz von einer Cylinderepithellage umfasst wird; diese lässt eine Anzahl von Vertiefungen erkennen, in welche ganz kleine, nur wenig verzweigte, schlauchförmige Drüsen einmünden; auf einem Schnitt zähle ich etwa 35-40 solcher Drüschen; sie liegen in der ganzen Schleimhaut, am meisten jedoch an den beiden Rändern des ganzen Drüsensackes, wo sie auch am grössten sind. In den Lumina dieser Drüschen sehe ich ein glasiges, in Pikrokarmin sich roth färbendes Sekret, das sich von der einfachen Epithellage etwas zurïckgezogen hat. Durch eine starke Muskellage ist der Drüsensack von dem Eileiter getrennt, nirgends erkenne ich eine Verbindung dieser Drüse mit der Schleimhaut der Tube, beide stehen in gar keiner Beziehung, ausser dass die Drüse in der Muskulatur der Tube liegt. Weiter nach hinten verschmilzt die Muskulatur des Eileiters mit derjenigen der Cloake und bildet eine in den Darm hervorspringende, etwas gestreckte Papille. An der Stelle nun, wo die Papille auftritt, mündet die Eileiterdrüse in die Cloake aus, jedoch setzen sich die kleinen Drüschen mit dem charakteristischen, glasigen Sekret noch eine Strecke weit nach hinten fort und sind in der Schleimhaut der Cloake, welche die Papille überzieht, und lateral 
von dieser in derselben Form zu erkennen. Wir können nach diesem die Eileiterdrüse als einen Blindsack der Cloake auffassen, der von letzterer nach vorwärts abgeht und in die Muskulatur der Tube eingedrungen ist; als Blindsack der Cloake dokumentirt sich dieser Drüsensack erstens dadurch, dass das Epithel der Cloake ohne Grenze in das seinige übergeht und diesem völlig gleich ist, und zweitens dass die Cloakendrüschen in gleicher Form und Anordnung auch in dem Drüsensack selbst vorhanden sind. Sie erreichen nach hinten in der Cloake ungefähr in gleicher Höhe mit der Ausmündung des Eileiters ihr Ende; an ihre Stelle treten dann viel breitere Drüsenschläuche mit höherem Cylinderepithel und einem sich in Pikrokarmin fast gar nicht färbenden, krümlichen Sekret, das am frischen Thiere weisslich erscheint und in Folge dieser Beschaffenheit erkennen lässt, dass die Drüsen der zweiten Art in einer Linie ausmünden, welche parallel dem hinteren Rande der Cloake zwischen den beiden Penis hinzieht.

Der Eileiter geht in der erwähnten, in die Cloake einspringenden Papille, noch weiter nach hinten und mündet endlich am hinteren, etwas abgeflachten Ende derselben in die Cloake. Dieser hintere Abschnitt des Eileiters von der Tasche an entbehrt der schlauchförmigen Drüsen, die sich namentlich, wie oben erwähut, in der Tasche reich entwickelt zeigen.

Nun noch kurz einen Blick auf das Verhalten des Harnleiters, der als $0,140 \mathrm{~mm}$. dicker Kanal auf der ventralen Fläche der etwas aus gehöhlten Niere verläuft und aus derselben die Sammelröhrchen empfängt er liegt genau da, wo das Bauchfellband des Eileiters an die Niere sich anheftet und gelangt weiter nach hinten, wenn die Tube in die Wand der Cloake eingetreten ist, in dasselbe Bauchfellband, das nun von der Cloake zur Niere geht; hier macht er dann, hinter der Ausmündung der Tube plötzlich eine Biegung ventralwärts und mündet auf der Fortsetzung der Tubenpapille, jedoch wie bei andern Reptilien getrennt vom Eileiter in die Cloake aus. Mit ihm vereinigt sich kurz vor der Mündung ein zweiter, etwas schmälerer Kanal, der nach der Dicke der Schnitte zu urtheilen noch nicht einen Millimeter lang ist und seitlich in denselben eintritt; ich halte diesen vorn blinden Kanal für einen Rest des Wolff'schen Ganges, der hier beim Weibchen in seinem hintersten $\mathrm{Ab}$. schnitt erhalten ist, während der grösste vordere Theil resorbirt ist; dazu bestimnt mich die seitliche Einmündung resp. Verbindung dieses Kanales mit dem Harnleiter kurz vor dessen Mündung und die Thatsache, dass auch bei andern Reptilien mehr oder weniger grosse Reste oder der ganze Wolff'sche Gang beim Weibchen erhalten bleiben. 
Hinter der Mündung in die Cloake geht der Harnleiter weiter nach hinten und liegt ebenfalls als einfacher Kanal auf der ventralen Fläche der nun immer schmäler werdenden Nieren, von denen man wenigstens bei andern Reptilien angibt, dass eine Vereinigung derselben nicht stattfindet; für den Gecko ist dies nicht der Fall; ich sehe auf meinen Schnittserien eine zweimalige Vereinigung der beiden Nieren, die vordere tritt in der Höhe der Einmündung des Eileiters auf und besteht in zwei Brücken von Nierensubstanz, eine dorsale und eine ventrale, welche ein Gefäss zwischen sich haben und von einer Niere zur anderen ziehen. Nach hinten zu löst sich diese Verbindung eigentlich nicht vollständig, doch habe ich einige Schnitte, auf denen die Brücke sicher fehlt und durch Bindegewebe ersetzt ist. Kurz vor dem Ende der Nieren verschmelzen dann beide völlig zu einem Complex von Nierenkanälchen und nur die nun auch gemeinschaftlich gewordene Vene gibt die ursprüngliche Theilung noch an.

Das Ovari u m ist wie bei allen von mir untersuchten Reptilien in eine besondere Bauchfellfalte ganz eingeschlossen, welche nach vorn und hinten einen Zipfel entsendet; es ist wie der grösste Theil des Oviducts vollkommen frei beweglich.

Lebhaft bedauern muss ich es, im Augenblick kein gut erhaltenes Männchen von Platydactylus facetanus zu besitzen; frisches Material konservirte ich nicht mit Rücksicht auf den Enddarm und die Exemplare, die ich lebend mitgebracht hatte, sind mir leider gestorben, ehe ich das eben erwähnte Verhältniss beim Weibchen fand; es ist nach meinen Erfahrungen schwer, den gewöhnlichen Gecko längere Zeit in Gefangenschaft zu halten, was nach einer brieflichen Mittheilung von Prof. v. Leydig auch diesem erfahrenen Herpetologen mit Exemplaren, die ich lebend ihm übersandte, nicht möglich gewesen ist.

Vom Urogenitalsystem des weiblichen Phyllodactylus europaeus liegen Angaben von Wiedersheim ${ }^{1}$ ) vor, die ganz eigenthümliche Verhältnisse darstellen. Sie weichen von den Befunden bei andern Reptilien bedeutend ab und müssen durch die hier gegebene Entwicklung erklärt werden. Bereits oben hatte ich Gelegenheit, die Ansicht Wiederheims über die angeblich einseitige Funktion des Ovariums bei Phyllodactylus, welche an die Vögel erinnern sollte, zu berichtigen;

3) Zur Anatomie und Physiologie von Phyllodactylus europaeus etc. Gegenbaur's morphol. Jahrbuch. I. p. 511-515 u. p. 516-517. 
es thut mir leid, auch jetzt wieder berichtigend und ergänzend auftreten zu müssen.

Vom Oviduct sagt Wiedersheim, dass er „auswärts vom dem Ovarium“ - besser wohl lateral vom Ovarium - liege und wie ein Vorhang den Eierstock überlagere; mit seiner Figur 13 tab. XIX. stimmt dies schon nicht ganz überein; der Anfang des Eileiters liegt dort nur auf einer Seite - der rechten - so, dass er das medial gelagerte Ovarium wie ein Vorhang deckt; links ist dasselbe Stück lateral auf dem UterusAbschnitt des Eileiters gezeichnet, also nach der entgegengesetzten Seite hinaus, wie es übrigens das normale Verhalten darstellt. Drei weibliche Exemplare habe ich untersucht und bei allen gesehen, dass wie bei anderen Reptilien der Trichter nach der lateralen Körperwand zu gerichtet ist; die Spalte misst im kontrahirten Zustande nur $2 \mathrm{~mm}$; ihr Rand ist wenig eingekerbt. Der Trichter liegt an dem lateralen Rande einer Bauchfellfalte, welche vorn an den Rippen beginnt und nach hinten allmählig breiter wird. Auf fig. 13 von Wiedersheim ist der Trichter gar nicht zu erkennen, er soll dem Text und der Tafelerklärung nach bei $\mathrm{F}$ liegen, in welchem zipfelartigen Theil ich jedoch Nichts als eine Bauchfellfalte erkennen kann; erst zwischen den Buchstaben Z. und S. käme nach meinen Präparaten der Trichter. An diesen schliesst sich wie beim Gecko ein platter, etwas gefalteter Kanal an, der „wie eine vielfach gefaltete Fahne in der Längsaxe des Körpers herunterhängen" soll, wofür ich aber in meinen Präparaten keinen Anhalt finden kann. Dieser Theil soll in doppelter Weise fixirt sein: erstens besteht nach Wiedersheim "eine innige Verwachsung fast mit der ganzen medialen Seite des Uterus und zweitens geht ein starker, glatte Muskelfasern enthaltender Strang vom "obern" (vordern) Ende des Uterus zu diesem Theil. Das letztere ist richtig, es ist dies der laterale Rand der Bauchfellfalte, in welcher der Eileiter liegt und die wie bei den andern Reptilien einen sehr langgestreckten Zug glatter Muskelfasern enthält. Das erstere jedoch, die innige Verwachsung mit dem Uterus, die es bedingt, dass das Lumen dieses Theiles „unter scharfer Knickung" in den Uterus übergeht, macht es mir zur Gewissheit, dass das Präparat, welches Wiedersheim vorlag, ein pathologisches war, zu welcher Ansicht ich bereits oben bei der einseitigen Funktion des Ovariums gekommen bin, und worin ich noch durch Folgendes bestärkt werde: In den von mir untersuchten drei Fällen sehe ich nämlich bei einem genau so wie bei den anderen, dass der platte Kanal des Eileiters sich ohne jede Knickung in den physiologischen 
Uterus, den von mir als Tasche bezeichneten Abschnitt des Eileiters fortsetzt, dass diese Tasche eine mehr oder weniger kreisrunde Circumferenz hat und ziemlich scharf abgeschnitten in das Endstück des Eileiters übergeht, wie es Wiedersheim für die linke, dem normalen Verhalten mehr entsprechende Seite seiner fig. 13 zeichnet. Diese Tasche hat eine Länge von 3,5 und eine Breite von $1,5 \mathrm{~mm}$. und ist auch bei dem nicht trächtigen Thier als solche vollkommen deutlich zu erkennen, wenn sie auch im Ganzen kleiner als im schwangeren Zustande ist. Von allen diesem ist in fig. 13 bei Wiedersheim Nichts zu erkennen dies zusammengehalten mit dem Früheren und der auch bereits erwähnten Differenz zwischen rechts und links lässt mich das Präparat als ein pathologisches betrachten und legt mir die Verpflichtung auf, ein völlig naturgetreues Bild hiervon zu publiciren, das ich einem der Sache fern stehenden Freunde J. v. Kennel verdanke (fig. 1 taf. X.).

An die Tasche schliesst sich nun der dritte Abschnitt dss Eileiters, der eigentliche ausführende, beim Ablegen des Eies in Betracht kommende Kanal, dessen Eigenthümlichkeiten Wiedersheim nur halb zur Kenntniss gekommen sind. An ein kurzes, nur $1 \mathrm{~mm}$. langes Verbindungsstück schliesst sich der Endabschnitt des Eileiters an, der sich auch äusserlich durch eine Verbreiterung des Kanales nach den Seiten hin kenntjich macht (cf. taf. $\mathrm{X}$ fig. 1 bei a.) Seine Zusammensetzung lässt sich durch Präparation nicht erkennen, hierzu sind Querschnitte, am besten Schnittserien nöthig. Es ist noch zu erwähnen, dass die beiden vordersten Abschnitte des Eileiters frei beweglich sind, der hinterste dagegen ziemlich fest mit seiner dorsalen Fläche auf die ventrale der Niere gekettet ist; schon die Tasche liegt, wenn man das Thier auf den Rücken gelegt denkt, der Niere auf; dies Verhalten, das übrigens beim gewöhnlichen Gecko sich wiederfindet, weicht von den andern mir bekannten Reptilien ab, wo der Eileiter nur ganz wenig nach der Mittellinie zu konvergirt, bis zu seiner Einmündung in die Cloake aber frei beweglichbleibt.

Betrachten wir nun die Querschnitte und zwar einen hinter der Tasche (fig. 2 taf. $\mathrm{X}$ ), da uns die vorderen weniger interessiren, so sehen wir den Eileiter durch ein schmales Band mit der Niere verbunden; sein Lumen, von einem Cylinderepithel begrenzt, ist lang: gestreckt, spaltförmig, in der Richtung vom Bauch nach dem Rücken zu zusammengedrückt; hierauf folgen nach aussen die beiden Muskellagen, eine innere cirkuläre und äussere longitudinale; von Drüsen ist Nichts zu bemerken. Der nächstfolgende Querschnitt (fig. 3 taf. X) 
zeigt eine Verbreiterung des Lumens der Tube nach der ventralen Fläche zu, so dass im Ganzen der Querschnitt mehr quadratisch wird; zahlreiche Falten der Schleimhaut und inselförmig abgesprengte Stücke des Epithels sind vorhanden; dieser Schnitt entspricht ungefähr der Stelle a in fig. 1. Dasselbe Verhalten bietet sich auch noch auf dem dritten Schnitt; auf dem vierten (fig. 4 taf. $\mathrm{X}$ ) aber finden wir wieder eine Verschmälerung des Lumens der Tube, die noch weiter geht, als die vorn geschilderte; während der gesammte Querschnitt des Eileiters im Ganzen gleich gross bleibt, nimmt die Tube einen kleinen ovalen Raum ein, der an der breiter gewordenen Brücke zwischen Eileiter und Niere also dorsal liegt; die Schleimhaut springt in grossen Falten hervor. Der übrige Raum wird von der sehr stark entwickelten muscularis circularis eingenommen, während die longitudinalis nur gering entwickelt ist. Der nächste Schnitt, also Nr. 5 von dem zuerst beschriebenen an - ich bemerke, dass die Schnitte alle ${ }^{1 / 20 ~} \mathrm{~mm}$. dick sind - lässt plötzlich in der dicken Ringsmuskelschicht, ventral von der Tube gelegen, aber in der Muskellage eingebettet, die Querschnitte der vordersten Enden von kleinen Schläuchen (cf. fig. 4. Dr.) erkennen, die mit kubischem Epithel ausgekleidet sind; im nächsten Schnitt Nr. 6 (fig. 5 taf. X) treten eine ganze Menge solcher Querschnitte auf und nehmen in der Ringsmuskularis einen halbmondförmigen Raum, um die ventrale Fläche des Tubenepithels gelegen, ein. Sehr bald dahinter (fig. 6 taf $\mathrm{X}$ ) sehen wir auf dem Querschnitt einen halbmondförmigen Spalt auftreten, in den kleine, schlauchförmige Drüsen einmünden; diese Drüsenschicht stellt eigentlich eine einzige Drüse mit breitem, rinnenförmigen Ausführungsgang dar, der parallel der Tube von vorn nach hinten und in der muscularis derselben gelegen verläuft; die Drüse umfasst wie eine Spange über $3 / 4$ der eigentlichen Tube (cf. fig. 7 taf. X), deren muscularis ebenfalls immer zunimmt, während das Lumen nach hinten bedeutend kleiner wird - wohl eine Folge der Einwirknng der Chromsäure auf die Contraktion des Muskeln; es erscheint fast, als ob in das Gewebe der Drüse, in einer lokalen wallartigen Wucherung der dorsalen Wandung des Ausführungsganges ein zweiter Kanal eingebettet sei, der mit dem ersteren gar Nichts zu thun habe und vielleicht wegen der Nachbarschaft der Niere als Harnleiter angesehen werden möchte. Dieser soll nämlich nach Wiedersheim (1.c. p. 517) den Eileiter in seiner hinteren Peripherie treffen, ihn in seiner ganzen Dicke durchsetzen und sich mit seinem letzten Ende in der ventralen Wand desselben förmlich einlöthen. Hierin liegt schon ein Widerspruch: zuerst trifft also der Harnleiter den Eileiter in seiner "hinteren" Peri- 
pherie - immer diese vom Menschen herrührende Nomenklatur, die auf die Wirbelthiere nicht passt, wenn man sie nicht aufhängt - und schliesslich löthet er sich auf der ventralen Fläche desselben ein, muss also doch wohl, um dahin zu gelangen, um den halben Eileiter herumgehen, was stillschweigend vorausgesetzt zu werden scheint. Nehmen wir jedoch an, es handle sich hier um eine Verwechselung oder einen Druckfehler und es solle heissen, der Harnleiter löthe sich auf der dorsalen Fläche des Eileiters ein, so stehen wir wieder vor einem Räthsel, für das wir auf unseren Präparaten keine Lösung finden, wenn wir nicht annehmen, dass Wiedersheim den von mir als eigentliche Tube bezeichneten Theil für den Harnleiter und die Drüse für den Eileiter angesehen hat; der erstere liegt allerdings in der dorsalen Wandung der letzteren förmlich eingebettet, ist viel kleiner und kann, wenn man nur etwa einen oder den andern Querschnitt macht, oder gar blos anatomisch präparirt, diesen Eindruck sehr leicht hervorrufen - es ist mir Anfangs ebenso gegangen, nur das Verfolgen der Schnittserie nach vorn und ninten und die zur sicherern Controle mit dem Zeichnenprisma angefertigten Zeichnungen ergaben mir die Täuschung und damit auch die Wahrheit.

Verfolgen wir nun Tube und Drüse bis zum Einmünden in die Cloake, so sehen wir, dass das Lumen des Ausführungsganges der Drüse immer grösser wird, während der Tubenkanal an Grösse abnimmt; endlich biegt der letztere ventral, die dicke Muskellage durchbohrend, und hört auf, ist also an seiner Mündung angelangt (cf. fig. 8 taf. $\mathrm{X}$ ); auf demselben Schnitt mündet jedoch die Drüse auch schon in die Cloake, ihre schlauchförmigen Drüsen gehen noch einen Schnitt weiter nach hinten. Wenn man von der Cloake ausgeht, so trifft man rechts und links der Mittellinie eine gemeinsame Mündung für Tubendrüse und Tube, die erstere liegt ventral, die letztere dorsal und bekommt kurz vor dem vordern Ende der Drüse eine kleine Aussackung, die dann nach vorwärts wiederum in einen Kanal und aus diesem in die Tasche führt. Dies ist nun ein von den andern Reptilien stark abweichendes Verhältniss, weil wir bei der gleichzeitigen Ausmündung der Drüse und Tube in die Cloake die Funktion der ersteren nicht verstehen; die Annahme, dass in der Cloake Theile der Eischale gebildet werden, scheint mir auszuschliessen zu sein. Die Anordnung ist auch derart, dass beim Gebärakt das vorrückende Ei die Tubendrüse ganz komprimirt, ihr Sekret also eher in die Cloake gelangen muss, ehe das Ei dahinkommt, welches ohnedem bereits seine Eischale besitzt, wie mich die Unter- 
suchung eines trächtigen Weibchens lehrte; wir müssen also für die Bildung der Eischale nach andern Drüsen suchen, die voraussichtlich dort liegen werden, wo das Ei sich am längsten aufhält, es ist dies die Tasche des Eileiters; in der That steckt diese gerade wie beim Gecko (Platydactylus) ganz voll von Drüsen; es sind auch ziemlich kurze, wenig verzweigte Schläuche, die mit einem Pflasterepithel ausgekleidet sind und in den Uterus münden.

Ueber die Bedeutung der Tubendrüse kann ich mich, so lange die Entwicklung noch unbekannt ist, nicht bestimmt aussprechen; sie könnte, da sie an derselben Stelle, wie der Eileiter in die Cloake mïndet, sowohl vom Epithel der Tube als auch der Cloake sich entwickeln. Ein Punkt scheint für die letztere Abstammung zu sprechen: Wir wissen durch Leydig ${ }^{1}$ ), dass in der Cloake der Eidechsen zweierlei Drüsenarten vorkommen, die eine, grössere Art gehört der Rückwand der Cloake an und ist nach Leydig eine Prostata, die andere, kleinere liegt in der Bauchwand der Cloake, hat einen traubigen Bau und ist eine Talgdrüse. Jedoch schon bei der Blindschleiche heisst es (p. 151): „es scheint, als ob hier bei der weiblichen Blindschleiche der Drüsenwulst die zweierlei, bei dem mänulichen Thier und den Eidechsen getrennten Formen der Prostata zugleich vorstelle"; es herrscht also schon zwischen Eidechse und Blindschleiche ein Unterschied. Beim Phyllodactylus finde ich in der Cloake nur eine Drüsenart, die in langen, mit hohem Cylinderepithel in die dorsale, mehr noch in die seitliche Wand der Cloake einmündet; vielleicht ist also die Tubendrüse der andern Drüse der Eidechsen (Prostata) zu parallelisiren.

Die nachträglich angestellte (oben mitgetheilte) Untersuchung eines weiblichen Platydactylus lässt die hier entwickelte Ansicht, dass die Tubendrüse in der That einem Complex von Cloakendrüsen gleichzusetzen ist, nur bestätigt erscheinen; dort ist die Entscheidung über die vermuthliche Herkunft leichter, weil die Drüse weit getrennt von dem Eileiter ausmündet und weil die sie zusammensetzenden, kleinen schlauchförmigen Drüschen mit niedrigem Epithel noch eine Strecke weit nach hinten in der Cloake zu erkennen sind; hier (Phyllodactylus) sind alle diese Drüschen in dem nach vorn abgehenden Blindsack der Cloake vereinigt, der in merkwürdige Beziehung zur Tube selbst tritt.

Die hier mitgetheilten Befunde veranlassten mich, einen männlichen Phyllodactylus zu untersuchen; bei der frischen Präparation glaubte

1) Deutsche Saurier. p. 141 u. 142.

Arbeiten a, d. zool.-zoot. Inst. Würzb. Bd. IV. 
ich in einer weisslichen Masse, welche auf der ventralen Nierenfläche lag und mit der Cloake in Zusammenhang stand, die Tubendrüse des Weibchens wiedergefunden $\mathrm{zu}$ haben, doch lehrte mich eine angefertigte Schnittserie, dass die weissliche, langgestreckte Masse, neben welcher lateral der prall mit Samen gefüllte Samenleiter in zierlichen Windungen verlief, nur durch eine besondere Anordnung der Sammelröhrchen der Niere bedingt wurde; diese ableitenden, sehr weiten Kanälchen, welche in den $0,104 \mathrm{~mm}$. dicken Harnleiter einmünden, nehmen an Masse wohl die Hälfte der secernirenden Nierensubstanz ein; die letztere liegt wie eine Schale dorsal um die Sammelröhrchen und ist kaum halb so breit wie diese, wohl aber noch einmal so lang. Diese eigenthümliche Anordnung ist beim Weibchen in der Niere nicht vorhanden; hier treten die Sammelröhrchen schon in der Niere zu wenigen Kanälchen zusammen und diese münden danı in den Harnleiter; eine von vorn nach hinten durchgehende Scheidung in einen secernirenden Theil mit Malpighischen Körperchen und engen, gewundenen Nierenkanälchen und einen ableitenden Theil mit zahlreichen, mehr gestreckt verlaufenden und weiteren Kanälen habe ich nirgends sonst bei Reptilien gesehen, als in der Niere des männlichen Phyllodactylus.

Eine Vereinigung der Nieren, wie ich sie oben beim Weibchen vom Platydactylus beschrieb, kann ich beim Männchen von Phyllodactylus nicht finden; die beiden Nieren treten zwar nach hinten nahe an einander, doch trennt sie immer eine Schicht Bindegewebe und die hinten in e in Gefäss zusammenfliessende Nierenvene.

Vom Hoden giebt Wiedersheim (1. c. p. 515) an, dass derselbe rundlich, hinten etwas zugespitzt ist; neben ihm liegt der goldgelbe Körper, der zu dem einzigen Ausführungsgang, den der Hoden an seinem "obern" (vordern) Ende abschickt, ein besonderes Verhältniss eingeht, indem er von dem Gang "förmlich durchsetzt wird" - so scheint es nach einem frischen Präparat allerdings der Fall zu sein, doch lehren Querschnitte anders: den Beginn des goldgelben Körpers finde ich weiter nach hinten, als der Ausführungsgang des Hodens liegt; dieser letztere bildet dann mit spärlichen, dünnen Kanälchen den sogenannten Nebenhoden, welcher durch ein bindegewebiges Band mit dem goldgelben Körper innig verbunden lst, ohne aber in seine Substanz einzutreten. Mit dem hinteren Ende des goldgelben Körpers hören denn auch die kleinen Nebenkanälchen im Nebenhoden auf und der Samenleiter zieht sich mannigfach windend nach hinten, kommt auf die ventrale Fläche der Niere, liegt hier an deren lateralen Rand um die bereits erwähnte 
weissliche Masse - der Summe der harnleitenden Nierenkanälchen, herum und verläuft nun ziemlich grade bis zur Cloake, in der er vereint mit dem Harnleiter auf einer Papille ausmündet.

Es bleiben noch die $\mathrm{Ni}$ eren und der Ausführungsgang derselben beim Weibchen übrig; von den ersteren gibt Wiedersheim (l. c. p. 516) an, dass sie "etwa birnförmige Gestalt mit dickerem oberen (vorderen) und spitz ausgezogenen unterem (hinteren) Ende" besitzen; "sie weichen also von demselben Organ der Eidechsen gewaltig ab"; weder bei diesen noch bei Phyllodactylus sind die Nieren birnförmig, der Querschnitt solcher müsste immer annähernd kreisförmig sein, dagegen sind sie bei beiden in der Richtung vom Bauch zum Rücken abgeplattet, auf dem Querschnitt bei Phyllodactylus viel platter als bei den Eidechsen; bei beiden jedoch sind die Nieren vorn breiter, spitzen sich nach hinten zu und kommen hinten mit dem medialen Rande sehr nahe aneinander zu liegen; der mediale Rand ist bei beiden ziemlich glatt, der laterale eingekerbt: bei beiden reichen die Nieren nach hinten über die Stelle hinaus, an welcher der Harnleiter in die Cloake einmündet.

Dieser liegt als einfacher, von einem einschichtigen Plattenepithel ausgekleideter Kanal, dessen Schleimhaut nicht in Falten vorspringt, in einer bindegewebigen Masse nach innen von der Nierenvene; das Bindegewebe füllt eine rinnenförmige von vorn nach hinten laufende Vertiefung der ventralen Fläche der Nieren aus; lateral davon ist die Tube durch ein kurzes Band mit diesem Bindegewebe verbunden; weiter nach hinten, wenige Schnitte vor der Einmündung der Tube in die Cloake ist der Eileiter durch Bindegewebe mit dem den Harnleiter umgebenden Gewebe verbunden, doch berechtigt Nichts zu der Meinung, der Harnleiter sei in die Wand des Eileiters eingelöthet. Nachdem nun der Eileiter mit der Drüse die Cloake durchbohrt hat, wendet sich der Harnleiter ziemlich plötzlich in einem Bogen nach der dorsalen Wand der Cloake, in die er eingebettet sein muss, um sie durchbohren zu können; 3 Schnitte weiter nach hinten mündet er gemeinschaftlich mit einem andern Kanal ein; dieser letztere nämlich kommt lateral aus dem Bindegewebe der dorsalen Cloakenwand, ist unverästelt und strebt medial ziemlich in der Querechnittebene verlaufend nach dem Harnleiter, mit dem er sich vereinigt und gemeinschaftlich ausmündet. Ich hetrachte diesen Kanal als den hintersten, erhalten gebliebenen Rest des Wolff'schen Ganges, der bei allen Reptilien gemeinschaftlich mit dem Harnleiter in die Cloake einmündet. Gleichzeitig ergiessen noch eine grosse 
Zahl von schlauchförmigen Drüsen mit hohem Epithel ihr Sekret in die Cloake, von denen schon weiter vorn die Rede war.

Ein etwa 8-9 Monate altes weibliches Exemplar von Phyllodactylus europaeus, das ich Anfangs Mai tödtete und untersuchte, hat mir Folgendes ergeben: der Eileiter stellt einen von vorn nach hinten verlaufenden ganz einfachen Kanal dar; kein Abschnitt desselben ist mit Ausnahme des Trichters besonders differenzirt; dieser von Cylinderepithel ausgekleidete Kanal hängt an einem kurzen Nesenterium rorn am Rest des Wolff'schen Körpers, hinten an der ventralen Fläche der Niere; erst ganz kurz vor der Einmündung in die Cloake erweitert sich die Tube, es erscheinen auf dem Querschnitt jederseits 2 spaltförmige Iumina mit Cylinderepithel ausgekleidet, von denen ich nicht entscheiden kann, ob dies durch eine Faltung des Eileiters oder einem kurzen Blindsack, der Anlage der Eileiterdrüse bedingt ist; nach hinten vereinigen sich beide wieder zu einem Kanal und dieser mündet im Verein mit dem der andern Seite in die Cloake. Gleichzeitig hat das schmale Mesenterium aufgehört, die Tube ist durch Bindegewebe mit der Niere vereinigt und in deren ventrale Fläche sieht man Harnleiter und Wolff'schen Gang nach hinten ziehen; beide vereinigen sich hinter dem Ende der Tube oder vielmehr der Harnleiter mündet in den Wolfe'schen Gang uud durch dessen Endstück in die Cloake.

Das Verhalten lehrt uns erstens, dass die Entwicklung der Eileiterdrüse in eine postembryonale Periode fällt, ebenso die Gliederung des Eileiters in die verschiedenen Abschnitte, zweitens dass der Harnleiter um diese Zeit in einer viel weniger engen Beziehung zur Tube steht als später, was mit der Entwicklung des Eileiters in gar keinen Zusammenhang zu bringen, vielmehr auf eine Verkürzung des ursprünglichen Mesenteriums zurückzuführen ist, und dass drittens der oben erwähnte kurze Blindsack, der mit dem hintersten Ende des Harnleiters sich vereinigt und gemeinschaftlich ausmündet, wirklich ein Rest des Wolff'schen Ganges ist. Ich konnte diesen Kanal bei dem jüngeren Thier bis zum später schwindenden Rest der Segmentalorgane verfolgen und mich überzeugen, dass er hinten in derselben Weise sich mit dem Harnleiter verbindet wie beim alten Thier, wodurch meines Erachtens die Deutung des Kanales ohne Zweifel richtig ist.

Wiedersheim hat im letzten Drittel des Oviducts (l. c. p. 514 und tab. XIX fig. 13) zwei Oeffnungen gesehen, von denen die "obere" (vordere), sternförmige die Ausmündung des Oviducts, die „untere" (hintere), kreisförmige die des Ureters ist resp. sein soll, denn weder im 
Text noch in der Figur sehe ich den Beweis; bei a fig. 13 soll nach dem Text der Eileiter ausmünden und doch geht derselbe, ohne hier sein Ende zu finden, weiter, bis zum zweiten runden Loch und, selbst hinter diesem sehen wir erst die Oeffinung in der Cloake. Ich erlaube mir keine Erklärung für diese Angaben, kann nur versichern, dass sie dem Sachverhalt nicht entsprechen. Nir scheint es, als ob Wiedersheim den länglichen Wulst der Cloake, auf welchem der Harnleiter ausmündet (cf. fig. 1 P. und 9 taf. $\mathrm{X}$ ) für die Fortsetzung der Tube angesehen habe, trotzdem diese bereits in die Cloake gemündet haben soll; es ist dies die Harnleiterpapille bei den andern Reptilien, die bei Phyllodactylus nur langgezogen erscheint und mit der Tube Nichts zu thon hat; sie liegt nur in der Verlängerung derselben, ihre zahlreichen Muskelfasern schliessen sich den Muskeln des Eileiterendes an und gehören zur dorsalen Cloakenwand. Gleich darauf kommt Wiedersheim zu dem gesperrt gesetzten Ausspruch (1. c. p. 515): „Genital- und Harnpapille sind also im vorliegenden Falle vollkommen von einander getrennt!" So ist das bei allen Reptilien, d. h. den weiblichen Thieren; Leydig ${ }^{1}$ ) sagt z. B. von der Blindschleiche: „Beim Weibchen bestehen die Mündungen der Eileiter in die Cloake, sowie diejenigen der Harnleiter nicht blos für sich, sondern sind weiter auseinander gerückt (sc. als beim Männchen). Die- Eileiter öffnen sich stark nach vorne und aussen; die Harnleiter mehr nach hinten und gegen die Mitte der Cloake." Von der Eidechse heisst es (p. 128): „Beim Weibchen besteht ebenfalls diese paarige, gefässreiche und mit glatten Muskeln versehene Papille; nur ist sie, da sie jetzt lediglich zur Papille des Harnleiters geworden, viel kleiner als beim Männchen"; also auch hier besteht die Trennung der Genital- und Harnpapille, auch hier münden beide gesondert wie beim Phyllodactylus, der durchaus keine Ausnahme in dieser Bezieh ung macht.

Da ich nun einmal bei Phyllodactylus europaeus und zwar beim Weibchen desselben bin, so möge es erlaubt sein, nur kurz noch einen Punkt zu berichtigen; Wiedersheim hat bekanntlich beim Männchen von Phyllodactylus europaeus zwei nierenförmige Spalten entdeckt, die sich beiderseits auf der hinteren Cloakenlippe finden und in einen von einer glasshellen Cutikula ausgekleideten Sack führen, den er in eine Reihe mit den sogenannten Schenkeldrüsen der Eidechsen bringt. Dieses letztere soll uns hier nicht beschäftigen, sondern nur der (1. c. p. 516)

1) Deutsche Saurier. p. 129. 
folgende Ausspruch: das Weibchen besitzt keine Andeutung jener spaltförmigen Oeffnungen an der Ventralseite der Schwanzwurzel. Der erste Phyllodactylus, den ich beim Auspacken in die Hand bekam, war ein trächtiges Weibchen mit zwei Eiern, bei dessen Betrachtung mir sofort diese spaltförmigen Oeffnungen auffielen; sie gaben den Grund zu einem Nachschlagen der Wiedersheim'schen Arbeit, um über sie am schnellsten Aufklärung zu finden - doch vergeblich, Wiedersheim negirt, wie wir sehen, ihr Vorkommen beim Weibchen völlig, was mir unverständlich bleibt, denn an jedem Weibchen, das ich darauf hin untersuchte, konnte ich diese Oeffnungen Jedem demonstriren. Näher habe ich diese Sache noch nicht untersucht, ich will mich mit dieser Berichtigung begnügen.

Anmerkung. Die hier geschilderten Verhältnisse, die interressante Abweichungen darstellen, sind für mich eine Aufforderung, die geplante, vergleichend anatomische Bearbeitung des Urogenitalsystems der Reptilien auch wirklich auszuführen; nach dem, was ich bisher in einer Voruntersuchung gesehen habe, ist der Bau nicht so übereinstimmend, wie man allgemein anzunehmen scheint. Bei der Schwierigkeit der Beschaffung von genügend conservirtem oder frischem Material muss die Arbeit langsam vorwärts schreiten und längere Zeit in Anspruch nehmen; ich möchte mir daher im Interesse der Sache erlauben, an alle Besitzer von gutem Material die Bitte $\mathrm{zu}$ richten, mit demselben mich, resp. meine Arbeit möglichst unterstützen $\mathrm{zu}$ wollen.

\section{Entwicklung der bleibenden Niere.}

Schon Rathke ${ }^{1}$ ) hebt die grossen Schwierigkeiten, „über den innern Bau der Nieren Einiges zu erfahren," hervor, welche sich dem Untersucher darbieten. Selbst mit den heutigen verbesserten Hilfsmitteln ist dies noch immer der Fall, so dass ich in diesem Kapitel am weitesten von einer vollständigen Darstellung der Entwicklung entfernt bin, wozu mehrere Umstände, deren Erörterung nicht hieher gehört, beigetragen haben. Doch glaube ich wenigstens über die Herkunft der Nierenepithelien positive Angaben machen zu können, ein Punkt, der von fast allen Bearbeitern der Nierenentwicklung selbst der höheren Thiere kaum erwähnt und berührt, geschweige denn erörtert worden ist, trotzdem er für die Beurtheilung der Niere in phylogenetischer Beziehung von grosser Bedeutung sein muss.

$\left.{ }^{1}\right)$ Entwicklungsgeschichte der Natter 1839. 
Bei der Entwicklung der Niere haben wir zweierlei zu unterscheiden: erstens die Bildung eines hinter den Segmentalorganen gelegenen, langgestreckten Zellenstranges, aus dem zum grössten Theil nach allen Beobachtern die Niere entsteht und zweitens die Bildung des Ausführungsganges, des Harnleiters, der ebenfalls einen Theil der Niere bildet.

Was nun den letzteren anlangt, so glaubt Rathke von der Natter, dass er nicht von der Urniere und deren Ausführungsgang abstamme, und auch nicht durch Ausstülpung aus dem Darm entstehe, was er aus der Analogie mit den Säugethieren, bei denen er den Harnleiter ausser Verbindung mit der Cloake gesehen hat, schliesst. In der That ist es aber der Wolff'sche Gang, von dem der Harnleiter abstammt; ich habe dies durch frische Untersuchung von Natterembryonen nach der Eiablage konstatiren können; ungefähr am 12. Tage nach derselben, wenn der Embryo im gestreckten Zustande vom Scheitel bis zur Cloakenspalte $47-50 \mathrm{~mm}$. misst, finde ich von der medialen Fläche des hintersten Endes des Wolff'schen Ganges einen nach vorn strebenden, kleinen Blindsack abgehend, die Anlage des Harnleiters; er ist ungefähr halb so dick im Lumen als der Wolff'sche Gang und wächst nun ziemlich rasch nach vorwärts; ich konnte ihn Tag für Tag länger werden sehen d. h. länger finden und stets mit dem Wolff'schen Gang in Verbindung, cf. taf. IX. fig. 6 vom 15. Tage nach der Eiablage; hier betrug das gemeinschaftliche Endstück 0,452 mm.; der Harnleiter war 1,356 mm. lang, hinten $0,101 \mathrm{~mm}$. breit, vorn $0,056 \mathrm{~mm}$.

Bei Lacerta agilis fand ich am 8. Tage nach der Eiablage auf Querschnittserien in derselben Weise den Harnleiter vom Wolff'schen Gang abtretend (fig. 7. taf. IX.); er reichte nur 4 Schnitte nach vorn von dem Ursprung aus dem Urnierengang.

Der Harnleiter wuchert in eine langgestreckte zwischen den Urwirbeln und Peritoneum gelegene Zellenmasse ein, die allgemein als Nierenanlage gilt, sich vorn an das hintre Ende der Urnieren anschliesst und hinten kurz vor der Cloake endet; ich will diesen Theil als Nierenzellstrang bezeichnen. Bei meiner Untersuchung kam es mir hauptsächlich darauf an, die Herkunft der den Nierenzellstrang zusammensetzenden Elemente zu erforschen, da wir über positive Angaben in dieser Beziehung nicht verfügen. Zu diesem Zweck dienten mir besonders Schnittserien von Embryonen von Lacerta agilis etwa von der Zeit der Eiablage oder kurz vorher an; was ich da nun fand, habe ich möglichst getreu in den Figuren 1-3. taf. IX. wiederzugeben versucht. Auf 
fig. 1 sehen wir das Peritonealepithel -- ich bemerke, dass das hintre Ende der Urniere völlig ausgebildet ist -- in der Richtung gegen die Urwirbel zu verdickt, der nächstfolgende Schnitt zeigt dasselbe, der dritte lässt Nichts davon erkennen. Die Verdickung ist gegen die Zellen des Bindegewebes nicht scharf abgegrenzt, wohl aber als solche durch die enge Aneinanderlagerung der Zellen und durch die intensivere Färbung der Kerne in Pikrokarmin gekennzeichnet; ein Schema, das ich mir wie bei den meisten untersuchten Embryonen durch Eintragen der Querschnitte auf karrirtes Papier herstellte, zeigte mir, dass mehrere solcher Verdickungen hintereinander, aber in unregelmässigen Abständen liegen; ob diese Knospen des Peritoneums an ihrer dorsalen Fläche mit einander verbunden sind, also einen Längsstrang darstellen, der an einzelnen Stellen mit dem Peritoneum zusammenhängt, ist mir nicht sicher geworden; bei der nicht scharfen Abgrenzung der Zellen ist es sehr schwierig, dies festzustellen.

Als späteres Stadium dente ich das folgende Objekt fig. 2, das von einem älteren Embryo stammt und zwar von demselben Mutterthier: Die Peritonealverdickung reicht weit in das Bindegewebe zwischen Urwirbeln und Peritoneum einerseits und zwischen Aorta und Wolff'schen Gang andrerseits hinein; sie geht im Bogen um den Wolff'schen Gang herum, von diesem aber durch Bindegewebszellen getrennt. Auch hier ist es mir nicht möglich eine scharfe Grenze zwischen dieser Einwucherung und den umliegenden Zellen zu sehen, nur die dichte Aneinanderlagerung und die Reaktion der Kerne gegen Pikrokarmin spricht für ihre Zusammengehörigkeit. Bestände die ganz deutliche Verbindung mit dem Peritonealepithel nicht, so könnte man versucht sein, eine dichtere Aneinanderdrängung von Zellen des Mesoderms hier zu sehen und diese Bilder so zu deuten, doch dann bliebe eben dieser Zusammenhang unerklärt, und ferner die Thatsache, dass mit dem Aelterwerden des Embryos die ursprünglich kleine Knospe des Peritonealepithels auch ferner grösser wird.

Endlich in dem dritten Stadium ist es nun schon zur Bildung des Nierenzellenstranges gekommen, es ist das jene Zellgruppe in fig. 3, welche medial am Wolff'schen (W. G.) Gang liegt und gegen die beiden Venen scharf abgegrenzt erscheint; noch deutlicher ist auf allen Schnitten die Grenze gegen den Wolff'schen Gang und schliesst eine Betheiligung desselben an der Herkunft dieser Zellen von selbst ans. Der Zusammenhang mit dem Peritoneum ist auf einigen Schnitten noch ziemlich deutlich zu erkennen, auf andern fehlt er, ohgleich die Zellen um den 
Wolff'schen Gang in derselben Weise vorhanden sind; wir dürfen also sagen, dass am Wolff'schen Gang ein Zellenstrang liegt, der linter der Urniere beginnend von vorn nach hinten länft und an einigen Stellen mit dem Peritoneum in Verbindung steht. Diese Verbindung, scheint mir, erleichtert sehr die Combination dieses Stadiums mit den vorhergehenden, bei denen es nicht sicher war, ob der Zellenstrang vorhanden ist; wir dürfen nur annehmen, dass eine Vereinigung der hintereinander liegenden Peritonealknospen stattgefunden hat, um das Bild des dritten Stadiuns zu erhalten. Gegen diese Combination kann es nicht sprechen, dass fig. 3 von einem nur 3 Tage nach der Eiablage getödteten Embryo stammt, während die Originale zu fig. 1 und 2 älter sind, jedoch von einem andern Mutterthier stammen; es ist bekannt, dass die jeweilige Eiablage bei den verschiedenen Thieren zu verschiedenen Zeiten stattfindet - wenigstens in der Gefangenschaft, und dass der Zeit nach gleich alte Embryonen vom Datum der Eiablage an gerechnet sehr verschieden weit ausgebildet sein können; meldet doch Bidder, dass um Dorpat Lacerta agilis lebendig gebärend sei.

Später wird die Verbindung des Nierenzellstranges mit dem Peritoneum völlig gelöst; er ist dann auf dem Querschnitt rund, die Kerne sind wie concentrisch geschichtet angeordnet, in der Mitte am dichtesten gedrängt. Aussen um diesen Zellenstrang lagert sich eine Schicht von Zellen ab, die durch das Auftreten von feinen Fasern sich sehr bald als Bindegewebszellen kundgeben; es ist dies die Anlage der Nierenkapsel, die aber immer nur eine geringe Ausbildung erfährt.

Schon während des Entstehens des Nierenzellenstranges ist aus dem Wolff'schen Gang der Harnleiter hervorgesprosst und wuchert nach vorwärts in den Nierenzellstrang hinein und zwar ziemlich in dessen seitlichen Theil. Zuerst füllt die Nierenanlage, das ist Nierenzellstrang und Harnleiter, den Raum zwischen dem hinteren Ende der Urniere und der Cloake aus; sehr bald wächst aber das Ganze über die Unniere hinaus, so dass das hintre Ende dieser das vordre der Nierenanlage deckt, ein Verhältniss, welches bis lange nach der embryonalen Periode bestehen bleibt.

In dem Nierenzellstrang eingedrungen entsendet nun der Harnleiter medial eine Anzahl von blinden Sprossen, die ziemlich regelmässig hinter einander von der medialen Wand des Harnleiters abtreten und den Nierenzellstrang in Abtheilungen zerlegen. Bereits am 15. Tage nach der Eiablage sah ich bei einem $53 \mathrm{~mm}$. langen Embryo von Tropidonotus natrix diese Sprossen auftreten und zählte bei einem 20 Tage 
alten Natterembryo von $59 \mathrm{~mm} .27$ solcher Sprossen, von denen die mittelsten sich bereits zu gabeln anfingen und einen kurzen vorderen und hinteren Ast entsendeten. Auch um diese tritt eine besondere Gruppirung der nächstgelegenen Kerne ein.

Die zuerst erwähnte Abtheilung des Nierenzellstranges geht nicht durch den ganzen Strang hindurch, sondern beschränkt sich auf die Rinde, ist jedoch so tief, dass ein Sagittalschnitt durch diese Region. einen völligen Zerfall in Zellhaufen vortäuschen kann cf. fig. כ. taf. IX. N. K. Jeder solcher Haufen bekommt zwei Aeste, den einen aus dem nächst vorderen Spross des Harnleiters, den andern aus dem nächst hintern, eine Vertheilung, die ich in dieser Weise bei der Eidechse nicht wiederfinden kann. Hier theilt sich vielmehr ziemlich früh der Nierenzellstrang - vielleicht nur auf bestimmte Strecken - in Längsgruppen, die also auf dem Querschnitt in solchen Abtheilungen liegen, wie bei Tropidonotus natrix auf dem Sagittalschnitt, jedoch nicht ganz getrennt sind.

Gesondert von diesen aus dem Harnleiter stammenden Sprossen resp. Kanälen, welche mir nur die Sammelgänge zu sein scheinen, entstehen im Nierenzellstrang und in dessen der Mittellinie zugewendeten Fläche eine Reihe von Bläschen; bei der Natter ist es, wie ich in Uebereinstimmung mit Rathke sehe, sicher zuerst nur eine Reihe, später erst werden es mehr; bei der Eidechse scheinen es von Anfang an 2, in der Mitte der Nierenanlage selbst 3 Reihen zu sein; diese Bläschen, welche welche bald zu kleinen Beuteln auswachsen, indem sich ihre seitliche Fläche nach dem Harnleiter zu in einen Fortsatz auszieht, sind die Anlagen des eigentlich secernirenden Theiles der Niere; aus ihnen gehen die Malpighischen Körperchen und die gewundenen Harnkanälchen hervor. Ein Theil der letzteren kann vielleicht auch selbstständig aus dem Nierenzellstrange entstehen; bei der grossen Menge von Kanälen ist dies durch Querschnitte nicht festzustellen.

Die weitere Ausbildung habe ich nicht verfolgt, auch die histologische Struktur der Nierenepithelien, auf welche Heidenhain zuerst aufmerksam gemacht hat, übergehe ich an dieser Stelle, da meine Untersuchungen darüber zu spärlich sind und wende mich nur noch zu dem Verhalten des Harnleiters bei Eidechsen und den Nerven der Eidechsenniere.

Es ist bekannt, dass die Niere der Eidechsen nach hinten über das Becken hinaus sich fortsetzt, dass also ein Theil der Harnkanälchen hinter der Einmündung des Harnleiters in die Cloake verläuft und dem entsprechend, um ihr Sekret entleeren zu können, entweder nach vorn 
streben oder in einen gemeinschaftlichen Sammelgang zusammenfliessen muss, in dem das Sekret von hinten nach vorn fliesst. Das letztere ist der Fall : schon der Nierenzellstrang wuchert als solcher nach hinten; in ihn dringt ein Canal ein, der von der Vereinigungsstelle des Wolff'schen Ganges und des Harnleiters nach hinten entspringt und welcher der Harnleiter für den hinteren Nierenabschnitt wird.

Auch im ausgewachsenen Zustande geht von der Vereinigungsstelle von Harn - und Samenleiter, die gemeinschaftlich beiderseits auf einer Papille ausmünden, ein Kanal nach hinten ab, welcher der Harnleiter für den hinteren Nierenabschnitt ist und nach kurzem Verlauf in eine grössere Anzahl von secundären Sammelröhrchen ausstrahlt, die in die Niere eindringen. In diesem Theile des harnleitenden Apparates findet also die Bewegung des secernirten Harnes von hinten nach vorn statt, in dem vordern Abschnitt umgekehrt.

Was den hinteren Nierenabschnitt selbst anlangt, so heisst es meist z. B. Leydig. Deutsche Saurier. p. 127, von Lacerta vivipera, dass eine Verwachsung am hinteren Ende nicht stattfindet; für Lacerta agilis kann ich mich diesem Ausspruch nicht anschliessen; da findet schon vor der Einmündung des Harnleiters in die Cloake eine Verbindung der beiden Nieren statt und zwar auf deren ventralen Fläche; die Anfangs sehr schmale Brücke, welche stets von secernirenden Nierenkanälchen gebildet ist, wird nach hinten immer grösser und verbindet die beiden Nieren ungefähr mit einander, wie das corpus callosum die beiden Grosshirnhemisphären; endlich verschmelzen ganz hinten die beiden Nieren fast völlig, es bleibt nur dorsal eine seichte Einkerbung bestehen.

Der hintre Nierenabschnitt von Lacerta agilis ist auch noch wegen seiner eigenthümlichen Beziehungen zu einem grossen Ganglion erwähnenswerth, das ich zuerst auf Querschnitten durch die ausgewachsene Niere bemerkte. Durch das dichte Aneinandertreten der beiden Nieren wird auf der ventralen Fläche eine Rinne gebildet, die zum Theil von Bindegewebe und Blutgefässen, beim Männchen zum Theil von den Windungen des Samenleiters ausgefüllt wird; zwischen diesen Windungen und der Niere liegt ein Paar von Ganglien, welche von einander durch spärliches Bindegewebe getrennt werden und wie es scheint, eine lange Strecke der Niere, jedoch in verschiedener. Gestalt begleiten. Meistens ist nämlich der Querschnitt dieser Ganglien rundlich, oder etwas abgeplattet; nach hinten $z$ גird er jedoch ganz langgestreckt; die Ganglien schmiegen sich hier der durch die Nieren gebildeten Rinne 
völlig an, gleichen also zwei Platten, welche unter einem stumpfen Winkel zusammentreten. Es ist mir wahrscheinlich, dass diese Verbreitung der Ganglien nur eine Communikation zwischen dem mittleren Ganglienpaar, das in der Tiefe der Rinne liegt, und einem mehr seitlich gelegenen Paar darstellt, das sowohl vor als hinter dieser Verbreiterung auf Schnitten erscheint. Ueber die Natur des Ganglion habe ich bei ausgewachsenen Thieren keine Untersuchungen angestellt, doch an Querschnittserien von Eidechsenembryonen bemerkt, dass der eine n. sympathicus in der hintern Nierengegend mit dem andern zusammentritt und ein Doppelganglion bildet, das meiner Ansicht nach dem beim ausgewachsenen Thier gefundenen entspricht.

Ob von diesem Ganglion Nerven in die Niere treten, dafür finde ich auf meinen Präparaten keinen Anhalt; um dies zu konstatiren, sind andere Untersuchungsmethoden nothwendig, als ich sie anwenden konnte.

Zum Schluss stelle ich noch einmal die Resultate der mitgetheilten Untersuchungen in folgenden Sätzen zusammen:

1. Die Urnieren entstehen bei Reptilien aus soliden Wucherungen des Peritonealepitbels in die Mittelplatten hinein, welche Sprossen eine segmentale Anordnung zeigen, d. h. der Zahl nach genau mit der Zahl der Körpersegmente übereinstimmen; an den Sprossen, die sich zu Blasen umwandeln, ist zwischen der Verbindungsstelle mit dem Peritoneum, dem Homologon der Semper'schen Trichter, dem verbindenden Strang $=$ Segmentalkanal und der Blase $=$ Segmentalbläschen zu unterscheiden; Trichter und Segmentalkanal schwinden sebr bald, das Bläschen entsendet seitlich nach dem Wolff'schen Gang einen Fortsatz, der zum Urnierenkanälchen wird und bildet sich selbst zum Malpighischen Körperchen um; dieses mit dem zugehörigen Urnierenkanälchen bildet ein Segmentalorgan und eine grosse, in einer Reihe angeordnete Zahl der letzteren die Urniere.

2. In der weiteren Entwicklung wird die Urniere beim Männchen zu einem Theil des Nebenhodens, der Wolff'sche Gang zum Samenleiter; beim Weibchen finden je nach den untersuchten Gruppen verschiedene Reduktionen statt, doch lassen sich Reste überall nachweisen; bei Eidechsen in Form von verschlungenen Kanälchen, von Cysten und Zellenhaufen im Peritoneum, bei Blindschleichen in Kanälchen, welche an einem öfters unterbrochenen Längskanal hängen, bei Gecko's als 
kleiner blinder Kanal, der vereinigt mit dem Harnleiter in die Cloake mündet und bei Schlangen als langer. am Ovarium beginnender Kanal, der wahrscheinlich in die Cloake mündet.

3. Bei beiden Geschlechtern wird der Eileiter angelegt und zwar durch eine lokale Einstülpung des Peritoneums, welche mit solider Spitze in eine vorher entstandene Falte, die sich im Verlauf fast ganz an den Verlauf des Wolff'schen Körpers anschliesst, hineinwächst und * bis zur Cloake vordringt. Beim Weibchen wird die Cloakenwand durchbohrt und es erfährt die Tube weitere Umbildungen; beim Männchen fällt sie der regressiven Metamorphose anheim, die von hinten nach vorn vorwärts schreitet; Reste erhalten sich bei Lacerta und Anguis in Form eines gewundenen Kanälchens, dessen Lage durch die Pigmentirung des Peritoneums bei den genannten Thieren bestimmt ist. (cf. Leydig.)

4. Die Geschlechtsdrüse wird in gleicher Weise bei beiden Geschlechtern angelegt; sie entsteht als langgestreckte, faltenartige Erhebung an der medialen Fläche der Urnieren und wird aus einem bindegewebigen Stroma und dem verdickten Peritonealepithel, dessen einzelne Elemente sich zum Theil in Ureier umgewandelt haben, zusammengesetzt. Jedes Malpighische Körperchen, deren Reihe an der Basis der Geschlechtsdrüse liegt, entsendet gegen die letztere einen soliden Fortsatz (Eidechse; Blindschleiche) oder einen Kanal (Ringelnatter), welche zu einem langgestreckten, vielfach durchbrochenen Zellstrange (Segmentalstränge) zusammentreten, von dem aus eine Einwucherung in dis Keimdrüse (Lacerta, Anguis, Platydactylus) stattfindet; die eingewucherten Segmentalstränge erscheinen wie ein Blatt in der Geschlechtsdruise und treten ventral mit dem verdickten und Ureier führenden Epithel in Verbindung, es erfolgt eine Einwanderung der Ureier sowohl durch diese Verbindung als auch durch das Stroma in die Segmentalstränge hinein. Bei Lacerta, Anguis und wohl auch bei Platydactylus bilden sich beim Männchen aus den Segmentalsträngen die Hodenkanälchen, während zu gleicher Zeit das Ureierlager allmählig schwindet; beim Weibchen degeneriren die eingewucherten Segmentalstränge, während das Ureierlager sich bedeutend vergrössert und in Form zweier spindelförmiger Wülste auf dem Ovarium sich anordnet. Bei der Natter sendet nur beim Männchen der von dem Malpighischeu Körperchen kommende Kanal, der, wie es scheint, wenigstens auf grössere Strecken sich mit davor und dahinter liegenden Kanälen zu einem Iaängskanal verbindet, eine Anzahl seitlicher Kanälchen in die Geschlechtsdrüse hinein, welche mit dem verdickten Peritonealepithel derselben in Verbindung treten; sie 
sind die Hodenkanälchen, die sich später wieder vom Peritoneum trennen. Beim Weibchen degeneriren diese ebenfalls von den Malpighischen Körperchen entstandenen Kanälchen sehr bald, während das Ureierlager sich vergrössert.

5. Die Eifollikelbildung geht während des ganzen Lebens vom Ureierlager aus vor sich, so, dass ein Urei, umgeben von einer Zahl von Peritonealzellen, sich abschnürt und von einer bindegewebigen Umhüllung umfasst wird.

6. Die bleibeude Niere entwickelt sich im Anschluss an die Urniere aus unregelmässigen Sprossen des Peritonealepithels, welche - wahrscheinlich — zu einem soliden Zellenkörper-Nierenzellstrang verschmelzen; in diesen dringt ein Blindsack vom hintersten Ende des Wolff'schen Ganges als Harnleiter ein; dieser entsendet eine Reihe von seitlichen Sprossen, die sammelnden resp. leitenden Kanälchen der Niere, die sich mit den im Nierenzellstrang selbstständig entstehenden secernirenden Kanälchen und Malphighischen Körperchen verbinden. 


\section{Die Beziehungen des Urogenitalsystems der Reptilien zu dem der anderen Wirbelthiere.}

\section{Wolff'scher Gang der Amnioten und Urnierengang der Anamnia.}

Durch die Semper'schen Untersuchungen ist bei Haien festgestellt worden, dass der zuerst als Ausführungsgang der Segmentalorgane auftretende „primäre Urnierengang" sich in zwei Kanäle der Länge nach spaltet; der eine bleibt Urnierengang (Leydig'scher Gang), der andere wird zum Eileiter. Erst dieser zweite Urnierengang kann mit dem Wolff'schen Gang der Reptilien homologisirt werden, denn der primäre enthält in sich die Anlage zweier Kanäle, was beim Wolff'schen Gang der Amnioten nicht der Fall ist. Ferner kommt hierzu noch die spätere Umwandlung des Urnierenganges beim Männchen zum Samenleiter, welche ebenfalls für die Homologie der beiden Kanäle bei Plagiostomen und Reptilien spricht. Die Identität der Entstehung des Wolff'schen Ganges ist zwar bei den Amnioten noch nicht ohne Widerspruch der Angaben festgestellt, namentlich bestehen noch $Z_{w}$ weifel, ob derselbe ursprünglich hohl oder solid angelegt wird, worüber ich leider auch bei den Reptilien zu keinem entscheidenden Resultat gekommen bin; doch herrscht wenigstens in Bezug auf den Ort der Entstehung eine ziemliche Uebereinstimmung, weun man von der Romitischen Angabe, die ich mit Anderen als nicht erwiesen betrachte, absieht; es ist dies derjenige Theil der Seitenplatten, der unmittelbar an die Urwirbel stösst und an der dem Ectoderm zugekehrten Fläche den Wolff'schen Gang erscheinen 
lässt. Den Wolff'schen Gang habe ich bei den Reptilien nie vorn offen gesehen, was auch bei dem Leydig'schen Gang gilt; der früher bestehende Trichter des primären Urnierenganges des Haien bildet bei der Spaltung dieses Kanales den Trichter des Eileiters und hat bei den Amnioten kein Homologon. Vielleicht bilden die in entwicklungsgeschichtlicher Beziehung über diesen Punkt noch unbekannten Amphibien eine verbindende Brücke.

Hier schliesst sich am besten

\section{2. der Eileiter}

an, dessen Entwicklung als von einer Einstülpung des Peritonealepithels an einem bestimmten Punkte ausgehend erkannt werden konnte; dieser peritoneale Blindsack schiebt sich nach hinten in eine auf dem Wolff'schen Körper gelegene, blattartige Erhebung - die Tubenfalte - ein und erreicht allmählich, ohne dass eine Betheiligung anderer als der ursprünglich eingestülpten Peritonealzellen nachgewiesen werden konnte, die Cloake. Ganz dieselbe Entstehung ist auch für das Hühnchen von Bornhaupt ${ }^{1}$ ) nachgewiesen worden; auffallend ist Bornhaupt die Peritonealverdickung an der Stelle des Wolff'schen Körpers, in welcher die Tube sich bildet; es ist das die Tubenfalte. Die Verdickung des Epithels schwindet wieder, wenn die Tube grösser wird und die Falte mehr ausfüllt (cf. taf. VIII. fig. 1 Tb.) und könnte dadurch erklärt werden, dass man hier an einen lokalen Wucherungsprozess denkt, der gleichsam eine Aufspeicherung von Baumaterial bedingt, das später mit dem Dickerwerden der Tube seine Verwendung zur einfachen Bekleidung der auch grösser werdenden Tubenfalte findet. Doch gibt es andere Verdickungen im Peritoneum, die uns vorläufig noch unverständlich sind; so erwähnte ich schon eine lokale Verdickung an der costalen Wand des Epithels, die sich ziemlich lange Zeit im Embryo erhält und dann schwindet, ohne dass wir hier den Aufbau eines Organes oder Organtheiles erkennen können.

Wesentlich zu derselbeu Ansicht üher die Entwicklung der Tube wie Bornhaupt ist Gasser ${ }^{2}$ ) gekommen, nach ihm hat der Müller'sche

1) Untersuchungen über die Entwicklung des Urogenitalsystems beim Hühnchen. In.-Diss. Riga. 1867. p. 37 etc.

$\left.{ }^{2}\right)$ Beiträge zur Entwicklungsgeschichte der Allantois, der Müller'schen Gänge uud des Afters. Habilitationsschrift. 1874. p. 37 etc. 
Gang - es gilt dies vom Hühnchen - in der ersten Zeit die Gestalt eines Trichters, der nach „oben" (vorn) rinnenförmig ausmündet, nach „unten" (hinten) mit solider Spitze „vorwärts" dringt. Eine Betheiligung der Peritonealverdickung auf der Tubenfalte, die Gasser mit Vorliebe Keimepithel nennt, an der Bildung des Eileiters konnte nicht erkannt werden; die Verdickung schwindet, indem „nur die oberste Zellenlage desselben den Charakter des Epithels behält; was aus den darunter liegenden Schichten desselben wird, ist noch nicht genügend eruirt"; ich habe schon oben meine Ansicht darüber ausgesprochen und kann nicht glauben, dass von Zellen, die morphologisch ganz gleichwerthig sind, die aus demselben Substrat, an derselben Stelle entstehen, die einen Peritonealzellen, die andern etwas anders werden, wenn sie nicht zu Grunde gehen oder weitere Umbildungen, wie z. B. die Ureier erfahren.

Zwischen diese beiden Arbeiten fallen die Untersuchungen Waldeyer's ${ }^{1}$ ), die, wie bekannt, die Tube als aus einer Rinne entstanden erklären, die sich auf dem Wolff'schen Körper bildet; ich hatte schon früher Gelegenheit, die Vermuthung auszusprechen, dass die Waldeyerschen Bilder in diesem Punkte sich irrthümlich erwiesen, indem ein künstliches oder vielleicht auch natürliches Aneinanderlegen der Tubenfalte und des Wolff'schen Körpers leicht solche Bilder vortäuschen kann, während in Wirklichkeit in der Tubenfalte selbst das hintere Ende der wachsenden Tube gelegen ist. Auch Sernoff ${ }^{2}$ ) bestätigt die Bornhaupt'sche Ansicht über die Entwicklung der Tube als eine einfache Einstülpung der Pleuroperitonealhöhle, die nach rückwärts (hinten) in das Mittelblatt zwischen Wolff'schen Gang und Keimepithel auswächst; er hält ausdrücklich Waldeyer's Ansicht für unrichtig. Dann kommen noch Foster und Balfour ${ }^{3}$ ), die sich wiederum in kurzen Worten ohne Beweise an Waldeyer anschliessen, übrigens zugeben, dass die Meinungsverschiedenheit im Vergleich zu dem Gesichtspunkt nicht von grosser Bedeutung sei, dass der Müller'sche Gang vom Keimepithel der Pleuroperitonealhöhle abstamme. Auch sagen Foster und Balfour, dass am Hinterende des Embryo, wo das Keimepithel mangelt, die ursprüngliche Grube (Rinne als Anlage der Tube) zu einer anfangs soliden, dann hohlen Einstülpung, die durch das Mittelblatt hindurch dringt und nach hinten

1) Eierstock und Ei. Leipzig 1870.

2) Centralblatt für medizin. Wiss. 27. Juni 1874 .

$\left.{ }^{3}\right)$ Grundzüge der Entwicklungsgeschichte der Thiere. Deutsche Ausg. Leipz. 1876. p. 161.

Arbeiten a. d. zool.-zoot. Inst. Würzb. Bd. IV. 
zur Cloake zustrebt. Nach diesen beiden Autoren sind drei Bildungsmodi vereinigt; der grösste Theil der Tube wird als Rinne angelegt, von dieser bleibt der vorderste Abschnitt offen und bildet den Trichter, der mittlere schliesst sich zur Tube, der hinterste stülpt sich solid ein und wird dann hohl. Nach den übereinstimmenden Angaben der genannten Autoren, zu denen sich noch die meinigen über Reptilien gesellen, können wir sagen, dass die Tube vom Peritonealepithel abstammt, dass jedoch die Art und Weise der Bildung strittig ist, wenn auch die grösste Wahrscheinlichkeit für eine lokale Einstülpung vorhanden ist, eine Bildungsweise, die bei den Reptilien keinem Zweifel unterliegt.

$\mathrm{Zu}$ den älteren Angaben über die Tubenentwicklung bei Säugern, die unter einander ziemlich differiren, wohl nur desshalb, weil man keine Entwicklungsreihe untersuchte, sondern mitunter nur von einem Stadium auf die ganze Entwicklung schloss, ist in neuester Zeit noch ein Autor ${ }^{1}$ ) hinzugekommen, der vom Kaninchenembryo am 14. Tage die Tubenentwicklung beschreibt: „Die Bildung geschieht in der Weise, dass das Oberflächenepithel des Wolff'schen Körpers am stumpfen Kopfende des letzteren, unten - aussen - vom Uebergang des Zwerchfellbändchens auf den Wolff'schen Körper in Gestalt eines Trichters in die Tiefe sich senkt und mit einem soliden Fortsatz zwischen dem lateralen Oberflächenepithel und dem Wolff'schen Gang gegen das. Beckenende vordringt." Diese Beobachtung steht in bestem Einklange mit den am Hühnchen und den Reptilien gewonnenen Resultaten, so dass wohl für alle Amnioten derselbe Bildungsmodus der Tube angenommen werden kann. Ich kann mich der Annahme Sempers ${ }^{2}$ ) nicht anschliessen, dass der Müller'sche Gang auch bei Amnioten vom Wolff'schen abstammt und dass die ursprüngliche Verbindungsstelle zwischen beiden ganz am Vorderende der Urniere liegen und sehr kurz sein muss. Die Beobachtung spricht dagegen: wie ich gezeigt habe, liegt der Entstehungsort der Tube vom Wolff'schen Gang weit entfernt (cf. die Abbildungen auf taf. VI) und kann schon desshalb mit diesem in gar keinem $\mathrm{Zu}$ sammenhang stehen. Es hat sich bei Reptilien trotz besonderer darauf gerichteter Aufmerksamkeit Nichts ergeben, was auf einen solchen $\mathrm{Zu}$ sammenhang deuten könnte. Zwischen der Tube der Plagiostomen und der der Amnioten besteht demnach ein morphologischer Unterschied;

1) Th. Egli: Beiträge zur Anatomie u. Entwicklung der Geschlechtsorgane I. Urogenitalsystem des Kaninchens. In.-Diss. Zürich. 1876 p. 32.

$\left.{ }^{2}\right)$ Urogenitalsystem der Plagiostomen. Diese Arbeiten Bd. II. p. 411. 
die erstere entsteht aus dem Epithel des primären Urnierenganges, sich in der ganzen Länge von diesem abschnürend, bei den letzteren aus dem Peritonealepithel am vordern Ende des Wolff'schen Körpers ohne jegliche Betheiligung des Urnierenganges. Wir vermissen wieder sehr die Kenntnisse über die Entwicklung der Tube bei den Amphibien, die vielleicht den Gegensatz zwischen Haien und Amnioten mildern würden. Denn bei den letzteren ist die Tube eine völlige Neubildung; der bei den Haien vorhandene Kanal, der wohl physiologisch dasselbe leistet, morphologisch aber etwas ganz anderes ist, hat bei den Amnioten gar kein Homologon, gar keine Spur hinterlassen, ist in der Entwicklungsreihe völlig verloren gegangen; an seine Stelle ist bei den Amnioten ein Kanal getreten, der zwar dieselbe Form hat, dasselbe leistet, jedoch auf ganz andere Weise und aus anderem Substrat entsteht. Man ersieht aus diesem Beispiel, wie voreilig es ist, aus derselben Form und Leistung im ausgebildeten Zustand irgend einen Schluss auf morphologische Homologie der zu vergleichenden Theile zu ziehen, so lange man die Entwicklung nicht kennt.

Es ist merkwürdig, dass sich das Auftreten des neuen Kanales, des Müller'schen Ganges in der Thierreihe an das Vorkommen des Amnion zu knüpfen scheint.

\section{Die Segmentalorgane.}

In den Erörterungen der allgemeinen Beziehungen des Urogenitalsystems der Wirbelthiere, dem dritten Abschnitt seiner Plagiostomenarbeit, hat Semper bereits unter Zuhilfenahme der damals vorliegenden Ergebnisse meiner Untersuchung die Urnieren der Reptilien für Segmentalorgane erklärt und sie mit den gleichen Organen bei Haien und Anneliden homologisirt. Die ausführlicheren Beobachtungen, die ich unterdessen bekam, haben diese Ansicht nur bestätigt. Ich konnte zeigen, dass die schon früher gekannten Beutelchen oder Bläschen der Urniere in der ersten Zeit ihres Bestehens bei allen untersuchten Reptilien segmental in gleicher Zahl mit der Zahl der Körpersegmente auftreten, und ferner, dass das Epithel derselben vom Peritonealepithel abstammt, welches sich mit oder ohne Bildung eines kurzen Kanales einstülpt; bei Eidechsen scheint wirklich ein Trichter und ein sich daran schliessender Segmentalgang zu existiren, die jedoch sehr bald obliteriren. Die Hauptsache bleibt aber die Abstammung vom Peritonealepithel, denn wir sehen, dass sehr früh die ur. 
sprünglich bestehende segmentale Anordnung bei allen Reptilien aufgegeben wird. Ich habe desshalb die Rathke'schen Urnierenbläschen Segmentalbläschen und die aus jedem einzelnen hervorgehenden Theile der Urniere Segmentalorgan genannt. Während nun bei den Anamnia die Verbindung der Segmentalorgane mit der Peritonealhöhle durch das ganze Leben bestehen bleibt, ist sie bei den Reptilien schnell vorübergehend und alle Versuche, bei den ausgebildeten Urnieren derselben ein ähnliches Verhältniss wie etwa beim Frosch nachzuweisen, blieben fruchtlos; eine ächte Communikation besteht nicht, sondern wird (Eidechsen ausgenommen) durch einen soliden Zellstrang vermittelt und angedeutet; die secernirenden Segmentalorgane der Reptilien haben mit der Peritonealhöhle keine Verbindung wie bei den Anamnia.

Doch gibt es der Uebereinstimmungen noch mehrere: Wir haben bei Reptilien gesehen, dass die Segmentalbläschen sich zu Malphighischen Körperchen entwickeln, wie bei den Haien durch Semper gezeigt wurde, dass das blinde, erweiterte Ende der Segmentalgänge, welches der Segmentalblase der Reptilien entspricht, auch einen glomerulus in sich aufnimmt und "das primäre Malpighische Körperchen" bildet, während die sekundären gleichfalls aus Nierenkanälchen hervorgehen, welche vom erweiterten Grunde des Segmentalganges entspringen, also aus demselben Substrat stammen. Für die Reptilien konnte ich die unzweifelhafte Vermehrung der Malpighischen Körperchen, die später, nachdem die ursprüngliche Segmentalblase sich völlig umgebildet hat, erst eintritt, nicht auf die Urnierenkanälchen zurückführen, sondern glaubte, einzelne Stadien als eine Theilung derselben deuten zu müssen.

Eine weitere Uebereinstimmung besteht in der Nichtbetheiligung des Wolff'schen Ganges an der Bildung der Segmentalorgane. Die Segmentalblase entsendet einen seitlichen Fortsatz, das primäre Urnierenkanälchen, welches den Wolff'schen Gang durchbricht und sich mit ihm verbindet; ich konnte nirgends sehen, dass vor dieser Verbindung der Wolff'sche Gang Sprossen nach den Segmentalblasen zu entsendet, und später, wenn die Verbindung eingetreten ist, dürfte es unmöglich sein, zu entscheiden, wie viel an der Verbindungsstelle von den ursprünglich gleichen Zellen zum Wolff'schen Gang und wie viel zum Urnierenkanälchen gehören. Ganz dasselbe Verhalten besteht bei den Plagiostomen.

Seit der Semper'schen Publikation 1875 sind mehrere Angaben erschienen, welche die von Semper erwarteten Beweise der Homologie der Urnieren der Amnioten mit den Segmentalorganen der Plagiostomen 
bringen. Kölliker ${ }^{1}$ ) schildert die Entwicklung des Wolff'schen Körpers beim Hühnchen, wie folgt: „Die Urnieren entstehen von der Bauchhöhle aus als Wucherungen der Mittelplatten, welche unterhalb der Urnierengänge zwischen denselben und den Aorten, gegen die Seitentheile der Urwirbel sich entwickeln und bis an dieselben hinanreichen. Die Urnierenschläuche besitzen Keulen- oder Kolbenform und münden durch schwer zu erkennende, rundliche, leicht erweiterte Oeffnungen in die Bauchhöhle, während ihre innere Höhlung sehr eng ist und nur in günstigen Fällen zur Anschauung kommt... Nachdem die Urnierenschläuche eine Zeitlang bestanden haben, setzen sie sich mit dem Urnierengang in Verbindung und stellen dann Sförmig gebogene Gebilde dar, die immer noch mit der Mittelplatte zusammenhängen und auch noch eine Mündung besitzen." Die weitere Entwicklung konnte nicht verfolgt werden, doch ist so viel sicher, dass die Urnierenanlagen bereits von den Mittelplatten am 4. Tage getrennt sind und keine Spur der früheren Mündungen mehr erkennen lassen. Von dem Urnierengang gehen jetzt von Stelle zu Stelle hohle Gänge aus (die Urnierenkanälchen), welche nach kurzem Verlauf zu der Anlage eines Malpighischen Glomerulus führen. Schliesslich glaubt Kölliker, dass seine "Urnierenschläuche" wohl unzweifelhaft als Homologa der Trichter sich darstellen werden, die bei Haien und Amphibien konstatirt sind. Das ist nun in der That der Fall: wir ersehen erstens: die Abstammung der Epithelien der Urniere von dem Peritonealepithel, zweitens die in einzelnen, getrennten Knospen erfolgende Anlage, drittens die Nichtbetheiligung des Wolff'schen Ganges am Ausbau der Urniere und endlich die Umwandlung der Enden der Urnierenschläuche - wenn man vom Wolff'schen Gang ausgeht, in die glomeruli, eine Uebereinstimmung mit den Reptilien und durch diese mit den Haien, die nicht besser gedacht werden kann. Nur fehlt noch die Segmentirung, die jedoch für das Hühnchen selbst in der ersten Anlage nicht zu erweisen sein wird; es beträgt die Zahl der Urnierenschläuche immer mehr, als die Zahl der Körpersegmente auf derselben Strecke; doch denke ich, wird man sich daran nicht stossen, wenn man nun weiss, dass auch bei den Reptilien die vorhandene der Lage und Zahl nach genau den Urwirbeln entsprechende Anordnung der Segmentalorgane sehr bald schwindet und nur eine mit der Segmentirung des Körpers nicht mehr congruente

1) Entwicklungsgeschichte des Menschen und der höheren Thiere. Leipzig 1876. p. 199. 
Gliederung darstellt. Die letztere besteht nun sicher bei dem Hühnchen; Remak $^{1}$ ) spricht von der Anlage der Urniere als von einer Reihe runder Körperchen, die anfangs solid sind, alsbald aber sich in Bläschen umwandeln; an der der Mittellinie zugekehrten Fläche dieser Blasen treten runde solide Zellenhaufen auf, welche die Grundlage des glomerulus bilden; die glomeruli bilden also anfangs auch eine Reihe und entwickeln sich wie bei den Reptilien aus der Segmentalblase und zwar aus deren medialen Wandung, was Bornhaupt ${ }^{2}$ ) direkt beobachtet und auch Kölliker gesehen hat. Auch Bornhaupt spricht von einer Reihe von Bläschen.

Es ist zu verwundern, dass Foster und Balfour, trotzdem der letztere der mit Semper fast gleichzeitige Entdecker der Segmentalorgane der Plagiostomen ist, in ihrer Entwicklungsgeschichte des Hühnchens auf die Frage nach der Herkunft der Urniere fast gar nicht zu sprechen kommen, auch die erste Entstehung nicht gesehen haben.

Um nun endlich auch die Säugethiere mit in das Bereich dieser Diskussion zu ziehen, so verdanken wir wiederum Kölliker (l. c. p. 287) den Nachweis, dass die Urnieren am 10. Tage als kolbenförmige Wucherungen der Mittelplatten beim Kaninchen auftreten, doch konnte eine Höhlung in den Urnierensprossen nicht erkannt werden: an diesen Umstand scheint sich Kölliker zu stossen, da er besonders darauf aufmerksam macht, dass Semper'sche Trichter vor der Hand als erste Anlagen der Urniere beim Kaninchen nicht nachzuweisen seien, doch könnte dies vielleicht eine Folge des Erhärtungsmittels sein. Das letztere ist allerdings möglich, doch nachdem es mir bei Blindschleichen und Schlangen auch nicht möglich war, solche Trichter zu finden, die beim Hühnchen und der Eidechse vorkommen, kann ihr Fehlen beim Kaninchen nicht auffallen und gar keinen Grund dafür abgeben, dass die Urnieren des Kaninchens etwa morphologisch andere Organe seien; die Hauptsache bleibt ihre Abstammung vom Peritonealepithel und diese scheint mir völlig gesichert $\mathrm{zu}$ sein.

Mittheilungen über die weitere Entwicklung fehlen fast völlig, Kölliker sah nur, dass die Verbindung der "Urnierensprossen" mit dem Peritonealepithel sich bald löst und diese mit dem Wolff'schen Gang sich verbinden. Die schon mehrfach citirte Arbeit von Th. Egli ent-

1) Untersuchungen über die Entwicklung der Wirbelthiere. Berlin 1850-55. p. 59 .

2) Untersuchungen über die Entwickelung des Urogenitalsystems beim Hühnchen. In.-Diss. Riga. 1867. p. 23.' 
hält über diese Punkte gar keine Angaben, trotzdem der Autor die Kölliker'sche Entdeckung auch vom Kaninchen kennt.

\section{Die Geschlechtsorgane.}

Diese entstehen bei den Reptilien aus zwei in der Längsrichtung verlaufenden und neben dem Mesenterium gelegenen faltenartigen Erhebungen des Peritoneums; diese Falten bestehen aus dem verdickten, scharf abgegrenzten Peritonealepithel mit vergrösserten Zellen $=$ Ureiern und dem bindegewebigen Stroma. Ueberall wuchern in die Geschlechtsdrüse oder Genitalfalte, Ureierfalte Zellstränge (Blindschleiche, Eidechse) oder Kanäle (Natter) ein, die wegen ihrer Abstammung von den ursprünglichen Segmentalblasen Segmentalstränge genannt wurden: sie bilden an der Basis der Genitalfalte einen zwar vielfach durchbrochenen, doch zusammenhängenden Zellencomplex (Blindschleiche, Eidechse) oder einen Kanal (Natter), der regelmässig von dem Epithel der Malpighischen Körperchen einen Fortsatz erhält, wodurch also eine Art Gliederung hervorgerufen wird und der nach der andern Seite (ventral) in die Geschlechtsdrüse einwuchert. Nun beginnt ein eigenthümlicher Durchwachsungsprozess zwischen Ureierlager und Segmentalsträngen, der beim künftigen Männchen zı einem völligen Schwinden des Ureierlagers und Einwandern der Ureier in die Hodenkanälchen führt; beim Weibchen dagegen zur Degeneration der Segmentalstränge und Eifollikelbildung vom Ureierlager aus. Ganz instruktiv sind in dieser Beziehung die Bilder von gleich alten Stadien des Hodens und des Eierstocks, die ich in fig. 9, 10, fig. 11, 12 taf. VII. und fig. 6, 7 taf. VIII. mitgetheilt habe. Bei den Schlangen macht sich schon vorher die Differenzirung der Geschlechter dadurch bemerklich, dass erstens beim Weibchen die Segmentalstränge nicht mit dem Ureierlager in Verbindung treten und zweitens, dass beim Männchen das Ureierlager von Anfang an kleiner erscheint.

Aus den Segmentalsträngen entwickeln sich die Hodenkanälchen; die eingewanderten Ureier nebst andern Peritonealzellen mengen sich mit den von der Segmentalblase stammenden Zellen der Segmentalstränge und bilden den secernirenden Theil des Hodens; in den leitenden Theil scheinen keine Ureier zu gelangen; die Verbindungen der Malpighischen Körperchen mit den Hodenkanälchen verschwinden zum grössten Theil, nur die vordersten führen in den zum Samenleiter umgewandelten Wolff'schen Gang. 
Beim Weibchen degeneriren die Segmentalstränge völlig; die Bildungsstätte für die Eifollikel bleibt die grösser werdende und bis ans Lebensende bestehende Ureierfalte auf dem Ovarium; die Bildung selbst findet durch Einstülpung eines Ureies, das von Peritonealzellen umgeben ist, und spätere Abschnürung dieses Theiles statt. Sie geht mit gewissen Pausen das ganze Leben hindurch fort.

Die Uebereinstimmung mit den Plagiostomen ist hinsichtlich der Geschlechtsorgane ziemlich gross; bei beiden haben wir ein indifferentes Stadium zu verzeichnen, in welchem das verdickte Peritonealepithel eine Bindegewebsfalte fast im ganzen Bereich der Segmentalorgane überzieht. Hierauf tritt dann bei den Haien eine Einwanderung der Ureier, beim Weibchen gruppenweise mit Peritonealzellen, in das Stroma hinein, ein; sie führt zur Bildung von Eifollikeln, oder beim Männchen zur Vorkeimfalte, aus der sich dann erst die samenbildenden Follikel, die Ampullen unter Betheiligung der Ureier bilden. Die samenleitenden Kanäle stammen von den Segmentalgängen her und verbinden durch das Hodennetz letztere mit den Ampullen. Die Reptilien weichen nun darin von den Haien ab, dass es beim Hoden nicht zur Bildung einer Vorkeimfalte kommt, von der aus ein regelmässiger Ersatz der verbrauchten und degenerirenden Ampullen stattfindet; das ganze Ureierlager wandert gleich in Theile ein, die von den ursprünglichen Segmentalblasen herrühren und ohne Zweifel mit dem Hodennetz der Haie zu homologisiren sind; bei den Reptilien schwindet eben der Segmentalgang oder wird überhaupt als Gang nicht angelegt, jedoch senden die aus demselben Substrat stammenden und zu gleicher Zeit gebildeten Segmentalstränge die Stränge ab, welche dann an der Basis der Geschlechtsdrüse zu einem Netz sich vereinigen. Man könnte vielleicht einen Punkt anführen, der die Segmentalstränge noch näher an die Segmentalgänge anschlösse: der dem Segmentalgang bei Haien entsprechende Theil ist bei Reptilien die Verbindung der Segmentalblase mit dem Peritonealepithel (cf. fig. 11 taf. V.); dieser wird bei der Blindschleiche sehr lang, ein Rest von ihm lässt sich an der bereits abgeschnürten Segmentalblase, die schon mit dem Urnierengang in Verbindung steht, noch erkennen; derselbe ist aber gegen diejenige Stelle des Peritoneums gerichtet, in der bereits die Ureier liegen und an der die Genitalfalte sich bildet. Man könnte nun diesen Rest von neuem sprossen lassen - in der That gehen von der entsprechenden Stelle der späteren Malpighischen Körperchen die Segmentalstränge ab -, um die Segmentalstränge zu erhalten. Doch ich kann dafür keine Beobachtungen anführen, schliesslich dürfte es ganz 
gleichgültig sein, ob die Segmentalstränge von dem Epithel der Malpighischen Körperchen ausgehen, oder von einigen Zellen, welche vielleicht an derselben Stelle vom früheren Segmentalgang übrig geblieben sind. Jedenfalls stammen sie wie bei den Haien vom Peritonealepithel her und zwar von der nämlichen Einstülpung desselben.

Wir hätten also Vorkeimfalte und Ampullen des Haihodens in denjenigen Theilen der Hodenkanälchen bei Reptilien vereinigt und umgebildet, welche einmal in der ganzen Zeit ihres Bestehens die Ureier aufgenommen haben, während das Hodennetz in den ausführenden Theilen derselben zu suchen ist. Wie bei andern Amnioten scheint auch bei Reptilien eine Degeneration einzelner Hodenkanälchen oder einzelner Abschnitte derselben nach einer Brunst nicht vorzukommen; eine Menge von Zellen werden allerdings bei der Spermatozoenbildung verbraucht, doch für deren Ersatz besteht kein besonderes Vorkeimlager, sondern es findet derselbe aus den tieferen Schichten der Zellenbekleidung eines Hodenkanälchens statt, die - so viel wir wissen - direkt an der Spermatozoenbildung nicht Theil nehmen.

Da nun das Vorkommen eines dem Hodennetz der Haie entsprechenden Theiles bei den Reptilien erwiesen ist, so lässt sich erwarten, dass bei der Verwandtschaft dieser mit den Vögeln - dieselbe sei einmal hier von uns betont, aber von der umgekehrten Basis ausgehend, als die meisten bisherigen Berufungen auf diese Verwandtschaft - auch beim Hoden der Vögel die Segmentalstränge sich werden wieder finden lassen. Thatsächlich ist nichts Sicheres bekannt, allerhand Andeutungen, ohne positive Beweise existiren und mögen zum Theil einstweilen hier herbeigezogen sein. Dass irgend Jemand die Malpighischen Körperchen als die Ursprungsstellen der Hodenkanälchen ansieht oder angibt, ist mir nicht erinnerlich, vielleicht hat H. Kapff ${ }^{1}$ ), der übereifrige Kritiker von Waldeyer, etwas hierher gehöriges gesehen, denn er sagt, dass dem äusserlichen Auftreten der Geschlechtsdrüse regelmässig im Innern eine Gefässwucherung von der Aorta und vielleicht auch von den glomerulis her gegen jene mediale Stelle des Wolff'schen Körpers vorangeht, wo eben die Geschlechtsdrüse aufgetreten; was die Aorta dabei zu thun hat, weiss ich nicht, aber die Gefässwucherung von den glomeruli scheint mir darauf hinzudeuten, dass Karpff wohl etwas den Segmentalsträngen der Reptilien Aehnliches und Entsprechendes gesehen hat. Andere

1) Untersuchungen über das Ovarium und dessen Beziehungen zum Peritoneum Müll. Arch. für Anatomie. 1872. p. 557. 
Autoren, z. B. Waldeyer ${ }^{1}$ ) lassen die Hodenkanälchen aus dem Wolff'schen Körper hervorgehen und zwar aus Kanälen desselben, den Beweis dafür ist W. uns schuldig geblieben, denn die engeren Kanäle der Segmentalorgane, welche Waldeyer in seiner fig. 58 taf. VI. dorsal zeichnet, sind die letzten Enden der Urnierenkanälchen und stehen kurz vor ihrer Einmündung in den Urnierengang; dass diese mit den Hodenkanälchen in Verbindung stehen, wie es Weldeyer gesehen zu haben glaubt, ist mir sehr unwahrscheinlich und wenn sie es wirklich thun, so ist doch durchaus noch nicht bewiesen, dass die Hodenkanälchen oder die Anlagen derselben auch von ihnen stammen; die Verbindung kann wenn sie überhaupt existirt, secundär erfolgt sein. Andere Beobachter sagen, die Hodenkanälchen entwickeln sich aus dem Wolff'schen Körper - womit gar Nichts gesagt ist und endlich lässt z. B. Kölliker ${ }^{2}$ ), die Hodenkanälchen in der Geschlechtsdrüse selbständig entstehen, doch gibt dieser die Möglichkeit des Uebersehens einer Verbindung zwischen Theilen des Wolff'schen Körpers und Hodenkanälchen zu. Auch beim Kaninchen lässt Egli ${ }^{3}$ ) die Hodenkanälchen gesondert vom Wolff'schen Körper entstehen, zu keiner Zeit ist eine Sprossung irgend eines Theiles der Urnierenkanälchen in der Richtung gegen die Geschlechtsdrüsenanlage zu sehen, wofür er noch als Beweis anführt, dass am nächsten der Geschlechtsdrüse die Malpighischen Körperchen, die doch wohl Theile der Urnierenkanälchen sind, liegen, während die Hodenkanälchen resp. deren erste Anlagen unter dem Epithel der Geschlechtsdrüse auftreten. (?)

Man sieht, dass die ganze Angelegenheit vom Hühnchen an aufwärts noch völlig dunkel und unentschieden ist; die Wichtigkeit einer recht baldigen Entscheidung brauche ich nach der Mittheilung meiner Beobachtungen an Reptilien nicht zu betonen, andererseits will ich auch nicht den Propheten spielen und diesen und jenen Punkt als durch Beobachtung sicher nachweisbar hinstellen; ich erinnere an die Tube der Haie und Reptilien!

Was nun endlich die Follikelbildung anlangt, so geht dieselbe ebenso bei den Haien wie Reptilien vor sich, d. h. Eizelle und Follikelzellen sind gleichwerthig und stammen vom verdickten Peritonealepithel

1) Eierstock und Ei. p. 152.

$\left.{ }^{2}\right)$ Ueber die Entwicklung der Graaf'schen Follikel der Säugethiere. Verhandl. der phys. med. Gesellsch. in Würzburg. Bd. VII. 1875. p. 92-95.

${ }^{3}$ ) Beiträge zur Anatomie und Entwicklung der Geschlechtsorgane. I. Zur Entwicklung des Urogenitalsystems beim Kaninchen. In.-Diss. Zürich. 1876. p. 49. 
des Ovariums; andere Theile treten nicht hinzu. Dasselbe wird für Vögel und Säugethiere auch von Waldeyer angenommen und zu beweisen gesucht, doch nicht ohne Widerspruch; oben nannte ich Kapff den übereifrigen Kritiker Waldeyers, seine Arbeit machte mir den Eindruck, als ob dadurch der Versuch gemacht werden sollte, die ihm selbst oder auch Anderen unbequeme Ansicht Waldeyers als auf lauter Irrthümern beruhend hinzustellen und zu beseitigen. Ein Verdienst hat sie allerdings, sie mahnt uns zu grosser Vorsicht in der Beurtheilung dieser Einstülpungsvorgänge. Doch nachdem ich etwas ganz Homologes auf dem Ovarium der Reptilien gesehen habe, wo wegen des Fehlens von Grübchen und wie es scheint normaler Epitheleinsenkungen, die Nichts bedeuten, eine Täuschung in dieser Beziehung nicht gut möglich ist, wo die Follikelbildung ohne offene Communikation mit der Oberfläche stattfindet, glaube ich auch an ihr Vorkommen bei den höheren Wirbelthieren.

Ein anderer Gegner der Ansicht von der Gleichwerthigkeit von Follikelepithel und Eizelle ist Kölliker ${ }^{1}$ ), der zwar die Eier aus dem Keimepithel ableitet, dagegen die Follikelzellen aus Strängen, die von den Kanälen des Wolff'schen Körpers stammen sollen. Kölliker hat die Ovarien 1-2 Tage alter Hündinnen untersucht und das ist doch nur ein Stadium, aus welchem allein einen Schluss auf die Entwicklung zu ziehen mir nicht gerechtfertigt erscheint; man mag oft genug ganz sicher in diesen Schlüssen sein; Geltung können sie erst haben, nachdem die Entwicklung wirklich beobachtet ist und den hypothetisch angenommenen Modus bestätigt. Ich habe bei der Blindschleiche, deren Ovarium viel weniger komplicirt ist als das einer Hündin, nicht durch einfaches, wenn auch sorgfältiges Mustern einer Schnittserie, in der kein Schnitt fehlte, zum Entscheid kommen können, ob nicht doch die Segmentalstränge etwas mit der Eifollikelbildung zu thun haben; man denke nur, dass z. B. eine schräg verlaufende Einstülpung in der Nähe der Reste der Segmentalstränge stattfände, bei Schrägschnitten sind die sonst vorhandenen Abgrenzungen von Zellenkomplexen schwer zu sehen und ein solches Bild könnte die Verbindung des Segmentalstranges mit der Einstülpung vortäuschen; oder aber die Einstülpungen sind unregelmässig, gebogen, ihre abgeschnittenen Ende gleichen genau (bei der Blindschleiche) den Resten der Segmentalstränge; wenn man nun nicht

1) Entwicklung der Graaf'schen Follikel der Säugethiere. Verhandlungen der phys. med. Gesellsch. in Würzb. Bd. VIII. 1875. p. 92-95. 
durch die Schnittserie kontroliren kann, wird man zum mindesten im Zweifel bleiben oder unrichtig urtheilen. Ich konnte nur dadurch zum Ziele, d. h. einem richtigen Urtheil kommen, dass ich mir Schnitt für Schnitt mit der Camera abzeichnete und dann die einzelnen in ihrer Folge genau verglich; so konnte ich bei Reptilien eine Betheiligung der Segmentalstränge bei der Follikelbildung völlig ausschliessen.

Um das junge Hunde-Ovarium kennen zu lernen, habe i h 1-2 Tage alte Hündinnen getödtet, die Ovarien gehärtet und geschnitten; ich finde da ein solches Durcheinander von Zellen, Epithelsprossen, Strängen, Zellhaufen etc., dass ich gern gestehe, hier keinen Entscheid geben zu können; mir ist es unmöglich, sagen zu können, diese Zellmasse stamme vom Epithel oder von eingewucherten Strängen. So lange also nicht jüngere Stadien resp. die Entwicklungsreihe selbst vorliegt, müssen wir die Kölliker'sche Entwicklungsansicht vom Graaf'schen Follikel aus als zwar möglich, doch noch nicht als bewiesen ansehen.

Wir werden einstweilen daran festhalten müssen, dass Eizelle und Follikelepithel auch bei den höchsten Amnioten morphologisch identisch sind, wie es für die Reptilien von mir zuerst erkannt wurde. Doch besteht ein Unterschied: während bei den Reptilien die Eifollikelbildung das ganze Leben hindurch von der bestehen bleibenden Ureierfalte vor sich geht, ist dies bei Vögeln und Säugern nicht der Fall, sondern findet nur in dem embryonalen Leben statt; das ganze Ureierlager scheint sich nach und nach einzustülpen und bleibt dann als besondere Schicht unter dem Peritonealepithel liegen (Pflüger'sche Schläuche), später sogar noch durch Bindegewebe von ihm getrennt. Man könnte darin Etwas der Vorkeimfalte der Haie Analoges sehen, es bildet das Lager, von dem aus der Ersatz verbrauchter Follikel stattfindet.

\section{Die bleibende Niere.}

Bei den Reptilien entsteht die Niere aus nicht regelmässig segmental geordneten Knospen des Peritoneums, die sich nach hinten von der Urniere bilden, vom Peritoneum sich abschnüren und dann zn einem cylinderförmigen Zellstrang zusammentreten, welcher die Anlage der Malpighischen Körperchen und der gewundenen Harnkanälchen, also des secernirenden Theiles der Niere bildet; der leitende Theil geht vom Epithel des Wolff'schen Ganges in Form eines nach vorwärts wachsenden Kanales, des Harnleiters ab, der in den cylinderförmigen Zellstrang eindringt und dort ziemlich regelmässige Aeste entsendet. 
Nach diesem hat die Niere der Reptilien mit den Segmentalorganen die Entstehung vom Peritonealepithel gemein, welches bei beiden den secernirenden Theil liefert; auch der ausführende Theil ist bei beiden gleich, nämlich der Wolff'sche Gang resp. ein von diesem abstammender, und in ihn mündender Kanal. Es fehlt die segmentale Entstehung, die wir aber auch bei der Urniere schwinden sehen und die bei der Niere dadurch wenigstens angedeutet ist, dass die Nalpighischen Körperchen in einer Reihe angelegt werden. Wir dürfen daher die Niere der Reptilien als einen hinteren Theil der Segmentalorgane auffassen, der, ziemlich selbstständig geworden, wohl im Anschluss an die ersteren entsteht, doch durch ein Zeitintervall getrennt ist; dieser verspätet auftretende Theil der Segmentalorgane enthält einen besonderen Ausführungsgang, der aber wie bei andern Amnioten vom Wolff'schen Gang, dem leitenden Kanal der Segmentalorgane abstammt.

Man fühlt sich versucht, die bleibende Niere der Reptilien mit dem hinteren Abschnitt der Segmentalorgane der Haie, der eigentlichen Niere derselben zu parallelisiren, während der vordere Abschnitt, Leydig'sche Drüse mit Leydig'schem Gang der Urniere mit Wolff'schem Gang der Reptilien entspricht. Dagegen kann nicht eingewendet werden, dass die Niere der Amnioten einen besonderen Ausführungsgang bekommt; derselbe ist nur ein Theil des Wolff'schen Ganges und scheint mir, während er die Selbstständigkeit des hinteren Abschnittes der Segmentalorgane dokumentirt, doch auch wieder seine Zusammengehörigkeit mit dem vorderen anzuzeigen.

Was die Abstammung des Nierenepithels bei anderen Amnioten anbelangt, so besteht darüber nichts Gewisses; ohne besondere Beweise leiten die Einen es von den Urwirbeln, Andere vom Wolff'schen Gang etc. ab; so viel scheint sicher, dass der Harnleiter ein Spross des hintersten Endes des Wolff"schen Ganges ist, dass derselbe in einen cylinderförmigen Körper, die Nierenanlage hineinwuchert, in welcher die Malpighischen Körperchen und ein Theil der Nierenkanälchen selbstständig entstehen. 


\title{
Tafelerklärung.
}

\author{
Gemeinsame Abkürzungen. \\ Ao $=$ Aorta \\ M.r. = Medullarrohr. \\ $\mathrm{Tr}=$ Trichter. \\ Ect. = Ectoderm. \\ Sg.g = Segmentalgang. \\ Uw. = Urwirbel. \\ Sg.bl = Segmentalblase. \\ Ur.k. = Urnierenkanälchen. \\ W. G. = Wolff'scher Gang. \\ M. K. = Malpighi'sches Körperchen. \\ P.h. = Peritonealhöhle. \\ gI. $=$ glomerulus. \\ P.ep. $=$ Peritonealepithel. \\ Ur.f. = Ureierfalte. \\ Ch. = Chorda dorsalis. \\ M.pl. = Muskelplatte. \\ Ms. $=$ Mesenterium.
}

\section{Tafel V.}

Fig. 1. Querschnitt aus dem hintern Theil eines Embryo von Lacerta agilis

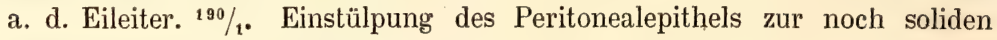
Segmentalblase.

$$
\begin{aligned}
& \mathrm{V}=\text { vena cardinalis. } \\
& \mathrm{D}=\text { Darm. }
\end{aligned}
$$

Fig. 2. Querschnitt aus dem vordern Theil eines Embryo von Lacerta agilis a. d. Eileiter ${ }^{190} / 1$, ein jüngeres Stadium als das vorige in der ganzen Ausbildung des Embryo. Die Einstülpung des Peritoneum hat sich zur Blase (Sg.bl.) umgewandelt, damit ist der Trichter geschwunden, doch besteht noch eine Verbindung der Blasenwand mit dem Epithel = Sg.g.

Fig. 3. Querschnitt eines Embryo von Lacerta agilis a. d. Eileiter ${ }^{74} /{ }^{\text {. Ver- }}$ bindung der Segmentalblase durch eine solide Sprosse mit dem Wolff'schen Gang; Anlage der Urnierenkanälchen.

Fig. 4. Sagittalschnitt eines Embryo von Lacerta agilis a. d. Eileiter ${ }^{12} / 1$, entstammt demselben Mutterthier wie fig. 2. Die hintersten 10 Segmentalblasen stimmen genau in ihrer Zahl mit den Urwirbeln überein. 
Fig. 5. Sagittalschnitt eines Embryo von Lacerta agilis a. d. Eileiter ${ }^{22} / \mathbf{1}$, aus dem vordern Theil des Embryo; die Zahl der Segmentalblasen, die bereits in Malpighische Körperchen sich umzuwandeln beginnen, stimmt auch hier noch mit der Zahl der Urwirbel überein, doch beginnt bereits nach vorn die Verschiebung.

Fig. 6. Bildung von Malpighi'schen Körperchen durch Einstülpung (a) des der Aorta zunächst liegenden Theiles der Wandung der Segmentalblase; La certa agilis a. d.. Eileiter ${ }^{190} / 1$.

Fig. 7. Ein ähnliches Stadium von einem andern Embryo von Lacerta agilis a. d. Eileiter ${ }^{190} / 1$.

Fig. 8. Bildung von Malpighi'schen Körperchen von Lacerta agilis. ${ }^{190} / 1$. In die Einstülpung (a) der Segmentalblase dringt ein noch einfacher Ast der Aorta.

Fig. 9. Ein fast völlig ausgebildeter glomerulus in der Segmentalblase liegend; Querschnitt aus einem 1 Tag nach der Eiablage gehärteten Embryo von Lacerta agilis ${ }^{190} / 1$. Die vasa afferentia sind seitliche Aeste der Aorta. $\mathrm{V}$. = vena.

Fig. 10. Querschnitt durch denselben Embryo, dem fig. 9. entnommen ist ${ }^{74} / 1$, zur Uebersicht der Lage der Urniere etc. Lacerta agilis.

Fig. 11. Querschnitt durch einen 8-10 mm. langen Embryo von Anguis fragilis. Die Segmentalblase einerseits noch im Zusammenhang mit dem Peritonealepithel, andrerseits davon abgeschnürt; jedoch schon in Verbindung mit dem Urnierengang (W. G.)

D. r. = Darmrinne.

Fig. 12. Querschnitt durch denselben Embryo (Anguis fragilis) weiter hinten; die Segmentalblase einerseits in einer ähnlichen Lage wie bei Lac. agilis (cf. fig. 2), auf der andern Seite ist ihre vordere oder hintere Wandung getroffen.

In fig. 11 und 12 im Peritonealepithel an der Uebergangsstelle auf das Mesenterium einzelne vergrösserte 'Zellen = Ureier.

D.r. = Darmrinne.

\section{Tafel VI.}

Figuren 1-12. Zur Entwicklung des Eileiters.

Fig. 1. Querschnitt durch den vordern Theil eines Embryos von Angu is f ragilis, $16 \mathrm{~mm}$. lang vom Scheitel bis After. Die Peritonealhöhle auf der einen Seite durch eine bindegewebige Brücke getheilt; auf der andern Seite ist die Brücke (Ur.f.) von der Bauchwand abgerissen, das Peritonealepithel, da wo sich die Tube bilden soll (P.h.) verdickt.

Ur.f. = Urnierenfalte.

Unterhalb der Aorta (Ao.) liegt der Darm, darunter die Lungenanlagen. 
Fig. 2. Querschnitt durch denselben Embryo, einige Schnitte weiter nach hinten In jeder Urnierenfalte ist die Urniere aufgetreten, die ganze Falte dadurch auf dem Schnitt mehr halbkreisförmig geworden. Auf der einen Seite ist das Peritonealepithel auf der Tubenfalte stark verdickt, auf der andern senkt es sich nach innen ( $\mathrm{Tb}$.), bildet also eine Rinne.

Fig. 3. Querschnitt durch densellen Embryo, einige Schnitte weiter nach hinten. Die Tubenrinne oder Trichter ist tiefer eingesunken in die Tubenfalte; auf der andern Seite liegt der Querschnitt eines Kanals. (Tb) in der Tubenfalte.

Fig. 1-3. Bei Hartnack. Ocular 2, Objektiv IV., eingesch. tub. gezeichnet.

Fig. 4. entspricht der einen Seite von Fig. 1. Ur.f. bei stärkerer Vergrösserung nach demselben Original; das Peritonealepithel an der ventralen Fläche der Urnierenfalte stark verdickt.

Fig. 5. Ein Schnitt der Tubenfalte etwas weiter nach hinten, wenn der Wolff'sche Körper bereits im Bereich des Schnittes aufgetreten ist; entspricht ungefähr Fig. 2 bei P.h.

Fig. 6. Die Tubenfalte hat sich sehr verbreitert; ihr verdicktes Epithel stülpt sich nach innen ein.

Fig. 7. Die Tubenfalte bildet hier eine breite Rinne, begrenzt von wallförmigen Erhebungen des Epithels; entspricht Fig. 2. Tb.

Fig. 8. Das Epithel der Tubenfalte steht nach Innen mit einem Kanal in Verbindung, der sich auf dem nächsten Schnitt vom Epithel abgeschnürt hat und wie in Fig. 3 bei $\mathrm{Tb}$. erscheint.

Fig. 9. In der Tubenfalte liegt an Stelle des Kanales ein ovaler Zellenkörper (Tb.), das nach hinten wachsende Ende der Tube; die Falte selbst erscheint in einer Richtung verkürzt, in der entgegengesetzten verbreitert.

Fig. 10 zeigt die Tubenfalte (Tb.f.) am Wolff'schen Körper hängend neben dem Wolff'schen Gang (W.G.); in ihr nur Bindegewebszellen.

Fig. 4-10 mit Hartnack Ocul. 2, Objekt VII. eingesch. tub. gezeichnet.

Fig. 11 u. 12. Zwei aufeinander folgende Stadien der Tubenentwicklung in der SeitenAnsicht, durch Eintragen einer Querschnittserie gewonnen. Die Richtung der Pfeile bedeutet die Wachsthumsrichtung nach hinten.

Figur 13-17 Entwicklung von Eifollikeln.

Fig. 13. Querschnitt des einen Ureierlagers eines zweijährigen Weibchens von La certa agilis. Innerhalb desselben grenzt sich um ein Urei eine Lage von Peritonealzellen zum jüngsten Follikel ab; der nächstältere liegt bereits ausserhalb des Ureierlagers, anstossend an den dritten bei a. ${ }^{199} / 1$.

Fig. 14. Querschnitt durch das Ureierlager von Platydactylus facetanus; ausgewachs. Exemplar, im August nach der Eiablage getödtet; im verdickten Epithel ein sich bildender Follikel. ${ }^{190} /{ }_{1}$.

Fig. 15. Querschnitt durch das Ureierlager von einem erwachsenen Exemplar von Anguis fragilis; im Mai getödtet; der jüngste Follikel im Durchtritt oder Abschnürung begriffen. Hartn. VII. 2. eingez. tub. 
Fig. 16. Ein junger Follikel im Querschnitt von einem andern, gleichalten Thier von A nguis fragilis, noch im Ureierlager gelegen; der Schnitt stammt vom hinteren Ende des Ureierlagers, desshalb die Grössendifferenz.

Fig. 17. Ein junger Follikel von Anguis fragilis erwachsenes Thier; aus dem Ovarialstroma. Hartn. VII. 2 eing. tub.

\section{Tafel VII.}

Fig. 1-12. Entwicklung der Geschlechtsdrüsen.

Fig. 1. Querschnitt durch einen Embryo von Lacerta agilis, dem Eileiter entnommen; 6-8 mm. lang.

Auf der einen Seite geht vom Wolff'schen Gang (W. G.) das Sförmig gewundene Urnierenkanälchen aus, das in die Segmentalblase neben der Aorta führt; diese ist nur an ihrer Peripherie getroffen. Das PeritonealEpithel ist am Uebergang auf das Mesenterium verdickt, einzelne Zellen vergrössert. ${ }^{199} / \mathbf{1}$.

Fig. 2. Querschnitt durch die Ureierfalten eines Embryos von Lacerta agilis. 1 Tag nach der Eiablage getöltet; $10 \mathrm{~mm}$. lang vom Scheitel bis zum After; hier ist es zur Bildung einer wirklichen Ureierfalte gekommen (Ur.f.), welche wallartig in die Leibeshöhle hineinsieht. ${ }^{19} \%$.

Fig. 3. Schnitt durch denselben Embryo mehr nach vorn, wo die Ureierfalte noch mehr hervortritt. ${ }^{190} / 1$.

Fig. 4. Querschnitt durch die eine Geschlechtsdrüse von La a erta a gilis. 17 Tage nach der Eiablage getödtet. Vom Malpighi'schen Körperchen aus bei a geht ein Haufen von Zellen in knieförmigem Verlauf in die Geschlechtsdrüse hinein und verdrängt das Stroma fast ganz.

NB. Die Stroma-Zellen sind etwas zu klein gezeichnet. $31 \%$.

Fig. 5. Schnitt durch denselben Embryo von Lacerta agilis, der Strang in der Geschlechtsdrüse hat sich mit dem Ureierlager in Verbindung gesetzt; einzelne Ureier in ihm, wie in Fig. 4 und

Fig. 6 von demselben Embryo stammend. $310 / 1$.

Fig. 7. Querschnitt durch die Geschlechtsdrüse und den angrenzenden Theil der Segmentalorgane von Anguis fragilis; Eileitereiern entnommen, $19 \mathrm{~mm}$. lang vom Scheitel bis zum After; die Mittellinie liegt nach fig. $8 \mathrm{zu}$. Von dem äussern Epithel des Malpighi'schen Körperchens (gl.) geht bei a ein keulenförmiger Zellenfortsatz aus nach der Keimdrüse zu und in mehreren Windungen, die hier quer getroffen sind in dieselbe hinein. Eine Abtheilung in Kanälchen hat bereits stattgefunden, in diesen und im Stroma die Ureier. Hart. VIl, 2. eingezog. tub.

Fig. 8. Querschnitt durch einen andern Embryo desselben Thieres, einem jüngeren Stadium entsprechend; fast die ganze Geschlechtsdrüse wird von den vom Malpighischen Körperchen stammenden Segmentalsträngen eingenommen; an der ventralen Fläche massenhafte Einwanderung von Elementen des Ureierlagers in die Segmentalstränge. Hartn. VII. 2. eing. tub. 
Fig. 9 u. 10. Gleichalte Stadien eines Ovariums (fig. 9) und eines Hodens (fig. 10) von einem $12 \mathrm{~mm}$. langen Embryo von Lacerta agilis, bei dem die erste Spur der Pigmentirung der Epidermis auftrat. ${ }^{190} / 1$.

Fig. 11 u. 12. Gleichalte Stadien eines Ovariums (fig. 11) mit Follikelbildung und eines Hodens (fig, 12) von Anguis fragilis, völlig ausgebildeter Embryo, der kurz vor dem Auskriechen stand. Hartnack VII. 2. eing. tub.

Fig. 13. Querschnitt durch ein Segmentalbläschen von einem Embryo von Tropi notus natrix, $11 \mathrm{~mm}$. lang. $175 / \mathbf{1}$.

\section{Tafel VIII.}

Fig. 1. Querschnitt durch Wolff'schen Körper und Keimdrüse eines Embryo's von Platydactylus facetanus von Menorka, $13 \mathrm{~mm}$. lang vom Scheitel bis zum After. Vergr. Hartn. VII. 2. eing. tub.

Nn. Nebenniere = goldgelber Körper, Paradidymis der neueren Autoren.

Fig. 2. Querschnitt durch den Hoden eines Embryo von Platydactylus facetanus von Menorka; $17 \mathrm{~mm}$. vom Scheitel bis After. Hartn. VII. 2. eing. tub.

Fig. 3. Querschnitt zweier Hodenkanälchen eines Platydactylus facetanus, junges Thier; peripher liegen kleine getrübte Zellen, central grosse Ureierähnliche Zellen, wahrscheinlich Ureier. Hartn. VII. 2. eing. tub.

Fig. 4. Querschnitt durch ein Hodenkanälchen eines ausgewachsenen Platydactylus facetanus zur Demonstration der weiteren Schicksale der grossen Ureierähnlichen Zellen; Umwandlung in Spermatoblasten. Hartn. VII. 2. eing. tuh.

Fig. 5. Ein Stück Peritoneum zwischen Ovarium (Ov.) und Eileiter (Eil.) mit dem erhalten gebliebenen Wolff'schen Gang (W.G.), der im Beginn auf der Nebenniere $(\mathrm{Nn})=$. goldgelben Körper verläuft; der Gang ist in der Lithographie etwas zu dick ausgefallen. Natürl. Grösse; Originalzeichnung von J. v. Kennel nach einem Präparat von Coronella laevis ausgen. Exempl.

Fig. 6 u. 7. Gleichalte Stadlen eines Ovariums (fig. 6) und eines Hodens (fig. 7) im Querschnitt von einjährigen Exemplaren von La certa agilis, bei verschieden starker Vergrösserung.

fig. 6 halbschematisch ${ }^{75} / 1$; die Richtung der Bildung von Eifollikeln ist vom Ureierlager aus durch Pfeile angedeutet; der Wolff'sche Körper functionirt in diesem Alter noch vollständig.

Fig. 7. Querschnitt durch einige Hodenkanälchen. ${ }^{190} / 1$.

Fig. 8- 16. Aufeinanderfolgende Stadien der Entwicklung der Geschlechtsdrüse von Embryonen von Tropidonotus natrix.

Fig. 8. Querschnitt durch die Geschlechtsdrüse und den angrenzenden Theil eines Malpighi'schen Körperchens mit der Verdickung (Sg.str.) eines Theiles seiner Wandung, welche nach der Geschlechtsdrüse zustrebt ${ }^{270} / 1$. Embryo $39 \mathrm{~mm}$. lang, einem Eileiterei entnommen. 
Fig. 9. Der nächstliegende Querschnitt desselben Embryo's ${ }^{270} / 1$.

Fig. 10. Querschnitt durch die Geschlechtsdrüse und den angrenzenden Theil eines Malpighi'schen Körperchens (gl.), an dem die Verdickung stärker geworden ist; entstammt einem weiter nach vorn gelegenen Schnitt desselben Embryo's und entspricht einem älteren Stadium, als fig. $8 .{ }^{310} / 1$.

Fig. 11. In der Verdickung der Wand des Malpighi'schen Körperchens (Sg. str.) ist ein Lumen aufgetreten; der Schnitt noch mehr nach vorn als der vorige geführt. ${ }^{310} / 1$.

Fig. 12. Die Verdickung der Wand des Malpighi'schen Körperchen's erscheint als eine Ausstülpung der Wandung und communicirt bei andern Schnitten mit der Höhlung des Körperchens. Embryo $50 \mathrm{~mm}$. lang; 14 Tage nach der Eiablage getödtet.

Fig. 13. Eindringen eines seitlichen Zweigkanales, der von dem am Malpighischen Körperchen entstandenen und gelegenen Hauptkanal ausgeht, in den Hoden; diese Zweigkanäle stellen die Hodenkanälchen dar. ${ }^{190} / 1^{\text {. }}$ Embryo $55 \mathrm{~mm}$. lang, 18 Tage nach der Eiablage getödtet.

Fig. 14. Demselben Embryo entnommen wie fig. 13, aber mehr nach vorn; Verbindung des Hodenkanälchens mit dem Peritonealepithel. ${ }^{190} / 1$.

Fig. 15. Querschnitt durch das Ovarium eines Natterembryo, gleichalt wie fig. 13 und 14; ist also auf dem Stadium von fig. 11 stehen geblieben. ${ }^{190}{ }_{1}{ }_{1}$.

Fig. 16. Querschnitt durch das Ureierlager von einem Natterembryo, $71 \mathrm{~mm}$. lang; 25 Tage nach der Eiablage getödtet; Bildung eines Eifollikels. ${ }^{31 \%} /{ }_{1}$.

\section{Tafel IX.}

Zur Entwicklung der bleibenden Niere von Lacerta agilis.

Fig. 1. Querschnitt durch das hintre Ende eines Embryo's von Lac. ag., 8 Tage abgelegt, das Peritonealepithel (P.ep.) nach dem Wolff'schen Gang zu verdickt. ${ }^{190 / 1}$.

Fig. 2. Querschnitt durch das hintere Ende eines Embryo's von Lac. ag. derselben Brut, 15 Tage nach der Eiablage getödtet; die Peritonealverdickung erstreckt sich weit in das Bindegewebe zwischen Aorta und Wolff'schen Gang hinein. ${ }^{190} / 1$.

Fig. 3. Querschnitt durch das hintere Ende eines Embryo's von Lac. agilis einer andern Brut als die Originale von fig. 1 und 2; 3 Tage nach der Eiablage getödtet; späteres Stadium mit dem Auftreten eines Zellstranges am Wolff'schen Gang $=$ Anlage der Niere. ${ }^{190} / 1$.

Fig. 4. Querschnitt durch den Nierenzellstrang, in der der Harnleiter (Hnl.) bereits eingedrungen und seitliche Aeste abgegeben hat. ${ }^{190} /{ }_{1}$.

N.k. noch nicht zur Bildung von Kanälen verbrauchter Theil des Nierenzellstranges, an den sich aussen die bindegewebige Nierenkapsel anlegt.

Fig. 5 Frontalschnitt durch die Niere eines $71 \mathrm{~mm}$. langen Natterembryo's cf. Text. Capitel Niere. p. 202. ${ }^{74} / 1$. halbschematisch. 
Fig. 6. Wolf'scher Gang und Harnleiter in situ eines 13 Tage alten NatterEmbryo's; stark vergrössert.

Fig. 7. Querschnitt durch die Cloake eines Eidechsenembryo's, in welche Wolff'scher Gang (W. G.) und Harnleiter (Hrnl.) zusammen einmünden. ${ }^{74} / 1$. halbschematisch.

Ect. $=$ Ectoderm.

\section{Tafel X.}

Zur Anatomie des Urogenitalsystems von Phyllodactylus europaeus.

Fig. 1. Das Urogenitalsystem eines weibl. Phyll. eur. in situ; etwa doppelt vergrössert. Originalzeichnung von J. v. Kennel.

Ov. = Ovarium.

Tr. = Trichter.

$\mathrm{Tb} .=$ Tube.

Ut. $=$ Uterus.

N. $=$ Niere.

a. = Verbreiterung der Tube, dem Querschnitt fig. 3 entsprechend.

P. = Papille, an deren hinteren Ende der Harnleiter ausmündet (cf. fig. 9. P.)

Unterhalb des hintern Randes der Cloake erscheinen in der Epidermis der Schwanzwurzel zwei Spalten, welche in ein blindes Säckchen führen.

Fig. 2. Querschnitt durch den Eileiter (Tb.) und die Niere (N.) dicht über der Verbreiterung bei a. fig. 1. halbschematisch. ${ }^{75} / 1$.

Hrnl. = Harnleiter.

Fig. 3. Querschnitt wie fig. 2. entsprechend a in fig. 1. ${ }^{75} / 1$.

Fig. 4. Querschnitt wie fig. 2. entsprechend dicht unterhalb a: in fig. 1. ${ }_{11}^{7}$.

Dr. = vorderstes Ende der Tubendrüse.

Fig. 5. Nächstfolgender Querschnitt. Verbreiterung der Drüse. ${ }^{75 / 1}$.

Fig. 6. Querschnitt derselben Serie wie fig. 2-5. In der Drüse der rinnenförmige, gemeinschaftliche Ausführungsgang. ${ }^{75} / 1$.

Fig. 7. Folgender Querschnitt mit Verkleinerung der Tube (Tb.), die fast völlig von der Drüse umspannt wird. ${ }^{75} / 1$.

Fig. 8. Ausmündung der Tubendrüse in die Cloake und der Tube (Tb.m.) auf einer Papille (P.) ${ }^{75} /$. $^{2}$

W.G. = Rest des Wolff'schen Ganges.

Fig. 9. Querschnitt durch die Cloakenwand (Cl.) mit den beiden Papillen, in deren einer sich der Wolff'sche Gang (W.G.) mit dem Harnleiter (Hrn.l.) kurz vor der Ausmündung des letzteren vereinigt. 


\section{In h a l t.}

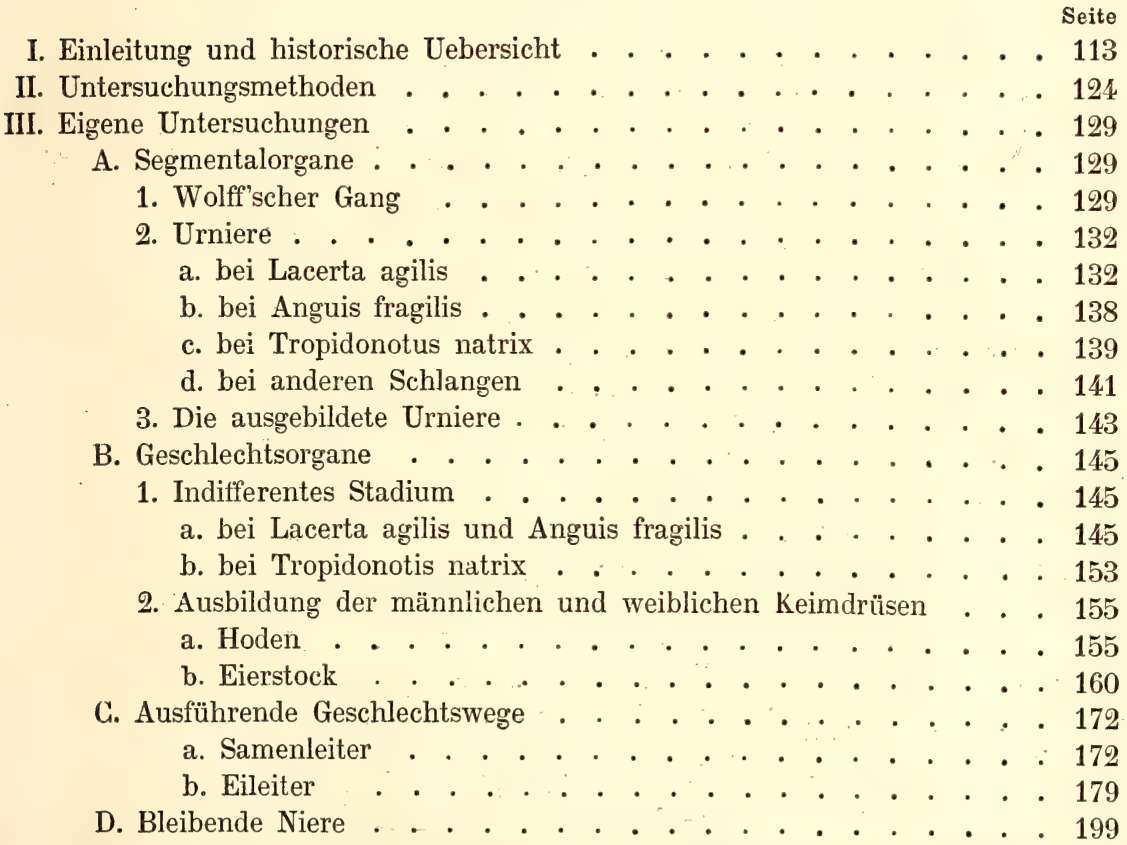

IV. Die Beziehungen des Urogenitalsystems der Reptilien zu dem der anderen

Wirbelthieren . . . . . . . . . . . . . . . 207

Tafelerklärung . . . . . . . . . . . . . . . . . . 222 

Taf: I.

5.

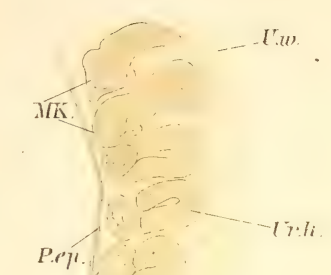

s.bl.

10.



Lith J, A. Hof maten Wurzburg. 



Taf. II

13.

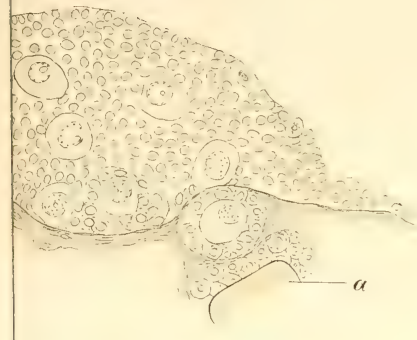

14.

15.

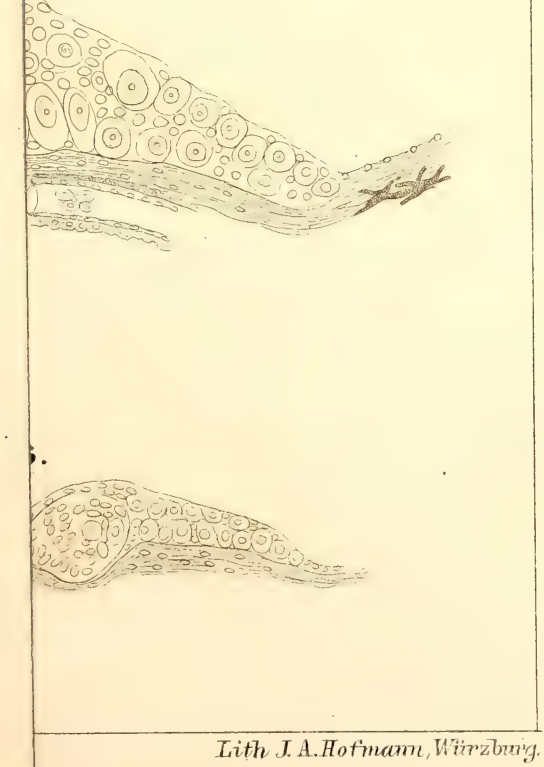





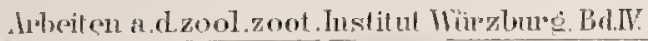

1.

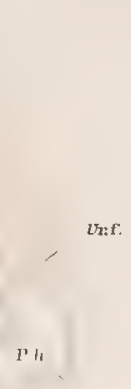

11.

$+$

Ir.

5.

2.

In

II

$$
\text { Th }
$$

i.

$P h$

3.

II*

B.

Q. ${ }^{\mathrm{Tn}}$

Th.

roh
I?7!

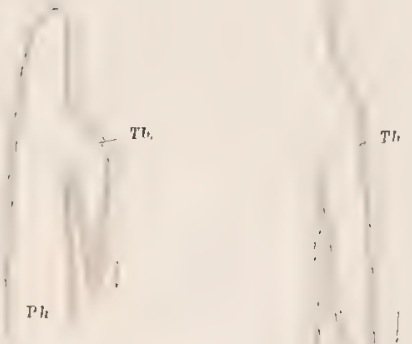

12

$1: 3$.

Tal'IT.

10.

1 .

(

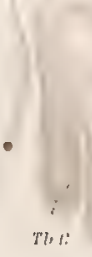

n?

(5).

s.

$1 \%$.

16.

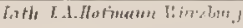





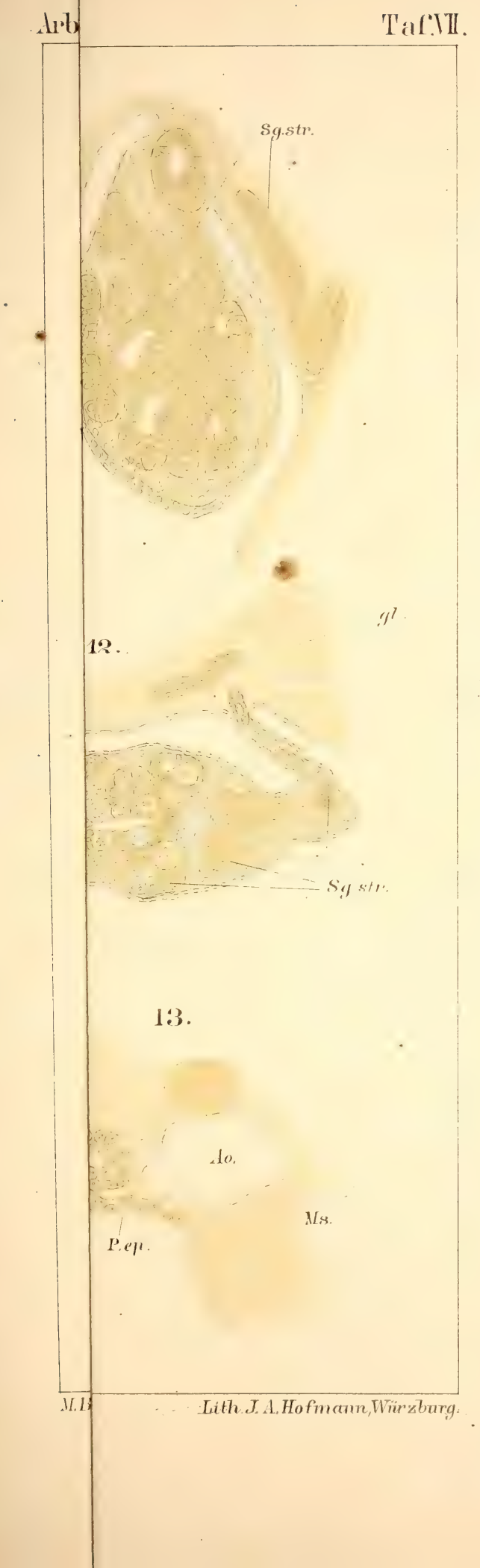





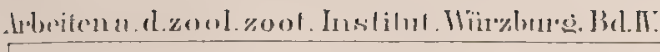

1.

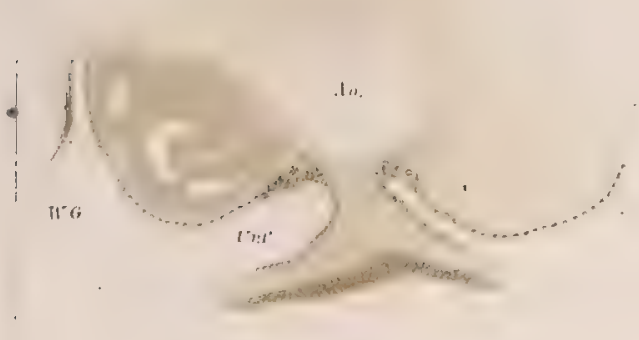

4

(1).

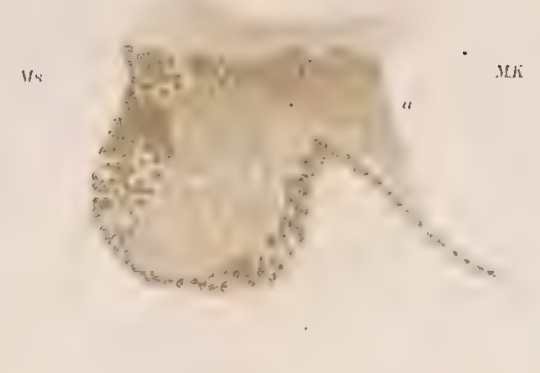

10 .

$\therefore i n$

T'illtit.

Sil str. Mis

11.
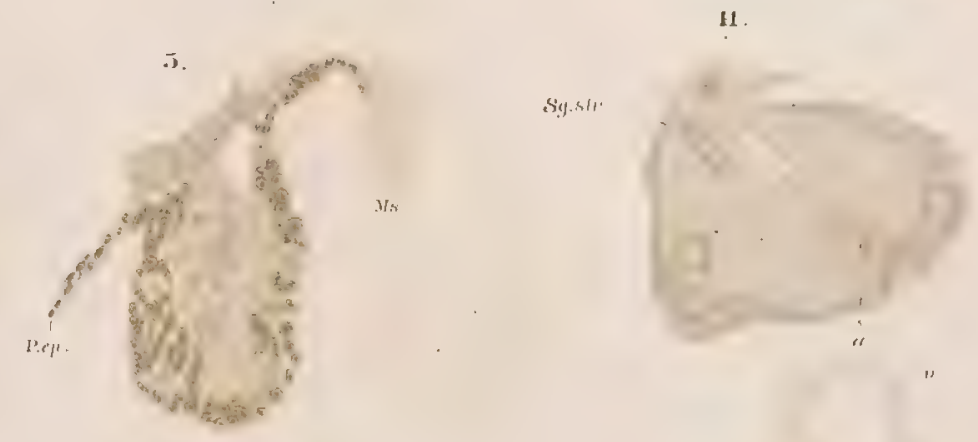

13.

8.

$1: 3$.

i3.

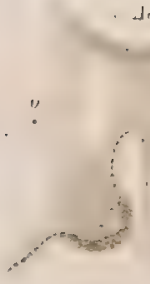

"

Ms. $\quad$ bi,

in.

M.Biam dit.

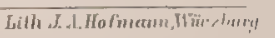





\section{Taf.IIII}

\section{0.}

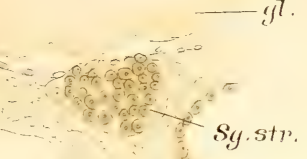

$=\frac{a_{0}}{40}$

$g^{7}$
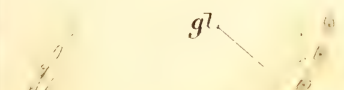

4
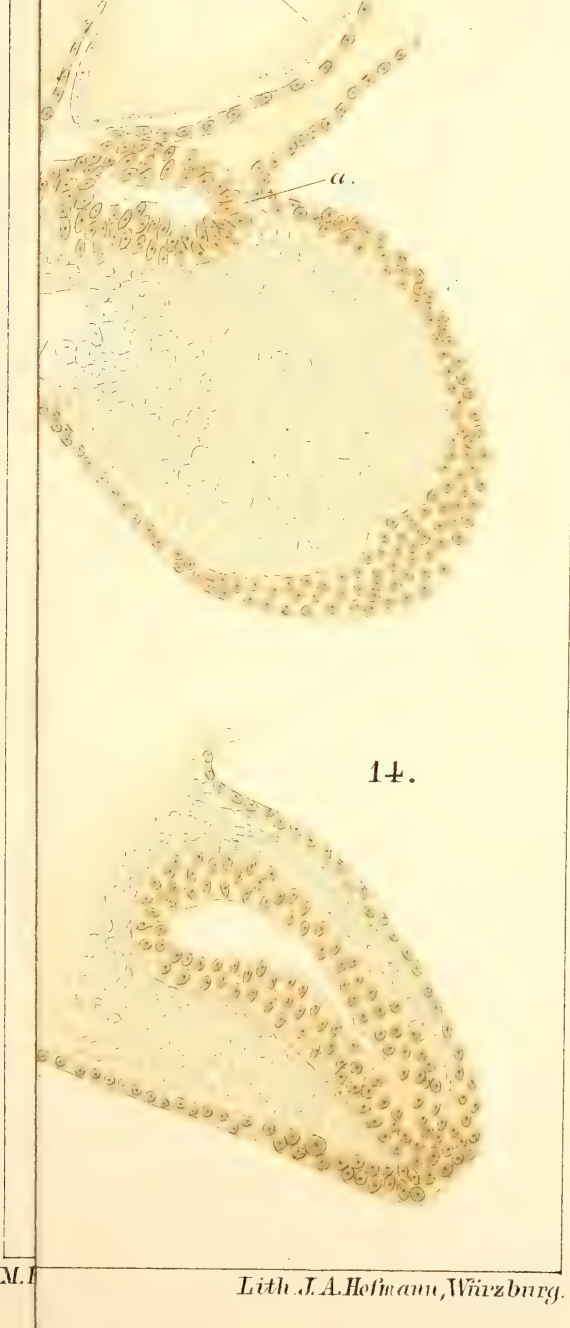

Ms

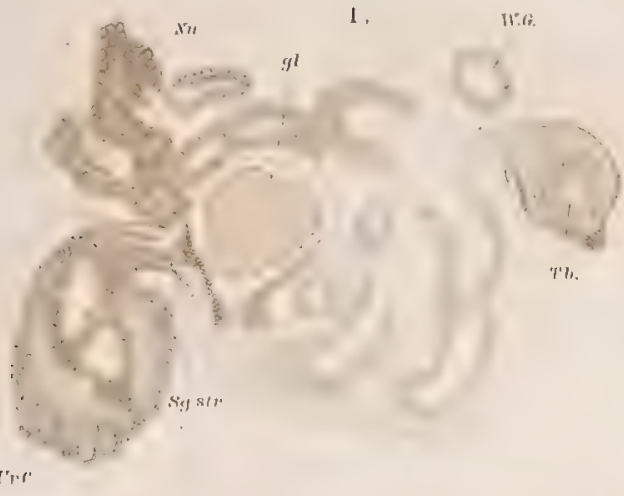

?.
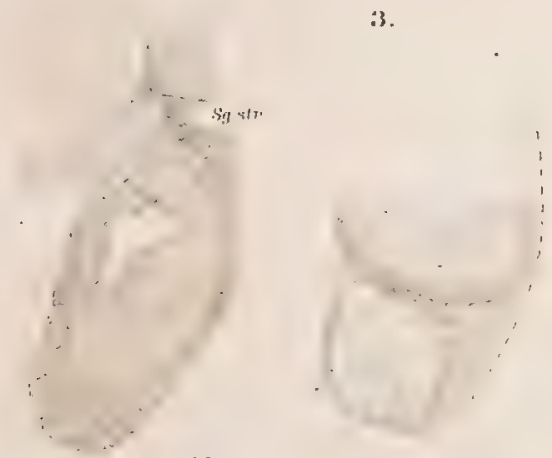

$11 ;$

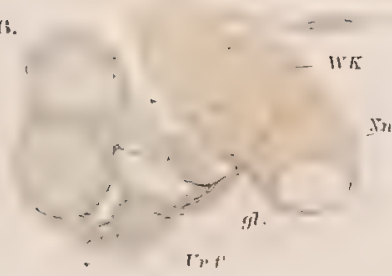

8.

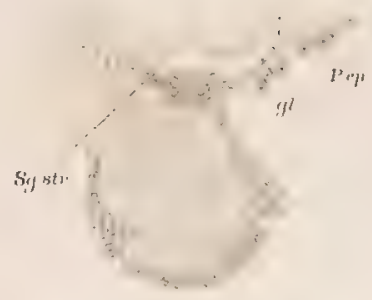

9

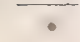

(1).

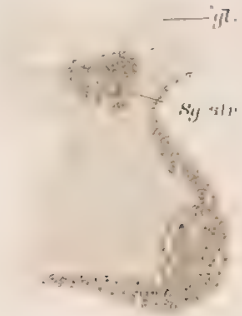

5.

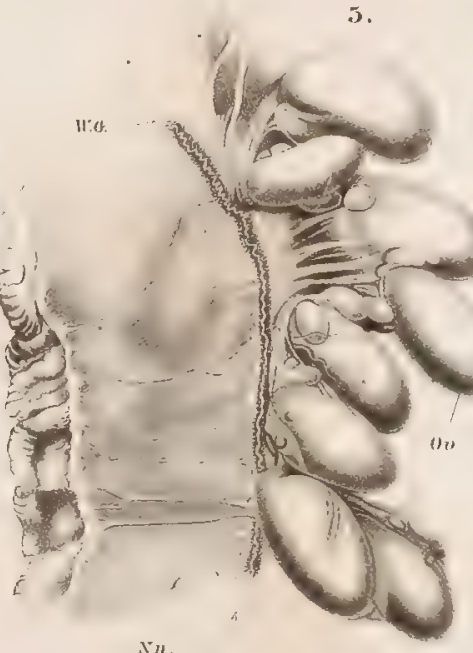

Nn
11.

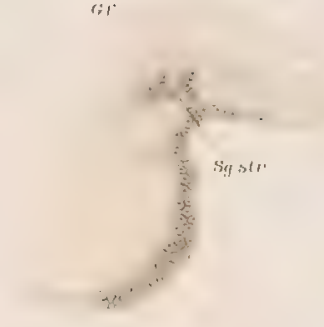

$!$

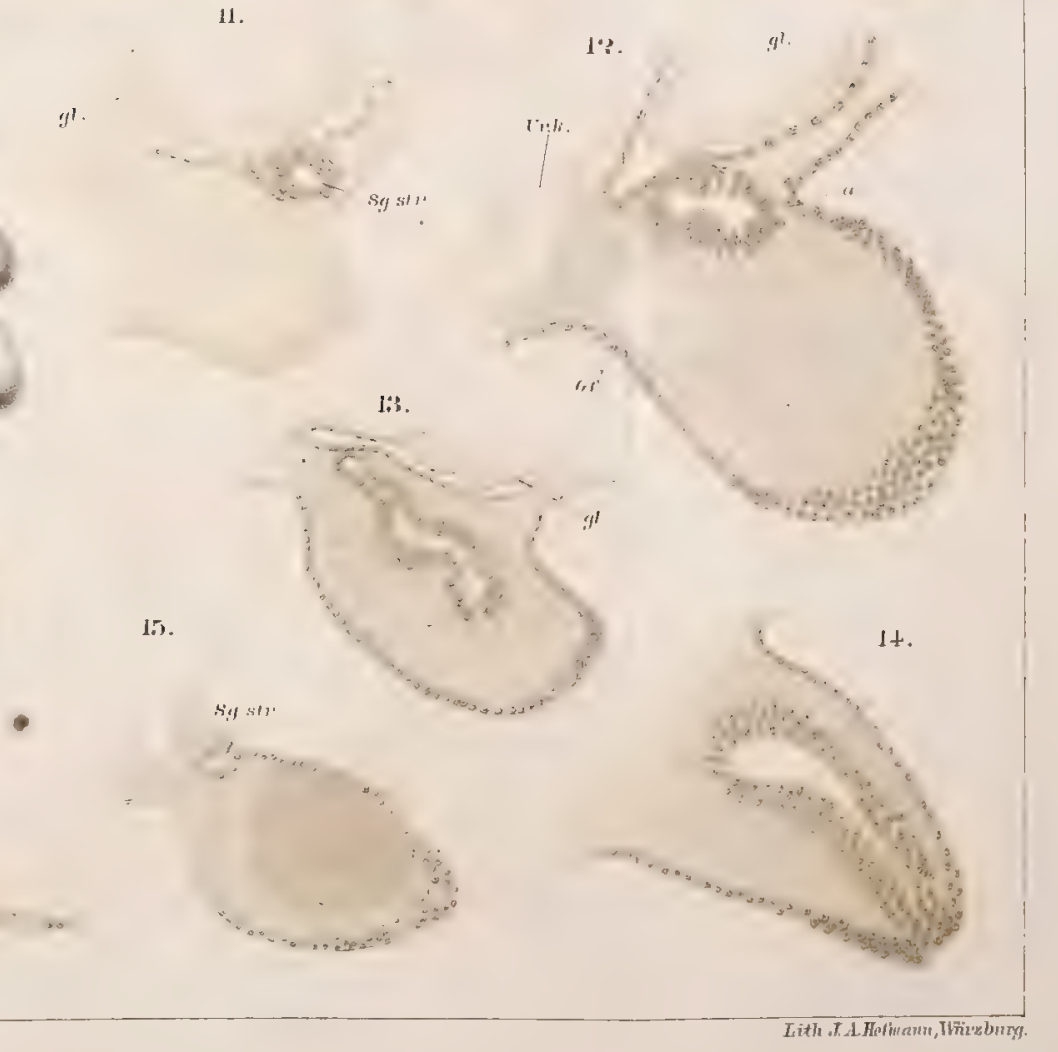



Ms.

1.

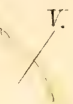

$\Psi$ I. . .

T:
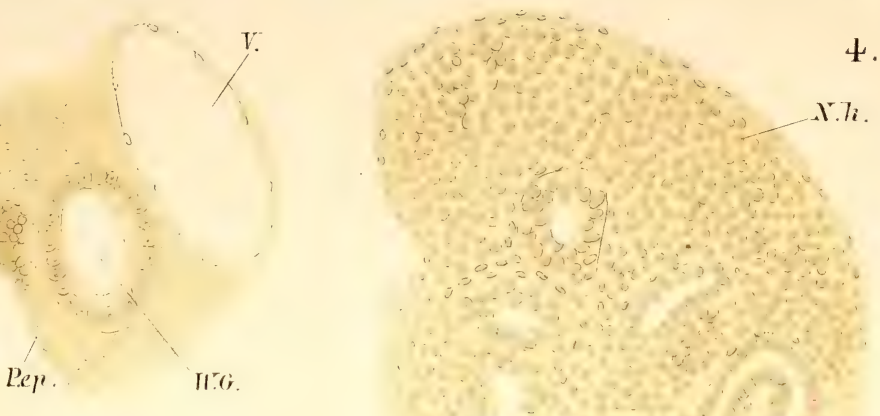

do.

9.



Hinl

5.

3.

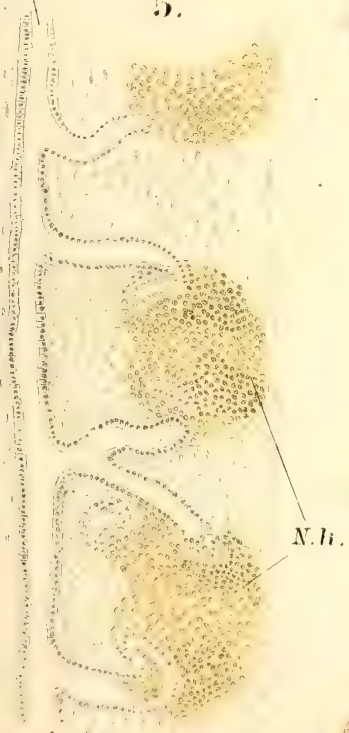

$\pi i$

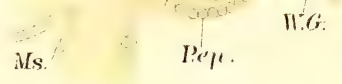

$\%$

.10.
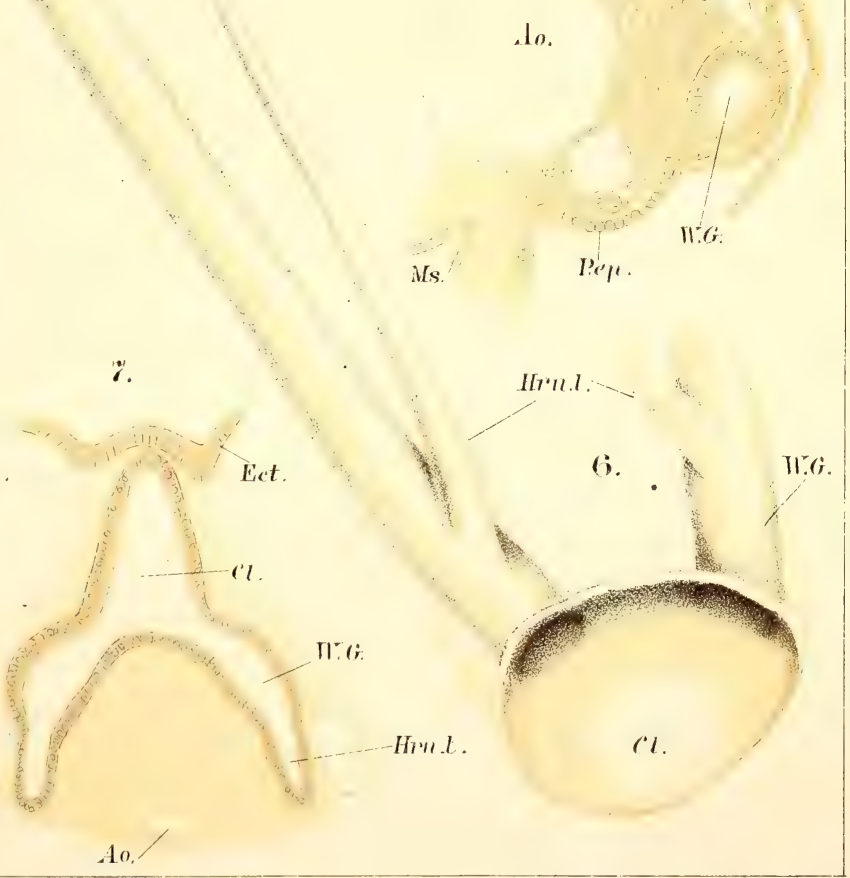

M.Brum, del.

I.th.J.A.Hofmann, Hüryburg. 



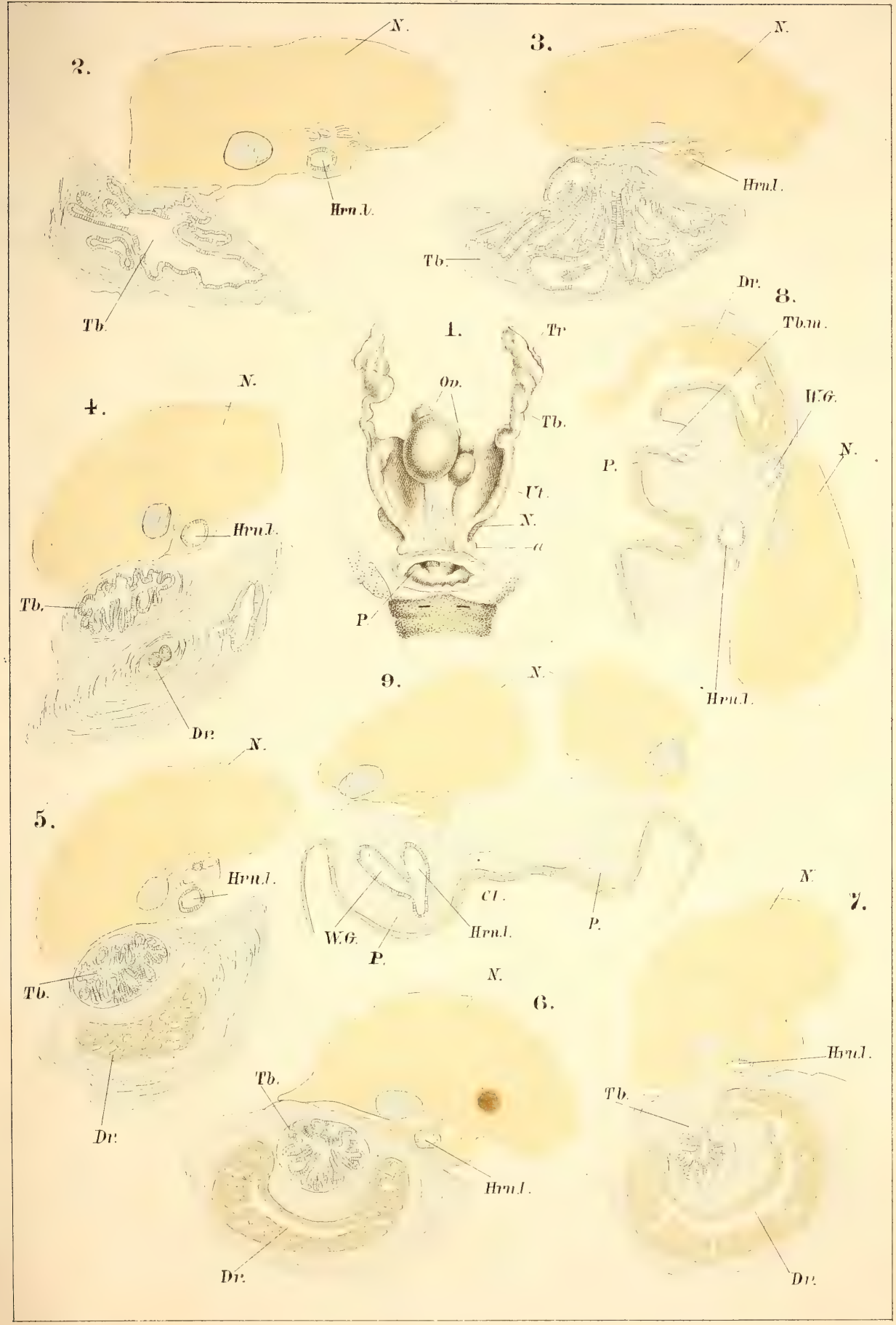




QL Braun, M. 669.2 Das Urogenital-system B82 der einheimischen Rept. Reptilien. 
SMITHSONIAN INSTITUTION LIBRARIES

39088003570504 nhrept QL669.2.882

Das Urogenital-system der einheimischen 